\title{
ESTUDIOS
}

\section{ANIVERSARIO DE LA ASOCIACIÓN ESPAÑOLA DE ORIENTACIÓN Y PSICOPEDAGOGÍA (1979-2004)}

\author{
XXV ANNIVERSARY OF THE “ASOCIACIÓN ESPAÑOLA DE \\ ORIENTACIÓN Y PSICOPEDAGOGÍA” (1979-2004)
}

\author{
José A. Benavent Oltra* \\ Universidad de Valencia
}

\section{RESUMEN}

La Historia de la Orientación Escolar y Profesional en España está en proceso de elaboración. Este artículo, resultado de una cuidadosa investigación, nos muestra el papel que ha desempeñado la Asociación Española para la Orientación Escolar y Profesional (AEOEP), actual Asociación Española de Orientación y Psicopedagogía (AEOP), en el desarrollo y consolidación de la Orientación psicopedagógica en España, desde su creación en 1979 hasta el 2004, año en que se cumple su 25 Aniversario.

Palabras clave: Historia de la Orientación Psicopedagógica en España. Asociación Española para la Orientación Escolar y Profesional. AEOEP. Asociación Española de Orientación y Psicopedagogía. AEOP.

\begin{abstract}
The History of Spanish Educational and Vocational Guidance is currently being written. This article, outcome of a careful historic research, sketches the role played by the "Asociación Española para la Orientación Escolar y Profesional (AEOEP)", current "Asociación Española de Orientación y Psicopedagogía (AEOP)" in the development and consolidation of the Educational and Vocational Guidance in Spain, from its foundation in 1979 until 2004, year in which we celebrate the 25 Anniversary.

Key words: History of Spanish Educational and Vocational Guidance. Asociación Española para la Orientación Escolar y Profesional. AEOEP. Asociación Española de Orientación y Psicopedagogía. AEOP.
\end{abstract}

* Doctor en Filosofía y Letras (Pedagogía) por la Universidad de Barcelona y Master in Educational and Vocational Guidance por la New York University (USA). Profesor Titular de Universidad del Departamento de Didáctica y Organización Escolar de la Facultad de Filosofía y Ciencias de la Educación de la Universidad de Valencia y Presidente de la Asociación Valenciana de Orientación y Psicopedagogía (AVOP). Líneas de investigación: Historia de la Orientación Psicopedagógica en España; programas y metodología de la orientación y la toma de decisiones en la educación secundaria; análisis, evaluación y prospectiva de la situación actual de la Orientación psicopedagógica en el sistema educativo español. 


\section{Introducción}

Rodríguez Docavo (1993) inicia su trabajo "Asociación Española para la Orientación Escolar y Profesional. Historia de una ilusión", publicado en la Revista de Orientación Educativa y Vocacional, y que constituye el primer intento serio de escribir la historia de la AEOEP desde sus orígenes en 1979 hasta el año1992, con las siguientes palabras:

A finales de la década de los setenta, un grupo de orientadores escolares y profesionales, unos de amplia experiencia y renovado ímpetu, otros que por entonces abrían su vocación y su mundo personal al abierto y apasionante del espíritu, decidieron crear la Asociación Española para la Orientación Escolar y Profesional (AEOEP)” (Rodríguez Docavo, 1987, p. 1).

Por tanto, los 25 años de historia de la AEOEP que presento a continuación, constituyen una nueva versión, elaborada, corregida y aumentada sobre la versión de Rodríguez Docavo hasta el año 1992, y original y nueva, desde 1993 hasta el 2004 en que gozosamente estamos celebramos el XXV Aniversario de la fundación de nuestra Asociación.

\section{Antecedentes}

En el IX Congreso Internacional de Psicotecnia celebrado en Berna en 1949, se iniciaron las primeras conversaciones conducentes a la creación de una asociación internacional de Orientación Profesional, en la que participaron 42 especialistas de distintos países, entre ellos, José Mallart por parte de España. Estos contactos iniciales culminaron en 1951 con la fundación en París de la Asociación Internacional de Orientación Profesional (AIOP) que celebró su I Seminario en Montecatini (Italia) en 1953, y al que asistieron más de 100 especialistas pertenecientes a 16 países, entre los que encontramos a Pilar García Villegas, psicóloga, estrecha colaboradora de José Germain y técnica del Instituto Nacional de Psicología Aplicada y Psicotecnia. La AIOP cambió su denominación en el III Congreso Internacional celebrado en París en 1962 por la de Asociación Internacional de Orientación Escolar y Profesional (AIOEP) y al que asistieron Germain, Mallart y Pilar García Villegas (Benavent, 2000). Así pues, desde los primeros momentos, España va a tener un papel relevante en el asociacionismo internacional de la Orientación Escolar y Profesional, hasta el punto que José Germain, Director del INPAP, fue presidente de la AIOEP (1966-73) y Pilar García Villegas, jefa del Departamento de Orientación Profesional del Instituto Nacional de Psicología Aplicada y Orientación Profesional (INPAOP), miembro del Consejo Ejecutivo y Vicepresidenta de la AIOEP (1976-83). Durante estos años fueron surgiendo, tanto en Europa como en América, distintas asociaciones nacionales de orientación bajo los auspicios de la AIOEP y en 1979 se funda en Madrid la Asociación Española para la Orientación Escolar y Profesional (AEOEP) (Benavent, 2004).

\section{Fundación}

La idea de fundar una asociación española que aglutinase a los profesionales de la orientación, tanto los pertenecientes al ámbito educativo y escolar como al profesional y ocupacional, a imagen y semejanza de las asociaciones existentes en los países europeos más 
avanzados, empieza a forjarse entre los especialistas españoles asistentes a los encuentros internacionales organizados por la AIOEP, gracias al desarrollo alcanzado por la Orientación escolar y profesional en España durante la década de los 1970s. En los años 1976 (VI Conferencia Mundial de la AIOEP de Salerno, Italia), 1977 (IX Seminario Internacional de la AIOEP de Nüremberg, Alemania), y 1978 (Conferencia Internacional de Atenas, Grecia), con motivo de estos eventos científicos internacionales, se encuentran Pilar García Villegas, del INPAOP y miembro del Consejo Ejecutivo de la AIOEP, Elvira Repetto, Profesora Adjunta de Orientación Escolar y Profesional de la Universidad Complutense de Madrid, José Zaragozá, Director del Instituto Municipal de Orientación de Valencia, José Antonio Rodríguez Docavo y Tomás Terrados, ambos del Cuerpo Técnico de Orientadores Profesionales del Ministerio de Trabajo. Como resultado de estos contactos asumen el compromiso de formar una comisión para la creación de la Asociación Española para la Orientación Escolar y Profesional (AEOEP).

En septiembre de 1978, y en el domicilio de Pilar García Villegas, se inician una serie de reuniones de trabajo para la redacción de los Estatutos de la AEOEP de acuerdo con la Ley de Asociaciones (Ley 191/1964), que culminan el 2 de abril de 1979 con la constitución de la Comisión organizadora de la AEOEP (Pilar García Villegas, Presidenta; Tomás Terrados Jarabo, Vicepresidente; Elvira Repetto Talavera, Secretaria y Ángel Arévalo Caballero, Tesorero). Se fija el domicilio social en la calle Bravo Murillo, $n^{\circ} 36,7^{\circ}$-A de Madrid (domicilio de la Presidenta), se presentan los Estatutos en el Ministerio del Interior para su aprobación y cada uno de los miembros de la Comisión organizadora aporta 1.000 pesetas para hacer frente a los gastos que pudieran derivarse de la tramitación del expediente durante el período constituyente. El 5 de junio de 1979 la Comisión organizadora se reunió para corregir deficiencias en los Estatutos que son remitidos de nuevo al Ministerio del Interior que los aprobó definitivamente el 17 de julio de 1979, fecha en la que quedó constituida legalmente la AEOEP con el número 30.903 del Registro Nacional de Asociaciones.

\section{Fines y actividades}

Los fines de la Asociación Española para la Orientación Escolar y Profesional vienen explicitados en el artículo $2^{\circ}$ de los Estatutos (AEOEP, 1979), vigentes hasta 1996, y que fueron los siguientes:

1. Promover el rigor científico de la Orientación, potenciarla y favorecer la mayor participación e integración de la persona en la sociedad.

2. Favorecer la formación y el perfeccionamiento especializado del personal de Orientación, del profesorado en su función tutorial y orientadora y de todos aquellos profesionales que intervienen en un asesoramiento orientador.

3. Impulsar y realizar las actividades de investigación en los diversos campos de la Orientación.

4. Colaborar con las autoridades educativas y laborales, con los medios familiares y sociales, en orden a la inserción de los jóvenes en el puesto escolar y laboral más adecuado a sus capacidades, intereses y aspiraciones, teniendo presente al mismo tiempo las necesidades de la sociedad.

5. Establecer relaciones con asociaciones y entidades afines de España y el extranjero. 
6. La Asociación excluye de sus fines la defensa de intereses económicos y profesionales por carecer de ánimo de lucro.

Para el cumplimiento de los anteriores fines la AEOEP se propuso, entre otras, las siguientes actividades (Estatutos, art. $3^{\circ}$ ):

1. Organizar reuniones científicas, cursos de formación, perfeccionamiento y actualización, misiones de estudio, seminarios y congresos a escala territorial, nacional e internacional.

2. Recabar y difundir documentación actualizada.

3. Facilitar la información y colaboración de entidades y organismos dedicados a la Orientación a fin de intercambiar experiencias y técnicas.

\section{Evolución}

Desde la creación de la AEOEP hasta el momento actual, la Asociación ha pasado por distintas vicisitudes y cambió su denominación fundacional por la de Asociación Española de Orientación y Psicopedagogía (AEOP) en 1995. Estos 25 años de historia los hemos dividido en dos etapas y cinco períodos, jalonados por acontecimientos que condicionaron significativamente su funcionamiento:

1. Etapa de la AEOEP (1979-1995). Comprende, desde la aprobación de los Estatutos de la Asociación, hasta su cambio de denominación por el de Asociación Española de Orientación y Psicopedagogía (AEOP). Esta primera etapa de 16 años de duración, para un mejor análisis y estudio, la hemos dividido en los siguientes períodos:

1.1. Período de iniciación (1979-1983). Comprende, desde la aprobación de los Estatutos por el Ministerio del Interior (17/07/1979), hasta el fallecimiento de su Presidenta Pilar García Villegas (03/01/1984).

1.2. Período de transición (1984-1989). Comprende, desde el fallecimiento de Pilar García Villegas, hasta el final de la Presidencia en funciones de José Zaragozá Antich (18/02/1989).

1.3. Período de consolidación (1989-1995). Comprende, desde el nombramiento como Presidenta de Elvira Repetto Talavera (18/02/1989), hasta el cambio de denominación de la AEOEP por AEOP en la Asamblea General Extraordinaria (AGE) de 24 de noviembre de 1995.

2. Etapa de la AEOP (1996-2004). Comprende, desde la aprobación de la denominación de Asociación Española de Orientación y Psicopedagogía (AEOP) y de los nuevos Estatutos (AEOP, 1996) por el Ministerio del Interior (31/01/1996), hasta el año 2004 en que se cumple el 25 Aniversario de la fundación de nuestra Asociación. Esta segunda etapa de 9 años de duración, para un mejor análisis y estudio, la hemos dividido en dos períodos:

2.1. Período de desarrollo (1996-2000). Comprende, desde la aprobación de la denominación AEOP por el Ministerio del Interior (31/01/1996), hasta el 31 de diciembre de 2000, en que la Asociación con 991 socios, llega al máximo número de asociados de su historia. 
2.2. Período actual o del siglo XXI (2001-2004). Comprende desde el 1 de enero de 2001, primer año del s. XXI, hasta el 31 de diciembre de 2004, año en el que se cumple el 25 Aniversario de su fundación.

\section{Período de iniciación (1979-1983)}

El Período de Iniciación se extiende desde la aprobación de los Estatutos de la AEOEP por el Ministerio del Interior (17/07/1979), hasta el fallecimiento de su fundadora y primera Presidenta, Pilar García Villegas (03/01/1984). Se caracteriza por:

a) La gran ilusión, empeño y escasez de medios con los que los componentes de la Comisión organizadora, cualificados profesionales de la Orientación escolar y profesional, contaron para fundar y lanzar un proyecto asociacionista gestado en las relaciones personales que mantuvieron sus miembros en distintos congresos internacionales de la AIOEP.

b) El esfuerzo realizado por los fundadores para aunar voluntades en la tarea común de promover una confluencia de intereses entre los especialistas españoles de la Orientación educativa y profesional, dividida y atomizada, no solo por la existencia de dos campos de intervención psicopedagógica independientes, el educativo, integrado en la estructura del Ministerio de Educación y Ciencia con los SOEVs (Orden de 30/04/1977), y el laboral, dependiente del Ministerio de Trabajo a través del recién creado INEM (Real Decreto-Ley 36/1978), sino también por las distintas titulaciones (Licenciados en Psicología, Licenciados en Pedagogía y Diplomados en Psicología por las Escuelas Superiores de Psicología de Madrid y Barcelona) que facultaban para el ejercicio profesional de la Orientación, y

c) El prestigio de la Presidenta fundadora a nivel nacional (Jefa del Departamento de Orientación Profesional del IOEP-M) e internacional (Vicepresidenta de la AIOEP), su profunda formación y dilatada experiencia como orientadora profesional y su gran personalidad, de la que Rodríguez Docavo dirá: "La Dra. García Villegas, con la escasa infraestructura que le da su despacho, con la información que recibe, con la fuerza de ser una autoridad en orientación, con su contacto con Iberoamérica, en poco tiempo lanza a la Asociación a los mejores logros. Allí realiza e imprime el modesto Boletín AEOEP, nueve números en cuatro años, organiza un brillante Seminario, en colaboración con la Delegación Valenciana dos Jornadas nacionales, publica dos tomos de Actas, da becas para asistir a congresos y deja un gran superávit en la Asociación, y quiere organizar el I Congreso Nacional de Orientación. Y desgraciadamente muere..." (Rodríguez Docavo, 1993, 263-264).

\section{Primeros pasos}

El Período de Iniciación comienza oficialmente con la aprobación de los Estatutos por el Ministerio del Interior el 17 de julio de 1979. A partir de septiembre, la Comisión organizadora, empezó una intensa campaña de divulgación, promoción, captación de socios y preparación de la primera Asamblea General Ordinaria (AGO) de la recién nacida Asociación. Entre las actividades de esta campaña cabe destacar: 
1) El informe sobre la creación de la AEOEP, por medio de carta personal y un extenso dossier documental que incluía los Estatutos, que fue remitido a los especialistas y catedráticos de universidad más relevantes de la materia en aquellos momentos, y que la Comisión organizadora consideró que habían contribuido de forma decisiva al desarrollo científico de la Orientación escolar y profesional en España: José Fernández Huerta, Víctor García Hoz, Juan García Yagüe, José Germain, José Mallart, José Luís Pinillos, Francisco Secadas, Miguel Siguán y Mariano Yela.

2) La aprobación por la Comisión organizadora de la incorporación de Manuel Olleros Izard, como vocal de la Comisión, para sustituir a Ángel Arévalo que había solicitado su dimisión por motivos profesionales.

3) La aportación de 5.000 pesetas a fondo perdido que hicieron cada uno de los miembros de la Comisión organizadora para hacer frente a los gastos de promoción y divulgación de la Asociación y

4) Las 14 reuniones de trabajo, reflejadas en las Actas, que mantuvieron los miembros de la Comisión organizadora, desde la aprobación de los Estatutos, hasta la celebración de la primera AGO el 7 de marzo de 1980, y en la que entre otros asuntos, se elaboraron las propuestas para el nombramiento de los socios de honor, socios fundadores y primera Junta Directiva (JD).

El 23 de noviembre de 1979 el Gobierno Civil de Madrid visa y legaliza el Libro de Actas, el Registro de Socios y el Libro de Cuentas, con lo que la Asociación dispone de todos los requisitos e instrumentos necesarios para su pleno funcionamiento, y el 26 de noviembre, se traslada el domicilio social de la AEOEP, desde el despacho particular de Pilar García Villegas, al Instituto "San José de Calasanz" del CSIC, C. Serrano n 127, 2º dcho. 25 de Madrid.

\section{Primeros acuerdos, actividades y acontecimientos}

La primera AGO de la AEOEP se celebró en el Salón de Actos del Consejo Superior de Investigaciones Científicas (CSIC) de Madrid, el 7 de marzo de 1980, y en la que, a propuesta de la Comisión organizadora, se tomaron los siguientes acuerdos:

1) Se aprobó por aclamación la primera JD que quedó constituida del modo siguiente: Presidente, Pilar García Villegas; Vicepresidente, Tomás Terrados Jarabo; Secretario, Elvira Repetto Talavera; Tesorero, Manuel Olleros Izard; Vocal $1^{\circ}$, José Zaragozá Antich; Vocal $2^{\circ}$, Ángel Lázaro Martínez y Vocal 3º Luis García Mediavilla.

2) Se aprobó por unanimidad nombrar socios de honor a Víctor García Hoz, José Germain y José Mallart.

3) Se aprobó por unanimidad nombrar socios fundadores a los 16 primeros socios inscritos, entre los que encontramos a José Luis García Mediavilla, Ángel Lázaro, José Antonio Rodríguez Docavo y José Zaragozá.

4) Se aprobó editar un boletín informativo con el título de Boletín AEOEP, con periodicidad cuatrimestral y con un presupuesto inicial de 75.000 pesetas anuales.

5) Se aprobó presentar solicitud de adhesión de la AEOEP a la Asociación Internacional de Orientación Escolar y Profesional (AIOEP) y 
6) A petición de José Zaragozá, la JD propuso a la Asamblea General, de acuerdo con los artículos $5^{\circ}$ y $13^{\circ}$ de los Estatutos, la constitución de la Delegación Territorial Valenciana (DTV), que se aprobó por unanimidad al cumplir los requisitos exigidos estatutariamente. En esta fecha, la AEOEP tenía inscritos 71 socios (Registro de Socios) y la cuota anual se fijó en 1.000 pesetas.

A partir de esta primera Asamblea, en la que legalmente quedó constituida la primera JD de la Asociación, ésta se reunió en quince ocasiones durante el Período de Iniciación, y se celebraron tres AGOs, las correspondientes a los ejercicios de 1980, 1981 y 1982.

El 8 de mayo de 1980 la AIOEP comunicó la aceptación de la solicitud de adhesión de la AEOEP, con lo que ésta quedará integrada desde los primeros momentos en el movimiento asociacionista internacional para la orientación escolar y profesional. Apoyada por la AIOEP, la AEOEP se compromete a promover la celebración del II Seminario Iberoamericano de Orientación Escolar y Profesional en Madrid y empiezan las primeras reuniones, gestiones y contactos para su organización. A finales de 1980 se llega a un acuerdo con Luis Buceta, director del Instituto de Orientación Educativa y Profesional de Madrid (IOEP-M), anterior INPAOP, para que el II Seminario Iberoamericano se celebre en la sede del mismo, sita en la C. Juan Huarte de San Juan, s/n de la Ciudad Universitaria.

En un clima distendido y expectante, ante la inminente celebración del II Seminario Iberoamericano (28 de marzo al 2 de abril de 1982), tuvo lugar la AGO de 1982 que se centró íntegramente sobre tan importante evento, y en la que la Asamblea manifestó su incondicional apoyo para que la celebración de este II Seminario fuera un éxito.

En mayo de 1982, y ante las serias objeciones que se plantean para que la sede de la AEOEP continúe en el Instituto "San José de Calasanz" del CSIC, ésta se trasladó al Instituto de Orientación Educativa y Profesional de Madrid (IOEP-M), al amparo del despacho de la Presidenta, en estos momentos directora del Departamento de Orientación Profesional de dicho Instituto. En octubre se aceptó la solicitud de dimisión, por motivos personales, del Tesorero, Manuel Olleros, y se nombró Tesorero en funciones a José Antonio Rodríguez Docavo. También se acordó, con motivo de la jubilación de José Zaragozá, proponer su nombramiento como "Socio de Honor" en la próxima Asamblea General. Finalmente, el año 1982 concluiría con la solicitud de creación de la Delegación Territorial de Cataluña (DTC) y la propuesta de la JD de colaborar en la organización del I Congreso Nacional de Orientación Escolar y Profesional que patrocinarán el MEC (D.G. de Enseñanzas Medias) y el Instituto Nacional de Empleo (INEM).

En la AGO de 22 de marzo de 1983, a propuesta de la JD, se acordó la participación de la AEOEP en la organización del I Congreso Nacional de Orientación Escolar y Profesional, a celebrar en Madrid en mayo de 1984, se aprobó el nombramiento de José Zaragozá como "Socio de Honor" y la subida de la cuota social de 1.000 a 1.500 pesetas anuales. El hecho más destacado de la Asamblea fue la aprobación de la constitución de la DTC promovida por Santiago Martí García, Orientador profesional del INEM (Barcelona). Además se informó del cambio de domicilio de la sede social de la AEOEP, de los trámites en curso para la creación de delegaciones en Andalucía y Galicia, de los resultados y conclusiones de las II Jornadas de Orientación de la AEOEP celebradas en Valencia en 1982 y de la edición de las Actas del II Seminario Iberoamericano. Miguel Beltrán Quera, Presidente de la recién constituida DTC, informó sobre los resultados de las II Jornadas de Orientación y Educación centradas en la persona (según el enfoque de C. Rogers), dirigidas por él y celebradas 
en Barcelona en 1982. Finalmente, se propuso la creación de una comisión para el estudio y reforma de los Estatutos, dada la nueva situación planteada por la transferencia de competencias en materia educativa a las Comunidades Autónomas. Esta fue la última Asamblea presidida por Pilar García Villegas, que aún asistiría a dos reuniones de la JD para dar cumplimiento al mandato de la Asamblea de crear la comisión para la revisión y reforma de los Estatutos, antes de su fallecimiento el 3 de enero de 1984.

\section{Primeras Delegaciones Territoriales}

Los Estatutos de la AEOEP (1979) fueron redactados teniendo en cuenta el espíritu y la letra de la Constitución Española, aprobada por referéndum nacional el 6 de diciembre de 1978. El nuevo concepto constitucional de España, como un Estado de Comunidades Autónomas, se recoge en los Estatutos, en los que se dice:

Art. 5․ La Asociación Española para la Orientación Escolar y Profesional tendrá su ámbito en el territorio del Estado Español. Podrán establecerse Delegaciones Territoriales en las Comunidades Autónomas u otras demarcaciones geográficas según lo previsto en el artículo 13.

De acuerdo con el artículo $5^{\circ}$ podían crearse Delegaciones Territoriales (DTs) en las distintas Comunidades Autónomas siempre que se cumplieran unos requisitos mínimos previstos en el artículo 13:

Art. $13^{\circ}$. Las Delegaciones Territoriales se constituyen cuando exista un grupo de socios activos, no inferior a 20, a petición de un mínimo de 11 socios, a propuesta de la Junta Directiva, con la ratificación de la Asamblea General.

Así pues, acogiéndose a lo establecido en los artículos citados, es como se solicitó y aprobó la constitución de las Delegaciones Territoriales de Valencia y Cataluña durante el Período de Iniciación.

\section{Delegación Territorial de Valencia (DTV)}

En Valencia, a principios del año 1978, se formó un nutrido grupo de orientadores escolares y profesionales (psicólogos y pedagogos pertenecientes a los SOEVs, el IMO, el IPPAP, el Centro de Orientación Profesional del INEM, gabinetes privados, y departamentos de orientación de colegios públicos y privados), en torno a los Seminarios permanentes de Orientación Escolar y Educación Especial organizados por la División de Orientación del ICE de la Universidad de Valencia. En abril de 1979 se produjo una reestructuración del MEC (Real Decreto 708/1979), por la cual, éste se dividió en Ministerio de Educación y Ministerio de Universidades e Investigación. En septiembre de 1979, temiéndose los componentes de los Seminarios permanentes una nueva regulación de las actividades docentes y de las comisiones de servicio del personal de los ICEs, los miembros de dichos Seminarios, para asegurar la continuidad de su funcionamiento decidieron constituirse en asociación cultural, sin embargo, “... a punto de cursar la solicitud, se optó finalmente por incorporarse a la Asociación Española para la Orientación Escolar y Profesional, que había iniciado re- 
cientemente su andadura como sección española de la Assotiation Internationale pour l'Orientation Scolaire et Professionnelle" (Orts, 1986, p. 17). Así, en la primera AGO de la AEOEP, celebrada en Madrid, el 7 de marzo de 1980, a propuesta de la JD que aceptó la solicitud de José Zaragozá, se aprobó por unanimidad la constitución de la DTV.

El 25 de marzo de 1980, en su sede social, sita en los locales del IMO del Ayuntamiento de Valencia, se celebró la Asamblea General constituyente en la que se procedió al nombramiento, por unanimidad de los 21 socios asistentes, de la primera JD de la Delegación Territorial, presidida por Miguel Pascual Sellés, que pasó a ser el primer Vocal nato de la JD de la AEOEP. En esta asamblea también se acordó nombrar un grupo de trabajo presidido por José Miguel Orts para organizar las I Jornadas de Orientación de la AEOEP, que se celebraron del 15 de mayo al 19 de junio de 1980.

La DTV asumió desde el primer momento la tarea de promover, promocionar y divulgar la Orientación psicopedagógica en la Comunidad Valenciana por medio de las I Jornadas, las reseñas que aparecían periódicamente en la prensa local y las actividades docentes y de investigación organizadas en estrecha colaboración con los Seminarios permanentes de la División de Orientación del ICE de la Universidad de Valencia y del IMO. Una prueba más de la vitalidad de la DTV fue la organización de las II Jornadas de Orientación en 1982.

En la AGO de 4 de marzo de 1981 presentó su dimisión, por motivos personales, el Presidente de la DTV, Miguel Pascual, siendo nombrado Presidente en funciones, el Secretario, Juan Bta. Codina, hasta la celebración de la próxima Asamblea, que tuvo lugar el 13 de mayo, y en la que fue elegido Presidente José Miguel Orts Timoner.

Finalmente, las actividades desarrolladas en 1983 se centraron en:

a) La preparación y participación de la Delegación en el XI Congreso Mundial de Orientación de la AIOEP celebrado en Florencia (Italia), y al que asistieron José Zaragozá, José Miguel Orts y María Luisa Monera Olmos.

b) La preparación de la participación de la Delegación en el I Congreso Nacional de Orientación Escolar y Profesional a celebrar en mayo de 1984 en Madrid, y

c) La planificación y organización de las III Jornadas de Orientación a celebrar en Valencia en junio de 1984 bajo el lema "La Orientación ante las dificultades del aprendizaje" (Boletín de Información AEOEP, 1984).

"Ello explica el brillante impulso de la Delegación Valenciana, ya integrada y rodada y que en los primeros tiempos da la pauta a toda la Asociación" (Rodríguez Docavo, 1993, p. 264).

\section{Delegación Territorial de Cataluña (DTC)}

Desde la fundación de la AEOEP se contó con un selecto número de socios en Cataluña liderados por Miguel Bertrán Quera, Profesor de Orientación Escolar y Profesional de la Universidad de Barcelona y Director de la Institución "Counseling” de Barcelona. A propuesta de la JD, que acogió la solicitud promovida por el socio Santiago Martí García, Orientador profesional del INEM en Barcelona, la AGO de 22 de marzo de 1983 aprobó la constitución de la DTC, de la que fue primer presidente Miguel Bertrán Quera, que pasó a ser Vocal nato de la JD de la AEOEP, a la que aportó su "seny", su talante conciliador y dia- 
logante, su capacidad organizadora, sus amplísimos conocimientos y su dilatada experiencia profesional.

El espíritu que animó la creación de la DTC queda claramente expresado en las siguientes palabras: "Desde su constitución, esta Delegación Territorial ha procurado que estuvieran presentes en su Junta personas pertenecientes a las instituciones privadas y públicas, la Universidad, la Generalitat y demás entidades; si bien, no con carácter de representación oficial, sino como simples profesionales que desean establecer relaciones de mutuo conocimiento y de relación con los demás. Otra característica de esta Delegación es la de haber tenido desde el principio reuniones o convocatorias abiertas, no limitadas a los miembros de la Junta ni a los estrictamente socios de la Asociación. Con ello pretendíamos y pretendemos dar a conocer a la AEOEP, dándonos a conocer personalmente e intentando poder llegar a conocer al mismo tiempo a todos aquellos que se dedican a la orientación, cualquiera que sea su especialidad o su campo de ocupación particular" (Anónimo, 1985, p. 82).

Las actividades que la DTC realizó desde su constitución hasta el final del Período de Iniciación se centraron en:

a) Varias reuniones en las que se formularon propuestas y sugerencias para la revisión y mejora de los Estatutos de la AEOEP, de cuya comisión reformadora formaba parte su Presidente.

b) La preparación, planificación y participación de sus socios en el XI Congreso Mundial de Orientación Profesional de la AIOEP celebrado en Florencia (Italia), del 19 al 24 de septiembre de 1983, y al que asistieron ocho de sus socios y se presentaron dos ponencias: "Funciones del orientador en formación profesional", por Francisco Falgueras y "Necesidades, objetivos y métodos de la Orientación Profesional en Cataluña”, por María Luisa Rodríguez Moreno. Además, la mesa $n^{\circ} 5$ del Congreso, "La preparación para la elección: el papel de la escuela", fue presidida por Miguel Bertrán Quera.

c) Preparación de la participación de la Delegación en el I Congreso Nacional de Orientación Escolar y Profesional a celebrar en mayo de 1984 en Madrid, y

d) Propuestas de actividades concretas de orientación en Cataluña y de organización de unas Jornadas Catalanas de Orientación para el año 1984 (Anónimo, 1984).

\section{Congresos, Jornadas y Seminarios}

Durante el Período de Iniciación (1979-1983), la AEOEP organizó y celebró las I Jornadas de Orientación, el II Seminario Iberoamericano de Orientación Escolar y Profesional y las II Jornadas de Orientación Escolar y Profesional.

\section{Jornadas de Orientación}

Las I Jornadas de Orientación, sobre el tema "La Función del Orientador", tuvieron lugar en Valencia, del 15 de mayo al 19 de junio de 1980, organizadas por la recién creada DTV en colaboración con el Instituto de Ciencias de la Educación (ICE) de la Universidad 
XXV Aniversario de la Asociación Española...

de Valencia, y se celebraron en los locales del Instituto Municipal de Orientación (IMO) del Excmo. Ayuntamiento de Valencia.

Inauguradas por José Zaragozá, director del IMO, y con la asistencia de casi un centenar de personas, en las I Jornadas se presentaron cinco conferencias y una mesa redonda de acuerdo con el siguiente programa:

1) Conferencias: José Zaragozá, "Funciones específicas del Orientador"; Francisco Rivas, "Perfeccionamiento del Orientador"; Gonzalo Anaya, "Organización y planificación de la Orientación en EGB”; Miguel Pascual y Joaquín Bonet, "Orientación profesional y mercado de trabajo"; y José A. Benavent, "Formación del Orientador: Perspectivas de futuro".

2) Mesa redonda: Ángel Tomás, Antonio Clemente, Rafael Reig y María Luisa Monera, "Ejercicio privado de la orientación".

No se presentaron comunicaciones ni se publicaron Actas, pero las conferencias y la mesa redonda se recogieron y editaron en un documento policopiado de difusión interna junto con las Conclusiones (AEOEP-DTV, 1980). Posteriormente, se publicaron los trabajos de Zaragozá (1980) y de Pascual y Bonet (1981) en el Boletín AEOEP.

\section{Seminario Iberoamericano de Orientación Escolar y Profesional}

El II Seminario Iberoamericano de Orientación Escolar y Profesional se celebró en los locales del Instituto de Orientación Educativa y Profesional de Madrid (IOEP-M), del 28 de marzo al 2 de abril de 1982, bajo el lema "Orientación integral para la Escuela, el Trabajo y la Vida”. Organizado por la AEOEP en colaboración con la AIOEP, fue patrocinado por la Dirección General de Enseñanzas Medias del Ministerio de Educación y Ciencia (MEC) y el Patronato de Promoción de la Formación Profesional (Ministerio de Trabajo). Asistieron 545 participantes de 26 países, entre ellos, los más relevantes especialistas a nivel internacional y los miembros del Comité Ejecutivo de la AIOEP presididos por Donald E. Super. El Comité de Honor estuvo integrado por el Ministro de Educación y Ciencia, Federico Mayor Zaragoza; el Ministro de Trabajo, Santiago Rodríguez Miranda; el Alcalde de Madrid, Enrique Tierno Galván; el Presidente de la Diputación de Madrid, José María Rodríguez Colorado y el Dr. José Germain. La Comisión Organizadora fue presidida por Pilar García Villegas, Presidenta de la AEOEP y vicepresidenta de la AIOEP. Se presentaron un total de 161 trabajos entre conferencias, ponencias y comunicaciones, publicadas íntegramente en las Actas, financiadas y editadas por el IOEP-M en dos volúmenes con más de 1.200 páginas (Actas y Trabajos, 1983).

El Seminario se organizó en una sesión inaugural, cinco sesiones plenarias, una sesión internacional y una sesión de clausura. La sesión de apertura fue presidida por el Ministro de Educación y Ciencia Federico Mayor Zaragoza que pronunció el discurso inaugural y en la que además intervinieron: Enrique Tierno Galván, Pilar García Villegas, Donald E. Super, José Ferreira (Univ. de Lisboa), Humberto Herrero (Univ. Nacional Autónoma de México) y Félix Díez (Director del INEM). Cada una de las cinco sesiones plenarias, a partir de unas ponencias generales introductorias, se dividieron en varios paneles en los que se agruparon, por afinidad, las 142 comunicaciones. La sesión internacional, con traducción simultánea, versó sobre el estado actual la Orientación educativa y profesional en los 
EE.UU., Francia, Alemania y Gran Bretaña, y tuvo un marcado carácter comparativo. En la Sesión de clausura, presidida por Antonio Lago Carballo, Subsecretario de Orientación Educativa del MEC, en representación del Ministro de Educación y Ciencia, que pronunció el discurso de clausura, intervinieron los Secretarios de las distintas Sesiones plenarias dando lectura a las valiosas Conclusiones del Seminario (Actas y Trabajos, 1983, vol. II, pp. 1.214-1.224), finalizando con unas palabras de Donald, E. Super, expresando su satisfacción y agradecimiento a los asistentes por el alto nivel científico alcanzado, y de Pilar García Villegas, de despedida, a la vez que emplazaba a los congresistas a asistir al próximo Seminario Iberoamericano a celebrar en Méjico.

\section{Jornadas de Orientación}

Las II Jornadas de Orientación, sobre el tema "Orientación para la educación y el empleo", tuvieron lugar en Valencia, del 31 de mayo al 5 de junio de 1982, organizadas por la DTV en colaboración con los Seminarios Permanentes de Orientación del ICE de la Universidad de Valencia, fueron patrocinadas por la Universidad Literaria de Valencia y se celebraron en el edificio del Rectorado de la Universidad. El Comité de Honor estuvo presidido por Joaquín Colomer Sala, Rector de la Universidad de Valencia, y el Comité Organizador, por José Miguel Orts Timoner, Jefe de la División de Orientación Escolar y Profesional del ICE de la Universidad de Valencia y Presidente de la DTV. Se contabilizaron 277 inscripciones y se presentaron un total de 32 trabajos entre discursos, conferencias, ponencias y comunicaciones, todos ellos, publicados íntegramente en las Actas (AEOEP, 1983).

Las II Jornadas se organizaron en una sesión inaugural, cinco ponencias y la sesión de clausura. La Sesión inaugural estuvo presidida por Vicente Montés Penadés, Director del ICE de la Universidad de Valencia, que pronunció unas palabras de bienvenida para dar paso a la conferencia inaugural, que con el título, "Una hipótesis dinámica del desarrollo vocacional", fue magistralmente expuesta por Francisco Secadas Marcos, Catedrático de Psicología de la Universidad de Valencia. Las cinco ponencias, alrededor de sus temas, organizaron las respectivas mesas para la exposición de las 23 comunicaciones presentadas. La Sesión de clausura, presidida por el Rector de la Universidad de Valencia, Joaquín Colomer Sala, se inició con la conferencia magistral pronunciada por Pilar García Villegas, Presidenta de la AEOEP, sobre "La formación del orientador". A continuación, hubo un sencillo y emotivo acto de homenaje a José Zaragozá Antich, Director del Instituto Municipal de Orientación de Valencia, por su reciente jubilación, y el acto concluyó con unas breves palabras de clausura del Rector (AEOEP, 1983).

\section{Publicaciones}

Durante el Período de Iniciación (1979-1983) se editaron nueve números del Boletín $A E O E P$ y las Actas de las I y II Jornadas de Orientación celebradas en Valencia.

Desde el momento de su fundación la AEOEP se preocupó de tener un órgano de expresión para difundir sus actividades, editar sus trabajos e informar a sus asociados sobre eventos, publicaciones y noticias de la Orientación escolar y profesional, tanto a nivel nacional como internacional. Así nació el Boletín AEOEP, cuyo primer ejemplar apareció en mayo 
de 1980 y el último en octubre de 1983, tras editarse nueve números, todos ellos diseñados y dirigidos por Pilar García Villegas hasta su fallecimiento en enero de 1984.

El Boletín AEOEP se publicó en formato cuartilla, reproducido por fotocopiado, en un solo pliego grapado, con tiradas reducidas adecuadas al número de asociados en cada momento y con una sencilla portada de papel que reproducimos a continuación (Fig. 1). Su contenido se estructuraba en los siguientes apartados:
a) Editorial.
b) Investigación.
c) La Orientación en España: documentos y noticias.
d) La Orientación en el Extranjero: documentos y noticias, y
e) Censo de orientadores y socios.

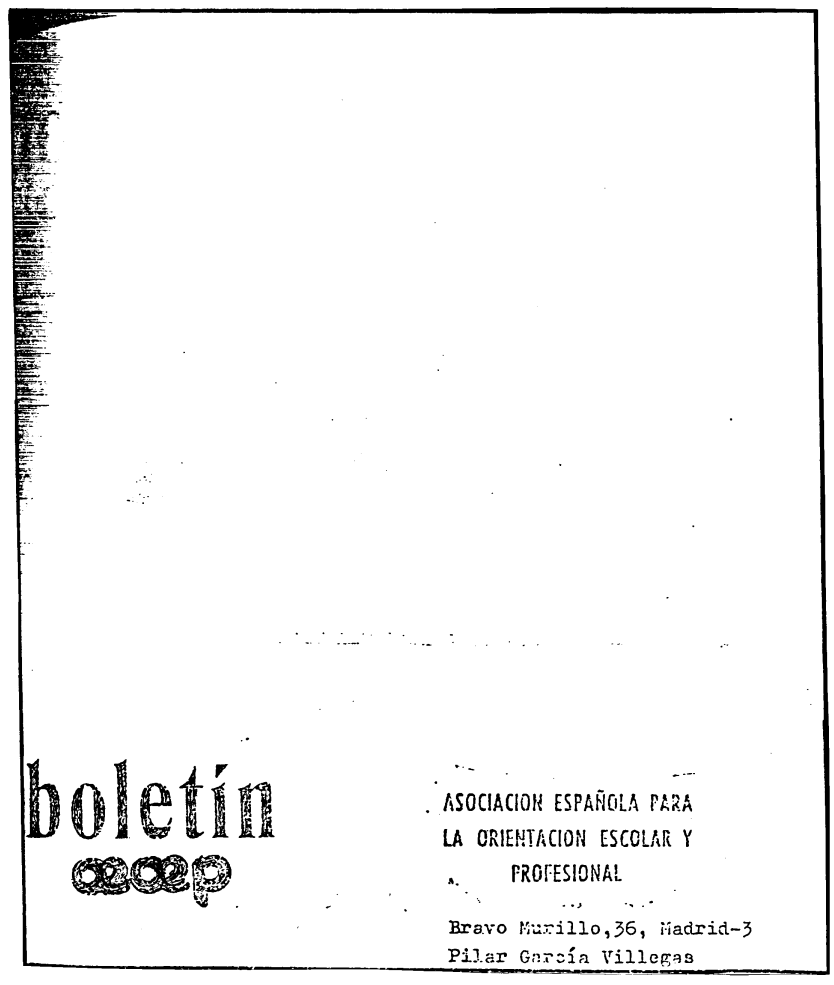

FIGURA 1.

Portada del Boletín AEOEP(1980-83).

Desgraciadamente los 9 números del Boletín AEOEP depositados en el Archivo de la Asociación se perdieron durante el último traslado de domicilio social, y hasta el momento, todas las gestiones realizadas para su recuperación han sido infructuosas. Las únicas referencias que actualmente poseemos sobre el número de ejemplares, su formato y contenidos 
se deben a dos documentos policopiados de difusión interna de Rodríguez Docavo (1987 y 1994) que presentamos en el Anexo I.

En cuanto a las Actas, la correspondiente a las I Jornadas de Orientación (Valencia, mayo-junio 1980), no se llegó a editar por falta de presupuesto económico, aunque el documento original que recogía las ponencias de la misma y las conclusiones se policopió y distribuyó entre los participantes (Actas-DTV, 1980).

En cuanto a las Actas del II Seminario Iberoamericano (Madrid, 1982), fueron financiadas, preparadas y editadas por el Instituto de Orientación Educativa y Profesional de Madrid (IOEP-M) en dos voluminosos tomos, y sus 1.260 páginas recogen el programa, la organización, todos los trabajos presentados, las sesiones de apertura y clausura, las conclusiones y la relación de congresistas inscritos. (Actas y Trabajos, 1983).

Las Actas de las II Jornadas de Orientación Escolar y Profesional (Valencia, junio 1982), se editaron gracias a la generosa ayuda del ICE de la Universidad de Valencia, y sus 474 páginas, tras el índice y la presentación, recogen la sesión de apertura, todos los trabajos presentados, las conclusiones, la sesión de clausura y la relación de participantes. Constituye la primera publicación oficial de la AEOEP con ISBN (AEOEP, 1983).

\section{Becas}

La JD de la AEOEP, para estimular y apoyar la participación de los orientadores asociados en las reuniones científicas internacionales, decidió dotar dos becas (gastos de inscripción, viaje y alojamiento), con los fondos económicos de la Asociación. La primera convocatoria se realizó en enero de 1983 para asistir al XI Congreso de la AIOEP que se celebró en Barga (Florencia), del 19 al 24 de septiembre de 1983. Para participar en la convocatoria los socios debían adjuntar el boletín de inscripción y el trabajo que habían presentado al Congreso. A la convocatoria se presentaron un total de ocho trabajos, siendo premiado con media beca el titulado "La orientación ante la elección de estudios universitarios", de María Luisa Monera Olmos (1983), publicado posteriormente en el número 9 del Boletín AEOEP.

\section{Período de transición (1984-1989)}

El Período de transición (1984-1989) comprende, desde el fallecimiento de Pilar García Villegas (03/01/1984) hasta el final de la Presidencia en funciones de José Zaragozá Antich (18/02/1989). Se caracteriza por:

a) La crisis institucional producida por la inesperada muerte de la Presidenta y la consiguiente remodelación de la JD.

b) La transición y adaptación a un nuevo estilo de dirección y gestión de la Asociación, más participativo y democrático.

c) Inestabilidad presidencial, pues durante estos 5 años hubo tres presidentes, dos en funciones y uno electo.

d) La constitución de nuevas delegaciones territoriales y la segregación de la DTC.

e) La proliferación de encuentros y jornadas científicas organizadas por la Asociación y 
f) La proyección internacional de la AEOEP y su significativa participación en las actividades organizadas por la AIOEP.

La desaparición de Pilar García Villegas, que había llevado en silencio y sin trascender a la Asociación la gravedad de su enfermedad, con su callado sufrimiento, dedicación, entereza, tesón, esfuerzo vigoroso y estilo personal de gestión, dejó una profunda y dolorosa huella en la Asociación y un significativo vacío en la JD. En la práctica, la Presidenta, al residir en un principio la AEOEP en su domicilio particular y posteriormente en su despacho del IOEP-M, había asumido tanto las funciones de la presidencia, como las propias de la secretaría, la tesorería y la dirección del Boletín AEOEP. Por ello, su súbita pérdida provocó un sensible vacío en el funcionamiento de la Asociación, el desalojo del domicilio social y un prolongado período de transición y adaptación al nuevo estilo de gestión promovido por el Presidente en funciones y la posterior JD elegida en febrero de 1985.

\section{Acuerdos, actividades y acontecimientos}

En la JD de 31 de enero de 1984 pasa a Presidente en funciones el Vicepresidente Tomás Terrados Jarabo, le sustituye como Vicepresidente José Zaragozá, y Luis García Mediavilla asume las funciones de Director del Boletín AEOEP con el compromiso de potenciarlo y mejorarlo. En reconocimiento a los servicios prestados se nombra a Pilar García Villegas "Presidenta de Honor" y se crea en su memoria, para estimular la investigación entre los socios de la AEOEP, el Premio Nacional "Pilar García Villegas", dotado con 100.000 pesetas que se financiaron de los beneficios obtenidos en la celebración del II Seminario Iberoamericano.

La primera y urgente tarea que ha de asumir la nueva JD es encontrar un domicilio social para la AEOEP, al ser desahuciada del despacho que ocupaba en el IOEP-M. A tal efecto, se acepta el generoso ofrecimiento de José Antonio Rodríguez Docavo que pone a disposición de la Asociación su domicilio particular, con lo que a partir del 1 de febrero de 1984, la sede de la AEOEP residió en la C. General Yagüe, n $15,2^{\circ}-\mathrm{C}, 28020$ Madrid. Otro problema a resolver, fue la baja presentada por algunos socios del entorno afectivo y laboral de Pilar García Villegas, situación agravada por la pérdida de un numeroso grupo de socios hispanoamericanos que se habían dado de alta con motivo del II Seminario Iberoamericano celebrado en Madrid, y que se perdieron, tanto por la crisis económica que atravesaban sus países de origen, como por las dificultades de relación postal y cobro de las cuotas.

Esta situación de provisionalidad se alargó durante más un año, hasta que en la Asamblea General Extraordinaria (AGE) de 22 de febrero de 1985 se aprobó por unanimidad la nueva JD que quedó constituida por: Tomás Terrados Jarabo, Presidente; José Zaragoza Antich, Vicepresidente; Elvira Repetto Talavera, Secretaria; José Antonio Rodríguez Docavo, Tesorero, y los Vocales, Ángel Lázaro Martínez, José Antonio Benavent Oltra y Gonzalo Musitu Ochoa.

El programa de actividades de la nueva JD puso el énfasis en potenciar el trabajo en equipo, con lo que se promovieron reuniones, jornadas, seminarios y encuentros para dinamizar la Asociación; se convocó y resolvió el I Premio Nacional "Pilar García Villegas"; se impulsó la publicación del nuevo Boletín de Información AEOEP, con la mejora de su presentación, contenidos e información, y cuyo primer número apareció en marzo de 1984; se estimuló la creación de nuevas delegaciones territoriales; la cuota social anual que desde 1983 estaba fijada en 1.500 pesetas se aprueba elevarla a 2.500 para el ejercicio económico de 1986; se mejoraron las relaciones con la AIOEP y se incrementó la participación en los 
eventos internacionales patrocinados por ella. En la reunión de la JD de 17 de enero de 1987, se informa oficialmente de la separación de la DTC, producida en el mes de abril de 1986, y de su transformación en asociación independiente con el nombre de Asociación Catalana de Orientación Escolar y Profesional (ACOEP).

El 9 de enero de 1988 tiene lugar en Madrid la celebración de la JD en la que Tomás Terrados presenta su dimisión irrevocable como Presidente por motivos laborales, al ser trasladado por el Ministerio de Trabajo a un área distinta a la Orientación Profesional y tener que desplazarse fuera de Madrid con un horario laboral que imposibilitaba su continuidad al frente de la Asociación. El talante dialogante y conciliador, la capacidad organizativa y el gran contenido humano de Tomás Terrados dinamizaron la Asociación y la dotaron de un estilo abierto, participativo, colaborador e integrador. La AEOEP, bajo su dirección, superó la crisis provocada por el cambio de liderazgo y transitó hacia un horizonte mejor en cumplimiento de los fines estatutarios, que propiciaron posteriormente la consolidación de la Asociación. La JD acuerda nombrar Presidente en funciones a José Zaragozá para que cubra el año que resta para la extinción del mandato presidencial y se convoquen las nuevas elecciones previstas para principios de 1989.

Durante el mandato en funciones de José Zaragozá, en la AGO de 28 de mayo de 1988, se aprueba la dimisión de Tomás Terrados, se informa de la organización de las I Jornadas Canarias de Orientación, del 19-21 de octubre de 1988 en Sta. Cruz de Tenerife y del proyecto de publicación de una nueva revista, en sustitución del desaparecido Boletín de Información AEOEP, que sería editada por la DTV. La JD del 26 de octubre de 1988 marcó las directrices a seguir durante los primeros años de la década de los 90, al aprobar:

a) La celebración de las V Jornadas Nacionales de Orientación en Valencia, durante 1989.

b) Las VI Jornadas Nacionales de Orientación, a lo largo de 1990 y el V Seminario Iberoamericano, para 1992, ambos eventos a celebrar en Canarias.

c) La publicación de la Revista de Orientación Educativa y Vocacional (ROEV) por la DTV para $1990 \mathrm{y}$

d) La propuesta de nueva JD a presentar en las inminentes elecciones de principios de 1989.

\section{Delegaciones Territoriales}

Durante el Período de Transición (1984-1989) la DTV funciona a pleno rendimiento, se consuma la separación de la DTC, que segregada de la AEOEP y constituida como asociación independiente ACOEP, pide y obtiene su ingreso en la AIOEP, y se solicita y aprueba la constitución de dos nuevas delegaciones, la Delegación Territorial de la Zona Centro (DTZC) y la Delegación Territorial de Canarias (DTCn).

\section{Delegación Territorial de Valencia (DTV)}

En la AGO de 29 de septiembre de 1983, la DTV aprobó el programa de actividades a desarrollar durante el curso 1983-84, que comprendía una amplia oferta de cursos de for- 
mación y perfeccionamiento para orientadores y tutores de EGB y BUP en colaboración con el ICE de la Universidad de Valencia (Anónimo, 1984a), y la organización de las III Jornadas de Orientación de la AEOEP, que se celebraron en Valencia, del 4 al 9 de junio de 1984.

El 22 de febrero de 1984 la DTV ofreció una misa en sufragio de Pilar García Villegas en la Iglesia del Real Corpus Christi (Patriarca) de la ciudad de Valencia (Anónimo, 1984b).

En el I Congreso de Orientación Escolar y Profesional, patrocinado por el MEC y el INEM, y celebrado en Madrid, del 2 al 5 de mayo de 1984, se matricularon 37 socios, muchos de los cuales presentaron y defendieron ponencias y comunicaciones (MEC-INEM, 1985). En septiembre de 1984, como consecuencia del desarrollo de la LRU y su incidencia en los ICEs, finalizó el convenio de colaboración entre el ICE de la Universidad de Valencia y la DTV, por lo que a partir de este momento, la DTV asume totalmente la responsabilidad sobre la organización y financiación de los cursillos y seminarios anteriormente copatrocinados. Y en noviembre, el domicilio social de la DTV se traslada al Departamento de Orientación Educativa, Facultad de Filosofía y Ciencias de la Educación, Universidad de Valencia, Avda. Blasco Ibáñez no 21, 46010 Valencia. En enero de 1985, la DTV firma un convenio de actividades docentes complementarias con el ICE de la Universidad Politécnica de Valencia (Anónimo, 1985a).

En la AGE de 13 de junio de 1985 se renueva la JD, siendo reelegido Presidente José Miguel Orts Timoner. La nueva JD impulsa el crecimiento de la DTV con la captación de nuevos socios y prosigue, durante los años 1986, 1987 y 1988, con la organización de cursillos y seminarios permanentes para la formación y perfeccionamiento profesional de sus asociados. Por problemas de financiación, dado el número y extensión de los trabajos presentados, las Actas de las III Jornadas de Orientación no se publicarán hasta octubre de 1986. En 1988, ante el vacío dejado por la desaparición del Boletín de Información AEO$E P$ y el fallido intento de sustituirlo por INDEFOR en 1987, la DTV propone a la JD Nacional responsabilizarse de la edición de una revista, que con el título de Revista de Orientación Educativa y Vocacional (ROEV), sea órgano oficial y portavoz de la AEOEP, pero que a la vez recoja y publique los trabajos e investigaciones de los asociados. El Período de Transición se cierra en la DTV con la finalización de la presidencia de José Miguel Orts y la elección, el 13 de febrero de 1989, de la nueva JD presidida por José Antonio Benavent Oltra.

\section{Delegación Territorial de Cataluña (DTC)}

El 22 de octubre de 1983 se reunió la JD de la DTC para programar las actividades del curso 1983-84 y preparar la participación de la Delegación en los congresos de Orientación de Madrid y Valencia, y en el de Pedagogía de Santiago de Compostela. En el I Congreso de Orientación Escolar y Profesional celebrado en Madrid en mayo de 1984 se inscribieron un total de 44 especialistas catalanes, muchos de ellos socios de la DTC, que presentaron y defendieron varias ponencias y comunicaciones (MEC-INEM, 1985). La participación de los socios de la DTC en las III Jornadas de Orientación Educativa de la AEOEP, organizadas por la DTV y que tuvieron lugar en la Universidad de Valencia, del 4 al 9 de junio de 1984, fue igualmente muy numerosa, presentando y defendiendo una ponencia y numerosas 
comunicaciones (AEOEP, 1986). En julio de 1984, son varios socios de la DTC los que asisten y participan activamente con comunicaciones, todas ellas sobre Orientación educativa, en el VIII Congreso Nacional de Pedagogía celebrado en Santiago de Compostela (Anónimo, 1985).

La primera mitad del curso 1984-85 la dedicó la DTC a organizar y celebrar las I Jornadas Catalanas sobre "La Escuela y la Orientación de los adolescentes", que desarrolladas totalmente en catalán, fueron patrocinadas por la AEOEP, la Generalitat de Catalunya y otras instituciones y organizaciones catalanas.

El 28 de agosto de 1985 muere repentinamente el padre Miguel Bertrán Quera, fundador, entusiasta impulsor y Presidente de la DTC, dotado de una profunda formación académica, una dilatada experiencia profesional y un probado espíritu conciliador que había conducido a la DTC bajo su dirección a sus más altas cotas, al ser también promotor y coordinador de las I Jornadas Catalanas sobre "La Escuela y la Orientación de los adolescentes". En su honor y memoria, la AEOEP se comprometió a editar las actas de dichas Jornadas, traducidas del catalán al castellano por la DTC, y a las que se dedicó monográficamente el número 6 (6) del Boletín de Información AEOEP de marzo de 1986.

Después del fallecimiento de Bertrán Quera, la facción más nacionalista de la DTC, que él supo conducir y conciliar con los intereses generales de la AEOEP, tomó las riendas de la JD, y una vez publicadas las Actas de las I Jornadas, se separó de la AEOEP para constituirse en asociación independiente con el nombre de Asociación Catalana de Orientación Escolar y Profesional (ACOEP), consumándose la segregación el 18 de abril de 1986. Posteriormente, la ACOEP solicitó el ingreso en la AIOEP, acompañando su solicitud, con una extensa y detallada memoria de actividades que se remitió tanto a la Presidencia, como a la Secretaría general, solicitud que fue aceptada por la AIOEP. No obstante, las relaciones entre la AEOEP y la ACOEP continuaron siendo fluidas en un clima de cordialidad y colaboración, pues aunque muchos socios de la DTC se dieron de baja de la AEOEP, otros permanecieron con la AEOEP causando baja en la ACOEP y otros tantos mantuvieron su inscripción en ambas asociaciones.

\section{Delegación Territorial de la Zona Centro (DTZC)}

Desde principios de 1985 existía entre los socios de Madrid la intención de constituir una Delegación Territorial que bajo la denominación de Zona Centro aglutinase a los asociados de las Comunidades Autónomas de Madrid, Castilla-La Mancha, Castilla-León y Extremadura. La JD celebrada en Valencia el 19 de octubre de 1985, con motivo de la entrega del I Premio Nacional "Pilar García Villegas", el socio Juan José García Jiménez presentó, apoyado por 27 firmas, la reglamentaria solicitud de creación de la DTZC junto con la propuesta de celebrar las IV Jornadas de Orientación de la AEOEP en Ávila. Ambas peticiones fueron aceptadas por la JD que las presentó para su ratificación a la AGO del 12 de abril de 1986 en la que se aprueba por unanimidad la constitución de la Delegación Territorial de la Zona Centro, así como la celebración de las IV Jornadas de Orientación en Ávila, del 25 al 27 de septiembre.

En mayo de 1986 tuvo lugar en los locales de la UNED, en Madrid, la AGO constituyente, en la que se aprobó por unanimidad la primera JD presidida por Juan José García Jiménez, que de acuerdo con los Estatutos pasa a ser vocal nato de la JD de la AEOEP. Las 
principales actividades desarrolladas durante el período inicial de funcionamiento de la nueva DT fueron: la preparación, organización y celebración de las mencionadas Jornadas de Orientación de Ávila y la publicación de 3 números del periódico INDEFOR. La andadura de la Delegación, durante el período que estamos analizando, estuvo enmascarada y confundida con el funcionamiento de la AEOEP-Nacional con la que compartió locales, organización de actividades y miembros de sus respectivas JDs. En diciembre de 1989, Juan José García Jiménez y la JD presentan su dimisión irrevocable y se abre un período constituyente para la presentación de nuevas candidaturas.

\section{Delegación Territorial de Canarias (DTCn)}

En las IV Jornadas de Orientación celebradas en Ávila en septiembre de 1986, el socio Miguel T. Ramírez, Inspector Jefe de EGB de Santa Cruz de Tenerife y Secretario de la Consejería de Educación del Gobierno de Canarias, se compromete con los miembros de la JD de la AEOEP a realizar las gestiones necesarias para promocionar, y potenciar el asociacionismo de los orientadores de Canarias y promover la constitución de una Delegación Territorial en dicha Comunidad Autónoma. En estos momentos, la AEOEP solo contaba con dos socios residentes en las islas Canarias, Miguel T. Ramírez y otra persona asociada. En unos pocos meses, Miguel T. Ramírez, logra la inscripción de un centenar de socios residentes en distintas localidades de la provincia de Santa Cruz de Tenerife. En la AGO de la AEOEP celebrada en Madrid, el 4 de abril de 1987, a propuesta de la JD, que había aceptado previamente la solicitud presentada por Miguel T. Ramírez, se aprueba por unanimidad la constitución de la DTCn, de la que Miguel T. Ramírez fue su primer Presidente y que como Vocal nato de la AEOEP participó por vez primera con voz y voto en la JD celebrada en Madrid el 9 de enero de 1988.

La fuerza e ilusión con que nace y se desarrolla la DTCn quedó plasmada en el crecimiento exponencial de sus asociados y en la organización de las I Jornadas Canarias de Orientación que se celebraron en Santa Cruz de Tenerife, del 19 al 21 de octubre de 1988.

\section{Congresos, Jornadas y Seminarios}

Durante el Período de Transición (1984-1989), la AEOEP, a través de sus DTs, organizó y celebró las III Jornadas Nacionales de Orientación Educativa en Valencia, las I Jornadas Catalanas sobre "La Escuela y la Orientación de los adolescentes" en Barcelona, las IV Jornadas Nacionales de Orientación Escolar y Profesional en Ávila y las I Jornadas Canarias de Orientación en Santa Cruz de Tenerife.

\section{Jornadas Nacionales de Orientación Educativa}

Las III Jornadas Nacionales de Orientación Educativa, bajo el lema "La Orientación ante las dificultades del aprendizaje", se celebraron en Valencia, del 4 al 9 de junio de 1984 organizadas por la DTV y patrocinadas por la AEOEP, la Generalitat, la Diputación, el Ayuntamiento, la Universitat de València y otras instituciones valencianas públicas y privadas. Las sesiones se desarrollaron en las distintas Facultades del Campus 
"Blasco Ibáñez" de la Universitat de Valencia con 456 congresistas inscritos y una nutrida asistencia.

Las III Jornadas se desarrollaron en una sesión inaugural, seis sesiones plenarias y una sesión de clausura. Se presentaron un total de 69 trabajos que se distribuyeron en 2 conferencias, 11 ponencias, 18 foros para la exposición de 56 comunicaciones y 2 talleres. Todos los trabajos, así como las distintas intervenciones de las sesiones de apertura y clausura, las conclusiones, la valoración de las Jornadas y la relación de los participantes se publicaron en las Actas (AEOEP, 1986).

La sesión de apertura fue presidida por el Vicerrector de Ordenación Académica, Dr. Ortiz Lahoz, en representación del Rector de la Universitat de València, e hicieron uso de la palabra, el Coordinador de las Jornadas, Prof. Orts Timoner, el Director del ICE, Dr. Iborra Martínez, y la Secretaria de la AEOEP, Dra. Repetto Talavera. Cada una de las sesiones plenarias, vertebradas por las ponencias, se dividieron en varios foros para la exposición y discusión de las comunicaciones. La sesión de clausura estuvo presidida por el Director General de Enseñanzas Básicas, Sr. Vives Moncho, en representación del Conseller de Cultura, Educación y Ciencia de la Generalitat Valenciana, interviniendo además en el acto, el Coordinador de las Jornadas, el Director del ICE, el Presidente de la AEOEP, Sr. Terrados Jarabo, el Teniente-Alcalde Delegado de Educación del Ayuntamiento de Valencia, Sr. Martí Figueres y el Director de los Servicios Territoriales de Educación de Valencia, Sr. Tomás Llopis. Con la conferencia del Dr. Miguel Bertrán Quera, "Prospectiva de la Orientación educativa y de la figura del orientador" y la lectura de las Conclusiones de las Jornadas, a cargo del Coordinador, el Sr. Vives Moncho, en nombre del Conseller de Cultura, Educación y Ciencia de la Generalitat Valenciana las dio por finalizadas.

\section{Jornadas Catalanas sobre "La Escuela y la Orientación de los adolescentes"}

Las I Jornadas Catalanas sobre "La Escuela y la Orientación de los adolescentes", se celebraron en Barcelona, los días 22 y 23 de marzo de 1985, organizadas por la DTC y patrocinadas por la AEOEP, la Generalitat de Catalunya y otras instituciones catalanas públicas y privadas. Las sesiones se desarrollaron en los locales de la Obra Social de la Caixa de Barcelona con un total de 439 inscripciones y más de 300 asistentes, en su totalidad de Cataluña, desarrollándose sus sesiones íntegramente en catalán, excepto las palabras de clausura pronunciadas por el Tesorero de la AEOEP Sr. Rodríguez Docavo en representación de su Presidente (Rodríguez Docavo, 1993).

Durante las sesiones de trabajo de las I Jornadas se expusieron dos ponencias, a cargo de Miguel Bertrán Quera y María Luisa Rodríguez Moreno, con "un programa exhaustivo compuesto de tres mesas para debatir experiencias, proyectos y conclusiones, ... programa que fue completado con un documento base para facilitar el proceso comunicativo de las tres sesiones entre profesionales de tan diversa procedencia" (Rodríguez Moreno, 1986, p. 14). En total se presentaron 21 trabajos (2 ponencias y 19 comunicaciones), todos ellos, junto con la evaluación de las Jornadas, las Conclusiones, una relación de los participantes y un dossier bibliográfico y documental, se publicaron, traducidos del catalán al castellano, en el número 6 (6) del Boletín de Información AEOEP, de marzo de 1986, que sirvió de Actas de dichas Jornadas y en cuya Editorial se dice textualmente: 
"Fue su principal alma y organizador Miguel Bertrán Quera, Presidente de la Delegación Territorial de Cataluña, con intervención de gran parte de nuestros socios, constituyeron un gran éxito, no sólo por la presencia de responsables y expertos de la Orientación, sino también por la viveza y profundidad de las intervenciones. El programa recogía un examen de las experiencias, un análisis de la situación actual, y un estudio de los proyectos, en tema tan fundamental como la orientación de los adolescentes. La presencia de altos cargos de la Generalitat de Cataluña dio más interés a las conclusiones. La repentina muerte del Profesor Bertrán Quera, que tanto trabajó por nuestra Asociación y por estas Jornadas nos lleva a dedicar este número al recuerdo de su memoria. Descanse en paz" (pp. 2-3).

\section{Jornadas Nacionales de Orientación Educativa y Profesional}

Las IV Jornadas Nacionales de Orientación Educativa y Profesional con el tema "Formación, Orientación y Vida Activa", se celebraron en Ávila, del 25 al 27 de septiembre de 1986, organizadas por la DTZC y patrocinadas por la AEOEP, la UNED, la Consejería de Turismo de Castilla y León y la Caja Rural. Las sesiones se desarrollaron en los locales del Centro Asociado de la UNED en Ávila con asistencia de más de un centenar de congresistas y con representación de delegados de empresas tan importantes como Telefónica, Pegaso, CAMPSA, Hidroeléctrica, etc., y estuvieron coordinadas por Juan José García Jiménez. La Agencia EFE, RC Española, Antena 3 y la prensa local difundieron el evento. No se editaron actas.

Las IV Jornadas se desarrollaron en una sesión inaugural, tres sesiones plenarias y una sesión de clausura. Se presentaron en total 34 trabajos (3 ponencias y 31 comunicaciones). La sesión inaugural fue presidida por Tomás Terrados, Presidente de la AEOEP, e intervinieron el Coordinador de las Jornadas, Juan José García Jiménez, el Director del Centro Asociado de la UNED en Ávila y la Secretaria de la AEOEP, Elvira Repetto. Las sesiones plenarias se desarrollaron en tres paneles rotulados con los lemas: Formación, Orientación y Empleo. Cada panel se iniciaba con la ponencia marco y recogía a continuación las comunicaciones afines. La sesión de clausura estuvo presidida por el Alcalde de Ávila, Mario Galán, e intervinieron en el acto, José Antonio Rodríguez Docavo, Tesorero de la AEOEP, el Delegado de la Consejería de Turismo de Castilla y León, Salvador Cerrada, el Presidente de la AEOEP, Tomás Terrados, el Coordinador de las Jornadas leyó las conclusiones y el Alcalde de Ávila clausuró las Jornadas con unas breves palabras de despedida. Una reseña de las Jornadas se publicó en el número 0 de INDEFOR (1987).

\section{Jornadas de Orientación Educativa y Profesional en Canarias}

Las I Jornadas de Orientación Educativa y Profesional en Canarias se celebraron en Santa Cruz de Tenerife, del 19 al 21 de octubre de 1988, organizadas por la DTCn y patrocinadas por la AEOEP, la Consejería de Educación, Cultura y Deportes, el Cabildo Insular de Tenerife, el Ayuntamiento de Santa Cruz de Tenerife, la Caja General de Ahorros de Canarias y la Librería Lemus. Las sesiones se desarrollaron en los magníficos locales municipales del Parque Cultural "Viera y Clavijo" con 324 congresistas inscritos y una nutrida asistencia. Las Jornadas estuvieron coordinadas por Miguel T. Ramírez García, Presidente de la AEOEP de Canarias. 
Estas I Jornadas se desarrollaron en una sesión inaugural, cuatro sesiones plenarias y una sesión de clausura. Se presentaron un total de 51 trabajos que se distribuyeron en 2 conferencias, 3 ponencias, 9 foros para la exposición de 46 comunicaciones y 3 mesas para debatir conclusiones. Las conferencias, las ponencias y las 34 comunicaciones leídas ajustadas a formato, así como las distintas intervenciones de las sesiones de apertura y clausura, las conclusiones, y la relación de comunicantes y participantes se publicaron en las Actas (AEOEP-DTCn, 1986).

La sesión de apertura fue presidida por el Consejero de Educación, Cultura y Deportes del Gobierno de Canarias D. Enrique Fernández Caldas, la presentación de las Jornadas corrió a cargo de Miguel T. Ramírez y la conferencia inaugural fue pronunciada por Elvira Repetto, Catedrática de Orientación de la UNED y Secretaria de la AEOP. Cada una de las 3 sesiones plenarias se dedicó a un área temática vertebrada por su respectiva ponencia, que a su vez estaba dividida en tres foros para la exposición y discusión de las comunicaciones $\mathrm{y}$, una cuarta sesión con tres mesas de discusión, se dedicó a la elaboración de las conclusiones parciales por área y las generales de las Jornadas. La sesión de clausura estuvo presidida por la Directora General de Promoción Educativa de la Consejería de Educación, Cultura y Deportes, Ana Rosa Corrales, la conferencia de clausura corrió a cargo de Sebastián Rodríguez Espinar, Catedrático de Orientación Educativa de la Universidad de Barcelona, y finalmente, las Jornadas fueron clausuradas con unas sencillas palabras de José Antonio Rrodríguez Docavo, Tesorero de la AEOEP.

\section{Publicaciones}

Durante el Período de Transición (1984-1989) se editaron cuatro números del Boletín de Información AEOEP, tres ejemplares del periódico trimestral de información para los orientadores españoles INDEFOR, las Actas de las III Jornadas Nacionales de Orientación de Valencia, de las I Jornadas Catalanas y de las I Jornadas de Canarias.

Con la muerte de Pilar García Villegas en enero de 1984 desaparece el Boletín AEOEP que ella componía y dirigía. En la primera JD presidida en funciones por Tomás Terrados, el 31 de enero de 1984, se aprueba para sustituirlo, la edición de una nueva publicación periódica como órgano oficial y portavoz de la AEOEP con la cabecera de Boletín de Información AEOEP y se nombra un consejo de redacción formado por Luis García Mediavilla, Elvira Repetto, José Antonio Rodríguez Docavo y Tomás Terrados, con dos Corresponsales, Santiago Martí García, para la DTC y Josefa Belloch García, para la DTV.

El nuevo Boletín de Información AEOEP, editado por CALPA, se publicó en formato cuartilla, reproducido por fotocopiado, en un solo pliego grapado, con una extensión mínima de 60 páginas y máxima de 120, con tiradas reducidas adecuadas al número de asociados en cada momento y con una mejorada portada de diseño en cartulina satinada (Fig. 2). Su contenido está estructurado en los siguientes apartados:

1) Editorial.

2) Colaboraciones técnicas.

3) Secciones fijas (Delegaciones).

4) Congresos y reuniones $y$

5) Noticias. 


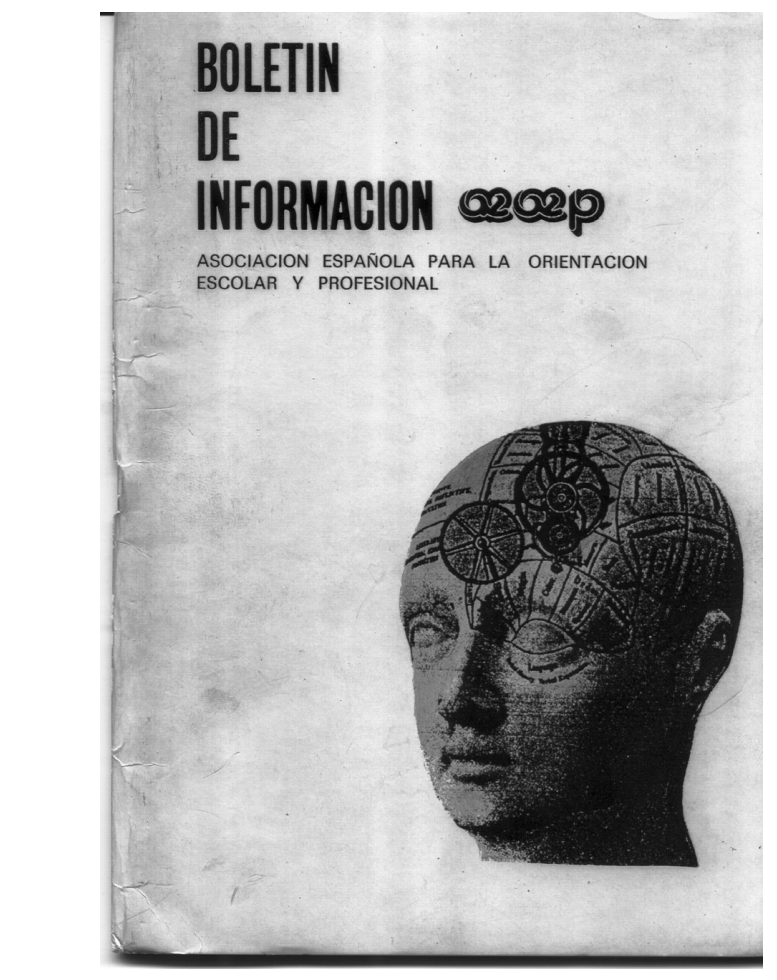

\section{Portada del Boletín de Información AEOEP (1984-1986).}

En total se editaron cuatro números, el primero apareció en marzo de 1984 y el último en marzo de 1986, número que sirvió de Actas de las I Jornadas de Orientación de la AEOEP celebradas en Cataluña. El Boletín desaparece al dimitir en 1986 García Mediavilla como Jefe de redacción e impresor de la publicación. El contenido de los cuatro números publicados se presenta en el Anexo II.

En su sustitución, y resultado del acuerdo al que se llegó en las Jornadas de Ávila entre la JD de la AEOEP y Juan José García Jiménez, nace en marzo de 1987, INDEFOR, Periódico trimestral de Información para los orientadores españoles, órgano de expresión de la AEOEP, cuyo título es el acrónimo de las palabras: Información, Desarrollo, Formación y Orientación. Impreso en los talleres tipográficos del Diario de Ávila S.A. en formato A4 y en un solo pliego de 4 hojas, tuvo una efímera vida, solo tres números, correspondientes a los tres primeros trimestres de 1987. Su cabecera se reproduce en la figura 3 y su contenido se presenta en el Anexo III.

En cuanto a las Actas, la correspondiente a las III Jornadas de Orientación Educativa (Valencia, 4-9 de junio de 1984), se editaron gracias a la generosa ayuda del ICE de la Universidad de Valencia, y sus 873 páginas recogen todas las ponencias y comunicaciones presentadas. Por su extensión, al generar unos costos de edición que superaban lo presupuesta- 


\section{N D E F O R \\ Información, Desarrollo, Formación y Orientación \\ Periódico trimestral de información para los orientadores españoles ORGANO DE EXPRESION DE LA ASOCIACION ESPANOLA PARA LA ORIENTACION ESCOLAR Y PROFESIONAL NUMERO O PRIMER TRIMESTRE 1987 DIRECTOR PERIODISTA G. JIMENEZ \\ FIGURA 3. \\ Cabecera del número 0 del periódico INDEFOR (1987).}

do, su publicación se retrasó dos años (AEOEP, 1986). Como ya hemos indicado anteriormente, las Actas de las I Jornadas Catalanas de la AEOEP, organizadas por la DTC se publicaron en el número 6 (6) del Boletín de Información AEOEP correspondiente a marzo de 1986. Finalmente, las I Jornadas de Orientación Escolar y Profesional de Canarias fueron editadas por la DTCn y en sus 421 páginas re recoge la organización, el programa, la sesión inaugural, las conferencias, ponencias y comunicaciones leídas y ajustadas a formato, las conclusiones, el acto de clausura, la relación de inscritos y el índice (AEOEP-DTCn, 1989).

\section{Becas y Premio "Pilar García Villegas"}

La política de becas, iniciada en el período anterior para ayudar a los socios en sus viajes al extranjero para participar en jornadas y congresos internacionales, siguió vigente.

El Premio Nacional "Pilar García Villegas", instituido en recuerdo y homenaje a nuestra Presidenta fundadora para incentivar la investigación de los asociados, y dotado con 100.000 pesetas procedentes de los beneficios del II Seminario Iberoamericano, fue convocado en enero de 1984 y se presentaron un total de 8 trabajos (5 de Valencia, 2 de Madrid y 1 de Barcelona). El fallo del Jurado, de 23 de abril de 1985, otorgó el premio al trabajo titulado "La disciplina familiar y su relación con la autoestima, rendimiento escolar y adaptación social” de Melchor Gutiérrez y Gonzalo Musitu, socios de la DTV. El premio fue entregado a los autores en un brillante acto académico que tuvo lugar en la Universidad de Valencia, con asistencia de toda la JD de la AEOEP, el 19 de octubre de 1985. Un artículo sobre el mismo y resúmenes de los trabajos presentados fueron publicados en el número 5 (6) del Boletín de Información AEOEP de enero de 1986, dedicado monográficamente al citado Premio.

\section{Proyección internacional}

La AEOEP empieza a tener una significativa presencia institucional a través de sus asociados en los principales foros científicos de Orientación Educativa y Profesional a nivel mundial. Así, durante el Período de Transición, sus socios participaron activamente representando a la AEOEP con ponencias y comunicaciones en los siguientes eventos internacionales:

- X Coloquio Internacional de la Asociation of Vocational Career Counseling, celebrado en Jerusalén (Israel), del 30 de abril al 4 de mayo de 1984, y en el que participaron Irene García Suárez, Elvira Repetto y José Zaragozá. 
- XXIII Congreso Internacional de Psicología, Ciudad de México (México), del 2 al 7 de septiembre de 1984, con asistencia de Miguel Bertrán Quera, Irene García Suárez y Elvira Repetto Talavera

- III Seminario Iberoamericano de la AIOEP, Morelia (México), del 20 al 22 de septiembre de 1984, y al que asistieron Santiago Castillo, Irene García, Elvira Repetto, José Antonio Rodríguez Docavo, José Luis Sebastiá y José Zaragozá.

- Congreso Internacional de la Juventud organizado por la UNESCO, Barcelona, 8-15 de julio de 1985, con participación de Elvira Repetto y María Luisa Rodríguez Moreno.

- XI Congreso Internacional de la AIOEP sobre "El papel de la Orientación profesional en las reformas educativas y el desarrollo vocacional" Dubrovnick (Yugoslavia), 2023 de septiembre de 1985, y en el que participaron Francesc Falgueres, Juan José García Jiménez, Fernando de Justicia, Elvira Repetto, María Luisa Rodríguez Moreno y José Zaragozá.

- Seminario Internacional de la AIOEP celebrado en Berlín (Alemania Occ.), del 9 al 13 de junio de 1986, bajo el lema "Transición de la escuela a la vida activa", con la participación de Francesc Falgueres, Irene García, Juan José García, Elvira Repetto y María Luisa Rodríguez.

- IV Seminario Iberoamericano de la AIOEP, Buenos Aires (Argentina), octubre de 1986, y al que asistieron Elvira Repetto y José Zaragozá.

- XII Congreso Internacional de la AIOEP, sobre "La contribución de la Orientación a la integración de los jóvenes al mundo social y laboral", Annecy (Francia), del 20 al 27 de septiembre de 1987 y en el que participaron Elvira Repetto, José Antonio Rodríguez Docavo, Tomás Terrados y José Zaragozá. Elvira Repetto es elegida miembro de la JD de la AIOEP (Anónimo, 1987a).

\section{Período de consolidación (1989-1995)}

El Período de Consolidación comprende, desde el nombramiento como Presidenta de Elvira Repetto Talavera (18/02/89), hasta la aprobación del cambio de denominación de la AEOEP por AEOP y de su revista ROEV por ROP, en la AGE del 24 de noviembre de 1995. Se caracteriza por:

a) La superación definitiva de la crisis institucional generada por el fallecimiento de su Presidenta fundadora y la consolidación y adecuación de las estructuras funcionales de la Asociación.

b) El nuevo estilo de liderazgo y la continuidad de la nueva Presidenta, Elvira Repetto Talavera y de su equipo al frente de la Asociación, al ser reelegida para un segundo mandato en 1993.

c) El continuado y progresivo crecimiento del número de asociados.

d) La modificación de los Estatutos (1992) para actualizarlos a las nuevas necesidades y la aprobación del Reglamento General de Régimen Interior (1992).

e) El nacimiento y la continuidad de la publicación periódica Revista de Orientación Educativa y Vocacional (ROEV) (1990-1995), nuevo órgano oficial y portavoz de la AEOEP. 
f) Adquisición en propiedad de un pequeño local para domicilio social.

g) Intensa y fecunda proyección nacional e internacional de la Asociación, con la organización y participación activa de sus socios en congresos, jornadas, seminarios, cursos y salones del estudiante, la firma de convenios de investigación financiados, y el nombramiento, en 1995, de Elvira Repetto como Vicepresidenta de la AIOEP y

h) El cambio de denominación de la Asociación y de su Revista (1995).

\section{Acuerdos, actividades y acontecimientos}

La propuesta de candidatura consensuada por la anterior JD para la renovación de sus miembros fue aprobada por unanimidad en la AGE de 18 de febrero de 1989. La candidatura, presidida por "Elvira Repetto, ya brillante catedrática de Orientación de la UNED, ... era la candidata adecuada para ocupar la Presidencia. Sus dotes personales, su encanto y saber hacer, su categoría humana, su nivel profesional, su relación con la AIOEP, etc. se ajustaban perfectamente a un perfil ideal para ocupar la presidencia de la AEOEP" (Rodríguez Docavo, 1993, p. 272). La nueva JD se completaba con José Miguel Orts Timoner, Vicepresidente; María Teresa Gullón Jalón, Secretaria; José Antonio Rodríguez Docavo, Tesorero; los Vocales electos, José Zaragozá Antich, Ángel Arévalo Caballero, Mari Carmen Ferrera Goya e Irene Gozalo Vaquero, y los Vocales natos, José A. Benavent Oltra (DTV), y Miguel T. Ramírez Suárez (DTCn), la DTZC no tiene vocal nato por detentar Elvira Repetto simultáneamente las presidencias de la AEOEP y de su DTZC. Ángel Arévalo, como asesor jurídico de la AEOEP, iba a tener durante este Período un papel relevante en el relanzamiento de la Asociación, tanto en el orden administrativo, como en la redacción del reglamento de régimen interno y las reformas estatutarias.

La nueva JD, durante su primer mandato, se fijó como principales objetivos, la adecuación de su funcionamiento al nuevo sistema educativo surgido con la aprobación de la LOGSE (1990), la consolidación del funcionamiento de sus DTs, la promoción de nuevas DTs, la potenciación de sus órganos de difusión y el relanzamiento de la Asociación a nivel nacional e internacional.

Para alcanzar los anteriores objetivos, la AEOEP realizó las siguientes actividades:

a) Una intensa campaña de promoción de la Asociación y de captación de nuevos socios.

b) El apoyo prestado a la DTV para la organización y celebración de las V Jornadas Nacionales de Orientación, noviembre 1989, en Valencia.

c) La ayuda facilitada a la DTCn para la preparación y celebración de las VI Jornadas de Canarias, octubre de 1990.

d) El estímulo y asesoramiento dispensado a la DTV para propiciar la aparición de la Revista de Orientación Educativa y Vocacional (ROEV), cuyo número cero aparece en 1990, d) La aprobación, en la AGE celebrada el 30 de noviembre de 1989 en Valencia, con motivo de las V Jornadas Nacionales, de la propuesta de la DTCn para la reforma de los artículos 7, 11, 12, 13 y 20 de los Estatutos, a fin de permitir la inscripción como socios a los "profesores-tutores de EGB" con titulación de diplomado universitario, reforma estatutaria que fue aprobada por el Ministerio del Interior el 10 de enero de 1992 (Estatutos, 1992). 
e) En la Asamblea General de 16 de junio de 1990 se aprueba el cambio de domicilio social a la nueva sede (UNED, Edificio Humanidades, Despacho 216, Calle Senda del Rey s/n, 28040 Madrid), el aumento de la cuota social a 3.500 pesetas y el ingreso de la AEOEP en EURO-ORIENTACIÓN, como asociación fundadora. f) La preparación y celebración, en colaboración con la DTCn, de las VI Jornadas Nacionales de Orientación, del 28 de octubre al 3 de noviembre de 1990, en Puerto de la Cruz (Tenerife).

g) La preparación y celebración, en colaboración con la DTZC, de las VII Jornadas Nacionales de Orientación, noviembre de 1990, en Madrid.

h) La preparación y celebración en colaboración con la DTCn del V Seminario Iberoamericano de Orientación, mayo de 1992, Puerto de La Cruz (Tenerife), h) Publicación de Actas de las reuniones científicas celebradas y de 5 números de la REOP (del 0 al 4), e

i) Este primer mandato finaliza con la aprobación, en la AGO de 10 de julio de 1992, del Reglamento General de Régimen Interior (1992), y en la última reunión de la JD, de la propuesta para su renovación y el nombramiento del comité organizador del XV Congreso Internacional de la AIOEP a celebrar en Madrid, en julio de 1994, en colaboración con la DTZC.

El segundo mandato de Elvira Repetto se inicia con la aprobación de su candidatura en la AGE celebrada el 27 de febrero de 1993, quedando constituida la nueva JD bajo su presidencia por: Elena del Campo Adrián, Vicepresidenta; María Teresa Gullón Jalón, Secretaria; José Antonio Rodríguez Docavo, Tesorero; Vocales electos: Laura Oliveros MartínVarés, Ángel Arévalo Caballero, Irene Gozalo Vaquero, Renzina Fossati Marzá, Mari Carmen Ferrera Goya, María José Gil de Gómez Rubio e Inmaculada Martínez Gonzalo, y Vocales natos: José A. Benavent Oltra (DTV) y Miguel T. Ramírez García (DTCn), la DTZC no tiene vocal nato al ser Elvira Repetto Presidenta simultáneamente de la AEOEP y de su DTZC. Se nombra por unanimidad "Miembro Permanente de Honor" de la JD a José Zaragozá, en reconocimiento de su valiosa y dilatada carrera profesional y los inestimables servicios prestados a la AEOEP.

Las principales actividades que se organizaron y desarrollaron durante este segundo mandato fueron las siguientes:

a) La primera, fue la celebración de las II Jornadas de Orientación de Canarias, organizadas por la DTCn en colaboración con la AEOEP, Las Palmas de Gran Canaria, mayo 1993.

b) Celebración de las I Jornadas Valencianas de Orientación, organizadas por la DTV en colaboración con la AEOEP, Valencia, septiembre de 1993.

c) Preparación, organización, gestión y celebración, conjuntamente con la DTZC, del XV Congreso Internacional de la AIOEP, Madrid, julio de 1994.

d) Adquisición conjunta por AEOEP y DTZC, para ubicar el domicilio social de ambas asociaciones, de un despacho de $12,50 \mathrm{~m}^{2}$ en la Calle Núñez de Balboa, 90, $2^{\circ}$ interior, 28006 Madrid. Compra aprobada el 14 de enero de 1995 y financiada con los beneficios generados por el XV Congreso Internacional de la AIOEP. 
e) El 24 de marzo de 1995 se celebra la primera JD en el nuevo local y se aprueba la adquisición del primer ordenador personal para gestionar y administrar conjuntamente la AEOEP y su DTZC.

f) En la JD de 20 de mayo de 1995 se propone la creación de tres nuevas DTs, las de Andalucía, País Vasco y Galicia, Dimite como Vicepresidenta Elena del Campo, que es substituida por la vocal $1^{\mathrm{a}}$, Laura Oliveros. También finalizó mandato como Presidente de la DTCn, Miguel T. Ramírez, que pasa a ser Vocal $7^{\circ}$, y la JD lo propone para el nombramiento de "Socio de Honor" por los valiosísimos e inestimables servicios prestados a la AEOEP como fundador, promotor y alma de la DTCn

g) Se publican las Actas de varias reuniones científicas y los números del 5 al 10 de la REOP.

h) En la AGO de 23 de junio de1995 se aprueba la constitución de las Delegaciones Territoriales de Andalucía (DTA) y País Vasco (DTPV) y se desestima la de Galicia, por no presentar la documentación preceptiva. Se nombra a Miguel T. Ramírez "Socio de Honor", e

i) El Período de Consolidación finaliza con la AGE de 24 de noviembre de 1995, en la que se aprueba el cambio de denominación de la Asociación Española para la Orientación Escolar y Profesional (AEOEP) por el de Asociación Española de Orientación y Psicopedagogía (AEOP) y el de su órgano oficial y portavoz, Revista de Orientación Educativa y Vocacional (ROEV), por el de Revista de Orientación y Psicopedagogía (ROP), ambos cambios de denominación se justifican por la creación del título de Licenciado en Psicopedagogía en la Universidad española.

\section{Delegaciones Territoriales (DT)}

Durante el Período de Consolidación (1989-1995), estaban funcionando a pleno rendimiento la DTV, la DTZC y la DTCn y se solicita y aprueba la creación de dos nuevas Delegaciones, la Delegación Territorial de Andalucía (DTA) y la Delegación Territorial del País Vasco (DTPV), ambas en 1995.

\section{Delegación Territorial de Valencia (DTV)}

En febrero de 1989, la nueva y recién elegida JD de la DTV, contando con la decidida colaboración y apoyo de la AEOEP, acepta dos retos importantes, la organización y celebración en Valencia, de las V Jornadas Nacionales de Orientación antes de finalizar el año, y la edición del número 0 de la Revista de Orientación Educativa y Vocacional (ROEV), actividades propuestas y comprometidas por la JD saliente, y que fueron aplazándose "sine die", tanto por problemas de organización como de financiación. En octubre de 1989, José Miguel Orts, presenta su dimisión como responsable de la edición de la ROEV ante la JD de la AEOEP, dimisión que no es aceptada y se le ratifica en el cargo de Director ejecutivo para que la ROEV se publique lo antes posible. Se continúan impartiendo cursillos de formación y perfeccionamiento para el profesorado en colaboración con el Servicio de Formación Permanente de la Universidad de Valencia, y del 27 al 30 de noviembre, se celebran las V Jornadas Nacionales de Orientación Educativa 
José Miguel Orts, como promotor y responsable de la edición del número 0 de la ROEV, logra finalmente su publicación gracias a que se aprueba financiar su edición con los beneficios obtenidos en las V Jornadas Nacionales y lo presenta a la JD de la AEOEP celebrada en Madrid en marzo de 1990, siendo felicitado por su trabajo y cesa en sus funciones de Director ejecutivo. A partir de este momento, los esfuerzos de la DTV se van a centrar en la preparación y organización de las I Jornadas Valencianas de Orientación que se celebraron en la Universidad de Valencia en septiembre de 1993. En la AGE de 19 de enero de 1993 se renueva la JD siendo reelegido Presidente José Antonio Benavent Oltra. La DTV participa activamente en el desarrollo del XV Congreso Internacional de la AIOEP celebrado en Madrid en julio de 1994 con la inscripción de 21 asociados. Finalmente, en la AGO de la AEOEP de junio de 1995, se aprueba la propuesta de la DTV de celebrar las VIII Jornadas Nacionales de Orientación en Valencia, en 1997, por lo que la actividad de la DTV se centrará principalmente, desde este momento, en la organización y preparación de este importante evento.

\section{Delegación Territorial de la Zona Centro (DTZC)}

Tras la dimisión de la JD de la DTZN en diciembre de 1988, se abre un período constituyente de presentación de candidaturas. En la AGE de 20 de febrero de 1989, se procede a la votación de la única candidatura presentada presidida por Elvira Repetto Talavera, que resulta elegida por unanimidad, así pues, la nueva Presidenta lo será simultáneamente de la AEOEP y de su DTZC. En marzo se inicia una campaña de divulgación de la DT y de captación de nuevos socios. En octubre, la JD presenta la programación de actividades para el curso 1989-90, en la que se propone la organización de cursillos de formación y perfeccionamiento para orientadores, la celebración de unas Jornadas locales, con el lema "El Orientador ante la Reforma" y la elaboración de un cuadernillo de trabajo, con periodicidad trimestral, que con la denominación "Apuntes de Orientación", recoja noticias puntuales y la actualidad de la DT. De su elaboración y edición se encargará Daniel Anaya.

En enero de 1991 se acuerda organizar, en colaboración con la AEOEP, la celebración de las VII Jornadas Nacionales de Orientación en Madrid, durante el mes de noviembre, y se procede al nombramiento del Comité organizador. Las VII Jornadas se desarrollaron con brillantez del 6 al 8 de noviembre, tanto por la nutrida participación, como por la cantidad y calidad de los trabajos presentados.

En la AGE de 18 de febrero de 1994, se procede a la renovación de la JD, siendo elegida por unanimidad la candidatura presentada por Elvira Repetto que renueva mandato como Presidenta de la DT. La tarea prioritaria que se fija la nueva JD es la organización y preparación, conjuntamente con la AEOEP, de la celebración en Madrid, del 13 al 19 de julio de 1994, del XV Congreso Internacional de la AIOEP. A los congresistas se les entregó un libro-programa de 220 páginas con los resúmenes de todas las ponencias y comunicaciones presentadas (AEOEP-UNED, 1994). Las Actas, en dos voluminosos tomos con más de 1.500 páginas, se publicaron con un notable retraso en 1998 debido a su extensión y a problemas de financiación (UNED, 1998).

En enero de 1995, al presidir Elvira Repetto simultáneamente la AEOEP y su DTZC, se llega fácilmente al acuerdo de adquirir un local para ubicar el domicilio social de la AEOEP 
y su DTZC, local situado en la Calle Núñez de Balboa, 90, $2^{\circ}$ interior de 28006 Madrid. La compra se financia con los beneficios generados por el XV Congreso Internacional de la AIOEP. En marzo, se crean las Vocalías que se responsabilizarán de dinamizar e impulsar las distintas actividades de la DT.

\section{Delegación Territorial de Canarias (DTCn)}

El éxito alcanzado y la experiencia adquirida por la DTCn con la celebración de sus I Jornadas de Orientación, en octubre de 1988, la animó a asumir el reto de organizar las VI Jornadas Nacionales de Orientación de la AEOEP que se celebraron, del 29 de octubre al 3 de noviembre de 1990, en El Puerto de la Cruz (Tenerife).

En 1991 se renueva la JD siendo reelegido Presidente Miguel T. Ramírez. Entre las múltiples actividades llevadas a cabo por esta Delegación durante el segundo mandato de su Presidente, cabe destacar por su importancia: la organización del V Seminario Iberoamericano de Orientación, celebrado en mayo de 1992 en El Puerto de la Cruz, y las II Jornadas de Orientación Escolar y Profesional en Canarias, que tuvieron lugar en Las Palmas de Gran Canaria, mayo de 1993. Estos encuentros han supuesto, a nivel general, la actualización y el intercambio de conocimientos y experiencias entre investigadores y profesionales de la orientación y, en particular, han sido una buena ocasión para que los asociados canarios pudieran comunicar sus experiencias y compartirlas con otros profesionales e investigadores nacionales e internacionales.

Durante este Período, la DTCn también dio una eficaz respuesta a las demandas de formación permanente de los orientadores mediante la celebración de diferentes cursos y cursillos sobre: educación para la salud, intervención en el medio familiar, prevención de la drogodependencia en el medio escolar, trastornos disociados de la personalidad, psicosis y autismo infantil, diseños curriculares y programaciones para el desarrollo de las capacidades en el marco de la LOGSE, estrategias y recursos para la mejora del aprendizaje y la orientación educativa, etc.

En mayo de 1995 se renueva la JD de la DTCn cesando como Presidente, Miguel T. Ramírez, que no se presenta a la reelección, y que por sus inestimables servicios al desarrollo, promoción y divulgación de la Orientación, fue nombrado "Socio de Honor" de la AEOEP en la AGO de 23 de junio de 1995. La nueva JD, presidida por Víctor José González Expósito, inicia su andadura con el reto de mantener el prestigio alcanzado a nivel nacional e internacional por la DTCn durante el brillante mandato de su Presidente saliente.

\section{Delegación Territorial de Andalucía (DTA)}

En la JD de la AEOEP de 20 de mayo de 1995, Juan Ruiz Carrascosa, profesor de Orientación Educativa de la Universidad de Jaén, presenta la solicitud de creación de la DTA acompañada del preceptivo pliego de firmas, propuesta que fue aprobada en la AGO de 23 de junio. En septiembre, la DTA convoca su primera AGE que se celebra en la Universidad de Jaén y en la que se proclama la primera JD presidida por Juan Ruiz Carrascosa, promotor de la DT. Inmediatamente después, se inicia una campaña de divulgación y captación de nuevos socios. 


\section{Delegación Territorial del País Vasco (DTPV)}

Carmen Valdivia Sánchez, Catedrática de Orientación Educativa de la Universidad de Deusto (Bilbao), presentó en la reunión de la JD de la AEOEP de 20 de mayo de 1995 la solicitud de creación de la DTPV apoyada por más de 30 firmas, solicitud que fue aprobada en la AGO de 23 de junio. La divulgación de la creación de la DT y la captación de nuevos socios fueron las tareas inmediatas que se fijaron los socios promotores de la DT para el ejercicio de 1995. En junio, se abre el período constituyente para la presentación de candidaturas y se acuerda celebrar la AGE para elegir la JD a principios de 1996.

\section{Congresos, Jornadas y Seminarios}

Durante el Período de Consolidación (1989-1995), la AEOEP, en colaboración con sus DTs, organizó y celebró las siguientes reuniones científicas: las V Jornadas Nacionales de Orientación Educativa, en Valencia; las VI Jornadas Nacionales de Orientación Escolar y Profesional, en El Puerto de la Cruz (Tenerife); las VII Jornadas Nacionales de Orientación Escolar y Profesional, en Madrid; el V Seminario Iberoamericano de la AIOEP, en El Puerto de la Cruz (Tenerife); las II Jornadas de Orientación Escolar y Profesional de Canarias, en Las Palmas de Gran Canaria; las I Jornadas Valencianas de la AEOEP, en Valencia y el XV Congreso Internacional de la AIOEP, en Madrid.

\section{Jornadas Nacionales de Orientación Educativa}

Las V Jornadas Nacionales de Orientación Educativa, bajo el lema "La Reforma Educativa: Un reto para la Orientación", se celebraron en Valencia, del 27 al 30 de noviembre de 1989 organizadas por la DTV con la colaboración de la AEOEP, la Consellería de Cultura, Educación y Ciencia de la Generalitat Valenciana, la Universidad de Valencia, el Colegio Oficial de Doctores y Licenciados, el Colegio Oficial de Psicólogos, el CEU San Pablo y la Editorial Anaya. Las sesiones se desarrollaron en la Escuela Universitaria de Formación del Profesorado de EGB con 406 congresistas inscritos y una nutrida asistencia.

Las V Jornadas se desarrollaron en un acto inaugural, nueve sesiones plenarias y un acto de clausura. Se presentaron un total de 61 trabajos que se distribuyeron en 2 conferencias, 9 ponencias y 9 mesas, una por ponencia, para la exposición de las 50 comunicaciones presentadas. Todos los trabajos, así como las distintas intervenciones de las sesiones de apertura y clausura, las conclusiones, la valoración de las Jornadas y la relación de los participantes inscritos se publicaron en las Actas (AEOEP-DTV, 1990).

El Acto de apertura fue presidido por el Director General de Universidades de la Consellería de Cultura, Educación y Ciencia de la Generalitat Valenciana, Antonio Clemente Carrión y la conferencia inaugural sobre "La Educación en la Comunidad Europea" fue pronunciada por Ricardo Marín Ibáñez, Catedrático Emérito de la UNED. Cada una de las nueve sesiones plenarias, vertebradas por las ponencias, se continuaban con una mesa para la exposición y discusión de las comunicaciones. El Acto de clausura estuvo presidido por el Rector de la Universitat de València, Ramón Lapiedra Civera, pronunciando la conferencia de clausura sobre "La Orientación y el éxito académico" Elvira Repetto Talavera, Presiden- 
ta de la AEOEP. A continuación, el Presidente del Comité Organizador de las V Jornadas,. José Antonio Benavent Oltra, dio lectura a las Conclusiones, cerrando el acto con unas breves palabras, el Rector de la Universitat de València.

\section{Jornadas Nacionales de Orientación Escolar y Profesional}

Las VI Jornadas Nacionales de Orientación Escolar y Profesional, bajo el título de "La Orientación Profesional ante la Unidad Europea" se celebraron en el Puerto de la Cruz (Tenerife), del 29 de octubre al 3 de noviembre de 1990 organizadas por la DTCn en colaboración con la AEOEP, el MEC, el Gobierno de Canarias, el Cabildo Insular de Tenerife, el Ayuntamiento del Puerto de la Cruz y otras instituciones públicas y privadas de Canarias. Las sesiones se desarrollaron en el Hotel Bonanza Palace e Interpalace del Puerto de la Cruz con más de 400 inscripciones y numerosos invitados, sumando en total unos 450 participantes.

Las VI Jornadas se organizaron en una sesión inaugural, una sesión de clausura y seis sesiones plenarias. En total se presentaron 79 trabajos que se distribuyeron en 13 conferencias, 5 ponencias y 61 comunicaciones. Las Actas se publicaron en dos volúmenes con distinto formato y editor: el primero, contiene las conferencias, ponencias, sesiones de apertura y clausura, conclusiones, valoración de las Jornadas y relación de inscritos (MEC-CIDE, 1991), mientras que en el segundo, se recogen las comunicaciones (AEOEP-DTCn, 1991).

La Sesión inaugural estuvo presidida por el Presidente del Parlamento de Canarias Victoriano Ríos Pérez, componiendo la mesa una nutrida y selecta representación institucional. La conferencia inaugural sobre "La Orientación Profesional en la Comunidad Europea. Algunos desafíos con vistas al Acta Única" fue pronunciada por Enrique Retuerto de la Torre, Director Adjunto del CEDEFOP (Berlín). Las sesiones plenarias se organizaron de tal modo que, "las conferencias, ponencias y comunicaciones se impartieron simultáneamente en tres salas. Al mismo tiempo funcionó otra sala donde se pudo conocer, mediante pequeños grupos, que se iban sucediendo, el programa $I$ see ... En las distintas mesas, que se reunían por afinidad temática, se iban extrayendo paulatinamente las conclusiones" (MEC-CIDE, 1991, p. 12). La Sesión de clausura estuvo presidida por el Consejero de Educación, Cultura y Deportes del Gobierno de Canarias, Juan M. García Ramos, la conferencia de clausura sobre "España en Europa en la década de los noventa" corrió a cargo de Ramón Sánchez Moro, Asesor Ejecutivo del Gabinete de Estado. Juan José García Jiménez como congresista asistente a las Jornadas, tuvo el honor de leer las Conclusiones y tras unas breves palabras de Miguel T. Ramírez, Presidente de la DTCn y del Comité organizador, y de Elvira Repetto, Presidenta de la AEOEP, el Consejero de Educación, Cultura y Deportes dio por clausuradas las VI Jornadas.

\section{Jornadas Nacionales de Orientación Escolar y Profesional}

Las VII Jornadas Nacionales de Orientación Escolar y Profesional con el lema "La Orientación en el sistema Educativo y en el Mundo Laboral", se celebraron en Madrid, del 7 al 8 de noviembre de 1991 organizadas por la AEOEP en estrecha colaboración con la DTZC y fueron patrocinadas por la UNED, las Universidades Complutense y Politécnica 
de Madrid, el INEM, el CIDE y otros organismos e instituciones públicas y privadas. Las sesiones se desarrollaron en el Edificio de Humanidades de la UNED con 376 inscripciones $\mathrm{y}$ una numerosa asistencia.

Las VII Jornadas se desarrollaron en un acto inaugural, nueve sesiones plenarias y un acto de clausura. Se presentaron un total de 77 trabajos que se distribuyeron en 5 conferencias, 7 simposios con 28 aportaciones de sus participantes, y 7 mesas redondas para la exposición de 44 comunicaciones. Todos los trabajos y la relación de los participantes inscritos se publicaron en las Actas, que desafortunadamente, no recogen ni las sesiones de apertura y clausura, ni las conclusiones (MIDE/UNED-AEOEP, 1993).

No existe referencia documental sobre la Sesión de apertura, aunque en el Programa de las Jornadas consta que la conferencia inaugural sobre "La Orientación en la Reforma Educativa" fue pronunciada por Alfredo Fierro, Subdirector General de Programas Experimenales del MEC. Las sesiones plenarias de trabajo se organizaron vertebradas en siete simposios que generaron siete mesas redondas para la lectura y discusión de las comunicaciones. Los temas desarrollados en los simposios con las aportaciones de 28 expertos fueron los siguientes:

I) La Orientación en la Educación Obligatoria.

II) La Orientación en la Educación Postobligatoria.

III-A) La Orientación en la transición del mundo educativo al laboral: la Orientación ocupacional.

III-B) La Orientación en la transición del mundo educativo al laboral: Los COIEs.

IV) La Orientación en la relación Universidad-Empresa.

V) La Orientación en la Formación Ocupacional y

VI) La Orientación y el desarrollo de los recursos humanos en la empresa.

Las tres conferencias plenarias corrieron a cargo de D. G. Marnette, Presidente de EuroOrientación, A. Watts, National Institut for Career Education and Guidance, Cambridge University (U.K.) y E. Retuerto de la Torre, Director Adjunto de CEDEFOP (Berlín), y la conferencia de clausura, fue pronunciada por J. R. García Moreno, Subdirector General de Gestión de la Formación Ocupacional, Ministerio de Trabajo.

\section{$V$ Seminario Iberoamericano de Orientación de la AIOEP}

El V Seminario Iberoamericano de Orientación con el título "El compromiso de la Orientación Escolar y Profesional con los cambios de la sociedad" tuvo lugar en el Puerto de la Cruz (Tenerife), del 13 al 16 de mayo de 1992, convocado por la AIOEP y organizado por la AEOEP en estrecha colaboración con su DTCn. Para su celebración se contó con el apoyo de las siguientes instituciones, organismos y empresas patrocinadoras: Gobierno de Canarias, Cabildo Insular de Tenerife, Ayuntamientos del Puerto de la Cruz y La Laguna, Universidades de La Laguna, Complutense de Madrid y UNED, la ONCE, El Corte Ingles, Canon Canarias S.A., Iberia y Yanes. Las sesiones se desarrollaron en el Hotel Bonanza Palace e Interpalace del Puerto de la Cruz con 335 congresistas inscritos, de los cuales, unos 50 pertenecían a 16 nacionalidades distintas. Hubo numerosos invitados y un elevado nivel de participación. 
Este V Seminario Iberoamericano se desarrolló en una acto inaugural, un acto de clausura y seis sesiones plenarias. En total se presentaron 87 trabajos que se distribuyeron en 8 conferencias ( 1 de apertura, 1 de clausura y 6 conferencias marco), 20 ponencias, 52 comunicaciones y 7 posters. Todos los trabajos presentados, las Conclusiones, la evaluación del Seminario y la relación de los congresistas inscritos se publicaron en las Actas, que no recogen ni el acto de apertura ni el de clausura (AEOEP, 1993)

El Acto de apertura estuvo presidido por Ángel Marrero Alayon, Viceconsejero de Educación del Gobierno de Canarias y la conferencia inaugural, sobre "Pasado, presente y futuro de la Orientación", fue pronunciada por Silvia B. Galván de Veistein, Presidenta de FAPOAL-Argentina. Las sesiones plenarias se organizaron en torno a cinco grandes bloques temáticos con sus respectivos paneles de expertos para las ponencias, sus talleres para la lectura y discusión de las comunicaciones, y una sala común para la exposición de todos los posters. Los cinco bloques temáticos desarrollados fueron los siguientes:

1) Objetivos, contenidos y técnicas de Orientación en Iberoamérica (2 conferencias marco, 2 paneles de expertos con 9 ponentes y 2 talleres con 11 comunicaciones).

2) La formación del Orientador (1 conferencia marco, 1 panel de expertos con 2 ponentes y un taller con 5 comunicaciones).

3) La Orientación y la Intervención Psicopedagógica (1 conferencia marco, 1 panel de expertos con 4 ponentes y 1 taller con tres áreas y 25 comunicaciones).

4) Formación profesional, Orientación ocupacional y Empleo (1 conferencia marco, 1 panel de expertos con 3 ponentes y 1 taller con 7 comunicaciones).

El Acto de clausura estuvo presidido por el Consejero de Educación, Cultura y Deportes del Gobierno de Canarias, Juan M. García Ramos, la conferencia de cierre sobre "Metodología y técnicas de Orientación desde la perspectiva de la investigación" corrió a cargo de José Ferreira Marques, Presidente de la AIOEP; Miguel T. Ramírez, Presidente de la DTCn leyó las Conclusiones y tras una breve alocución de agradecimiento y despedida de Elvira Repetto, Presidenta de AEOEP y del Comité Organizador del V Seminario, el Consejero de Educación, Cultura y Deportes pronunció las palabras de clausura.

\section{Jornadas de Orientación Escolar y Profesional en Canarias}

Las II Jornadas de Orientación Escolar y Profesional en Canarias se celebraron en Las Palmas de Gran Canaria, del 20 al 22 de mayo de 1993 organizadas por la DTCn con la colaboración de la AEOEP, la Consejería de Educación, el Cabildo Insular de Gran Canaria, el Ayuntamiento y la Universidad de Las Palmas de Gran Canaria y otras instituciones públicas y privadas. Las sesiones se desarrollaron en la Escuela Universitaria de Formación del Profesorado de EGB de la ULPGC con casi 200 inscripciones y un alto nivel de participación.

Estas II Jornadas se organizaron en un acto inaugural, tres sesiones plenarias y un acto de clausura. Se presentaron un total de 25 trabajos que se distribuyeron en 1 conferencia, 3 ponencias y 21 comunicaciones. Todos los trabajos, las conclusiones, la valoración de las Jornadas y la relación de los participantes inscritos se publicaron en las Actas (ULPGC, 1993). 
El Acto de apertura fue presidido por el Viceconsejero de Educación, Cultura y Deportes del Gobierno Canario, Sr. Alduán. La presentación de las Jornadas corrió a cargo de Miguel T. Ramírez, Presidente de la DTCn, y tras las intervenciones de bienvenida del Concejal de Cultura del Ayuntamiento de LPGC y de la Directora de la EUFP-EGB, la conferencia inaugural sobre "Evaluación de programas y mejora profesional" fue pronunciada por Ramón Pérez Juste, Catedrático de MIDE de la UNED. Cada una de las tres sesiones plenarias estuvo vertebrada por una ponencia que se continuaba con una mesa redonda para la lectura y discusión de las comunicaciones afines. En la mesa del Acto de clausura estuvieron representados el Cabildo Insular, la Dirección General de Promoción Educativa, la ULPGC y la AEOEP. Después de la lectura de las Conclusiones, Miguel T. Ramírez, Presidente de la DTCn, expresó su agradecimiento a los participantes y a las instituciones colaboradoras dando por finalizadas las Jornadas.

\section{Jornadas Valencianas de la AEOEP}

Las I Jornadas Valencianas de la AEOEP bajo el lema "Desarrollo de la carrera: Modelos y programas actuales", se celebraron en Valencia, del 27 al 30 de septiembre de 1993, organizadas por la DTV con la colaboración de la AEOEP, la Consellería de Educación y Ciencia de la Generalitat Valenciana, el Ayuntamiento de Valencia, la Universitat de València y Bancaja. Las sesiones tuvieron lugar en la Facultad de Filosofía y Ciencias de la Educación de la Universitat de València, con 123 congresistas inscritos, numerosos invitados y una nutrida asistencia.

Las I Jornadas se desarrollaron en un acto inaugural, cuatro sesiones plenarias y un acto de clausura. Se presentaron un total de 41 trabajos que se distribuyeron en 4 conferencias marco, y cuatro talleres-coloquio para la exposición de las 37 comunicaciones, además se organizaron cuatro visitas guiadas a centros educativos con Departamento de Orientación y a otros tantos Servicios Psicopedagógicos Escolares (SPEs). Todos los trabajos, así como los actos sociales y visitas organizadas, las conclusiones, la valoración de las Jornadas y la relación de los participantes inscritos se publicaron en las Actas (AEOEP-DTV, 1994).

Presidió la mesa del Acto de apertura el Director General de Ordenación e Innovación Educativa de la Consellería de Educación y Ciencia de la Generalitat Valenciana, Pascual Masiá González, e intervinieron en el acto, Elvira Repetto, Presidenta de la AEOEP, que resaltó la importancia y actualidad temática de las Jornadas, Luis Miguel Lázaro, Decano de la Facultad de Filosofía y Ciencias de la Educación acogiendo a los congresistas en el seno de la Universitat de València y José Antonio Benavent, Presidente de la DTV, que pronunció unas palabras de bienvenida y finalmente, el Director General deseando un trabajo fructífero declaró abiertas las Jornadas. Cada una de las cuatro sesiones plenarias, vertebradas por la correspondiente conferencia-marco, se continuaban con un taller-coloquio para la exposición y discusión de las comunicaciones y experiencias. El Acto de clausura estuvo presidido por el Rector de la Universitat de València, Ramón Lapiedra Civera, y tras las intervenciones de Elvira Repetto Talavera, Presidenta de la AEOEP, y de José Antonio Rodríguez Docavo, Tesorero de la AEOEP, el Presidente del Comité Organizador, José Antonio Benavent, leyó las Conclusiones y el Rector de la Universitat de Valencia declaró finalizadas las Jornadas. 


\section{Congreso Internacional de la AIOEP}

El XV Congreso Internacional de la AIOEP, que bajo el lema "Recursos humanos, Orientación y Mercado laboral" tuvo lugar en Madrid, del 13 al 16 de julio de 1994, convocado por la AIOEP y organizado por la AEOEP en estrecha colaboración con su DTZC, contó con el apoyo de las siguientes instituciones, organismos y empresas patrocinadoras:

a) UNED, por medio de los Vicerrectorados y el IUED; la Facultad de Educación: Departamentos MIDE, DOE, TE y PS.; la Facultad de Psicología: Departamento de PSE y E y la Facultad de Empresariales.

b) CIDE.

c) MEC, a través de la Sección de Orientación Profesional de la Subdirección General de Formación Profesional.

d) Consejería de Educación de Madrid (CAM).

e) Universidad Politécnica de Madrid.

f) CEDEFOP.

g) EURORIENTACIÓN y

h) Iberia Líneas Aéreas.

Las sesiones se desarrollaron en el Campus de la UNED y en el INEF, con más de 500 congresistas inscritos y un altísimo nivel de participación. Las lenguas oficiales fueron el español y el inglés y hubo traducción simultánea en todas las conferencias.

El XV Congreso se estructuró en cuatro divisiones científicas:

I) Desarrollo de recursos humanos.

II) Orientación y reformas educativas en la Unión Europea.

III) Orientación y Formación y

IV) Orientación y Mercado laboral.

Dentro de cada uno de estos cuatro grandes capítulos se desarrollaron conferencias, sesiones plenarias, sesiones temáticas, experiencias, talleres y posters. Se presentaron un total de 190 trabajos que se distribuyeron en 7 conferencias, 24 ponencias, 154 comunicaciones y experiencias, 2 talleres y 3 posters.

El Congreso ofreció un foro idóneo para debatir temas y problemas de rabiosa actualidad sobre orientación, relaciones humanas y mercado del trabajo, en un mundo dominado por la economía global y la crisis de empleo. Este programa atrajo el interés de profesionales de la economía, la empresa, el derecho, la pedagogía y la psicología para intercambiar experiencias y debatir la problemática actual y las perspectivas de futuro a nivel mundial. La calidad del Congreso la podremos juzgar cuantitativamente con la aportación de los siguientes datos globales sobre su programa científico, que nos permiten valorar el esfuerzo que supuso su organización, gestión y celebración, y que presentamos en las tablas 1, 2 y 3 (Anónimo, 1994):

El Comité de Honor estuvo presidido por Alfredo Pérez Rubalcaba, Ministro de Educación y Ciencia; el Comité Ejecutivo, por José Ferreira Marques, Presidente de la AIOEP; y el Comité Organizador, por Elvira Repetto Talavera, Presidenta de la AEOEP. Las siete conferencias marco sobre las que se vertebró el Congreso fueron las siguientes: "Las em- 
TABLA 1: Número de trabajos presentados por días.

\begin{tabular}{|c|c|c|c|c|c|}
\hline Días & 13 & 14 & 15 & 16 & Totales \\
\hline Conferencias & 2 & 2 & 1 & 2 & 7 \\
\hline Sesiones plenarias & 3 & 6 & 6 & 9 & 24 \\
\hline Sesiones temáticas & 24 & 25 & 31 & 28 & 108 \\
\hline Experiencias y comunicaciones & 22 & 6 & 8 & - & 46 \\
\hline Talleres & 1 & 1 & - & - & 2 \\
\hline Posters & 1 & 1 & - & 1 & 3 \\
\hline Totales & 53 & 51 & 46 & 40 & 190 \\
\hline
\end{tabular}

TABLA 2: Número de trabajos presentados por países.

\begin{tabular}{|l|r|l|r|l|c|l|c|}
\hline \multicolumn{1}{|c|}{ País } & N & \multicolumn{1}{c|}{ País } & N & \multicolumn{1}{c|}{ País } & N & \multicolumn{1}{c|}{ País } & N \\
\hline Alemania & 2 & Dinamarca & 1 & Islandia & 1 & Portugal & 2 \\
\hline Argentina & 10 & España & 130 & Italia & 1 & Suecia & 2 \\
\hline Austria & 1 & EE.UU. & 7 & Japón & 1 & Sudáfrica & 1 \\
\hline Bélgica & 3 & Francia & 6 & Luxenburgo & 1 & Taiwán & 1 \\
\hline Brasil & 1 & Grecia & 1 & Perú & 1 & U.K. & \\
\hline Canadá & 12 & Hungría & 1 & Polonia & 1 & Total & $\mathbf{1 9 0}$ \\
\hline
\end{tabular}

TABLA 3: Número de trabajos presentados por grandes áreas temáticas.

\begin{tabular}{|l|c|}
\hline Recursos humanos & 32 \\
\hline Orientación Escolar y Profesional & 110 \\
\hline Empresa y mercado de trabajo & 48 \\
\hline Total & $\mathbf{1 9 0}$ \\
\hline
\end{tabular}

presas de aprendizaje y el papel de la tecnología", por P. Potter (Bélgica); "Cooperación de las universidades y las empresas en el desarrollo de los recursos humanos del mundo del trabajo del s. XXI", por E. Herr (Pensilvania, USA); "La formación de orientadores para el trabajo en la industria y la empresa", por B. Bingham (Rutgers, Inglaterra); "La Orientación en España: Evolución y prospectiva”, por V. García Hoz (España); “ Orientación e intervención psicopedagógica en la Unión Europea”, por E. Repetto (España); ”Orientación y mercado laboral: problemas y enfoques desde una perspectiva internacional"; y "El desafío de la Orientación en el mundo", por J. Ferreira Marques (Portugal). Impartidas por 
expertos de gran prestigio y valía científica a nivel internacional, constituyen un índice de calidad del Congreso, y fueron una excelente puesta al día de los temas candentes que centraban en estos momentos el interés y las actividades de los profesionales de la Orientación (Anónimo, 1994).

La organización, programación de actividades y los trabajos presentados al Congreso se recogen en dos publicaciones: un Libro-Programa de 220 páginas con la programación detallada y el resumen de todos los trabajos presentados, que se entregó en el acto de acreditación y recogida de materiales (AEOEP, 1994), y las Actas, en dos tomos, con 1.574 páginas y 130 trabajos, se publicaron con una demora de cuatro años por problemas de financiación y de edición, pues tuvieron que desecharse 60 trabajos por no estar bien formateados o presentar daños en sus soportes electrónicos. No contienen las conclusiones ni la reseña de los actos de apertura y clausura (Repetto y Vélaz de Medrano, 1998). El programa científico se completó con un amplio y variado repertorio de actos sociales, culturales y lúdicos.

\section{Publicaciones}

Durante el Período de Consolidación(1989-1995) se editaron once números de la Revista de Orientación Educativa y Vocacional (ROEV) y las Actas de las V Jornadas Nacionales de Orientación Educativa, de las VI Jornadas Nacionales de Orientación Escolar y Profesional, de las VII Jornadas Nacionales de Orientación Escolar y Profesional, del V Seminario Iberoamericano de la AIOEP, de las II Jornadas de Orientación Escolar y Profesional en Canarias, de las I Jornadas Valencianas de la AEOEP. y el Programa del XV Congreso Internacional de la AIOEP.

Tras el fallido intento de dotar a la AEOEP de un órgano oficial y portavoz de la Asociación, al desaparecer el periódico INDEFOR en el cuarto trimestre de 1987, después de la publicación de tres números, se plantea la necesidad de crear una revista que recoja además de información y noticias puntuales sobre Orientación, los trabajos e investigaciones de los asociados. Así, en la JD de 26 de octubre de 1988, se aprueba el proyecto presentado por José Miguel Orts, Presidente de la DTV, de crear una nueva publicación periódica con la denominación de Revista de Orientación Educativa y Vocacional (ROEV), se le nombra director de la misma con el compromiso de publicar el número 0 en 1989. En septiembre de 1989 la ROEV todavía no había aparecido y en la JD del 20 de octubre, José Miguel Orts presenta su dimisión por motivos de salud, como Vicepresidente de la AEOEP y como responsable de la ROEV, pero la JD no acepta su dimisión y le emplaza a que cumpla los compromisos adquiridos con el apoyo de la DTV y de su nuevo Presidente José A. Benavent.

Una vez terminadas las V Jornadas Nacionales de Orientación celebradas en Valencia, los esfuerzos de la DTV se centrarán en hacer viable el proyecto de la ROEV, tal como lo había presentado José Miguel Orts: tirada de 1.000 ejemplares, periodicidad semestral, y coste de 250.000 pesetas, a financiar a partes iguales entre la AEOEP y la DTV. Pero la AEOEP no pudo cumplir con su compromiso económico por falta de liquidez, y finalmente, para no demorar más tiempo su aparición, la DTV financió íntegramente la edición del número 0 con los beneficios obtenidos en las V Jornadas de Orientación. El número 0 de la ROEV, aunque se editó en Valencia, fue presentado oficialmente en Madrid, ante la JD del 31 de marzo de 1990, que felicita al Sr. Orts por el trabajo realizado, acepta su dimisión y se compromete a registrar la cabecera en el Registro Nacional de Patentes y Marcas y soli- 
citar la asignación de un ISSN. También se acuerda que la JD Nacional asuma la responsabilidad de la financiación y publicación del número 1, para que la ROEV en lo sucesivo se edite en Madrid, y se nombra el nuevo Consejo de Redacción que quedó constituido por: Directora, Elvira Repetto; Jefe de Redacción, Daniel Anaya y Secretaria Técnica, Irene Gozalo. Se aprueba dotar a la ROEV de fondos propios deducidos de las cuotas sociales (1.000 pesetas por cuota), y nombrar dos Consejos Asesores, uno nacional y otro internacional.

Desde 1990 a 1995 se editaron 11 números, el 0 en Valencia y los números 1 al 10 en Madrid, con una periodicidad semestral y sus contenidos se estructuraron en las siguientes secciones:
1) Editorial.
2) Estudios.
3) Experiencias y
4) Información general.

Para agilizar la publicación de la ROEV, en la JD de 19 de junio de 1992 se acuerda dotarla con 1.000.000 de pesetas procedentes del beneficio económico obtenido en la celebración de las VII Jornadas Nacionales de Madrid. En los 11 números de la ROEV, con sus 1.643 páginas, se publicaron 77 artículos y 23 experiencias (ver Anexo IV). La portada del número 0 de la ROEV se presenta en la figura 4.

En cuanto a las Actas, a lo largo del Período de Consolidación, aparecieron las siguientes publicaciones:

1) Actas de las V Jornadas Nacionales de Orientación Educativa (27-30 de noviembre de 1989), Valencia. Fueron financiadas íntegramente por la DTV, y en sus 440 páginas se recogen, la organización, el programa, todas las conferencias, ponencias y comunicaciones presentadas, las conclusiones, la evaluación de las Jornadas y la relación de participantes (AEOEP-DTV, 1990).

2) Actas de las VI Jornadas Nacionales de Orientación Escolar y Profesional (29 de octubre al 3 de noviembre de 1990) Puerto de la Cruz (Tenerife). Se publicaron en dos volúmenes: el primero, con formato A4, fue financiado íntegramente por el MEC y sus 146 páginas contienen los actos de apertura y clausura, todas las ponencias y conferencias leídas, las conclusiones, la evaluación y la relación de participantes (MEC, 1991); en el segundo volumen, de 456 páginas, financiado por la DTCn, se publican todas las comunicaciones (AEOEP-DTCn).

3) Actas de las VII Jornadas Nacionales de Orientación Escolar y Profesional de (6-8 de noviembre de 1991), Madrid. Financiadas por el Departamento MIDE de la UNED con la colaboración de la AEOEP, sus 510 páginas presentan la organización, programa, todas las ponencias, conferencias y comunicaciones, y la relación de participantes; no da información ni del acto de apertura ni de la clausura, no contiene conclusiones y su publicación se demoró dos años (MIDE/UNED-AEOEP, 1993).

4) Actas del V Seminario Iberoamericano de la AIOEP (13-16 de mayo de 1992), Puerto de la Cruz (Tenerife). Se imprimieron en Madrid y fueron financiadas por la AEOEP. Sus 496 páginas nos ofrecen información sobre la organización y el acto de apertura, todas las ponencias, conferencias y comunicaciones, las conclusiones, la 


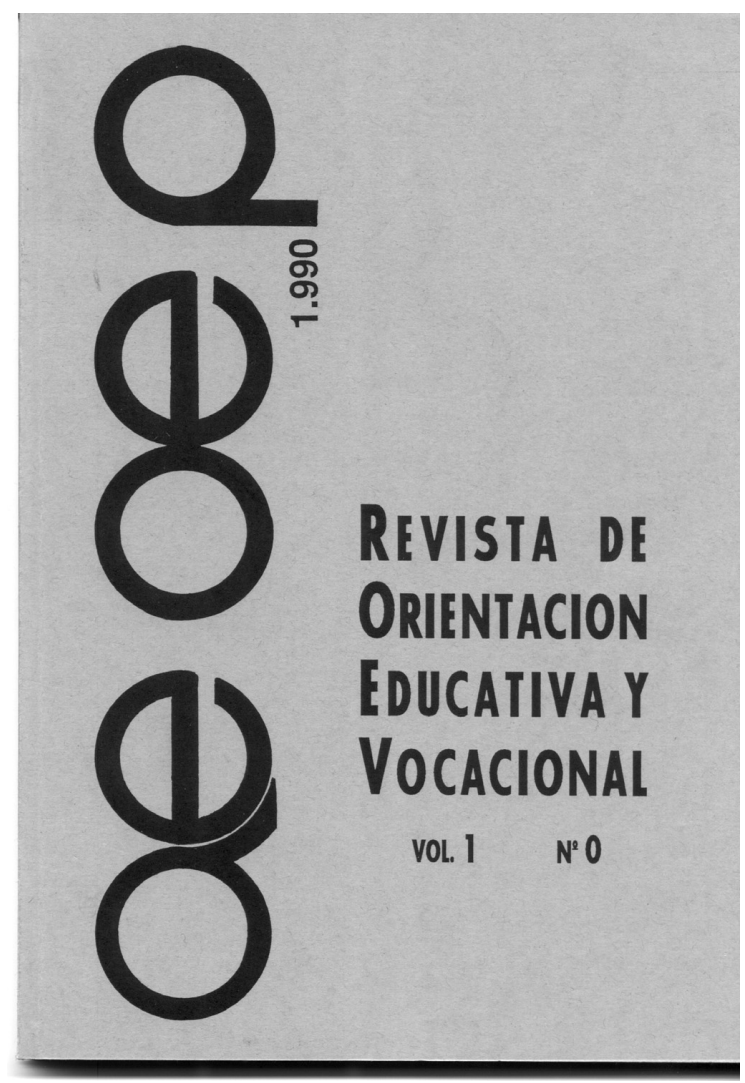

FIGURA 4.

Portada del no 0 de la Revista de Orientación Educativa y Vocacional (1990-95).

evaluación del seminario y la relación de los congresistas inscritos. No hay datos sobre la clausura. (AEOEP, 1993).

5) Actas de las II Jornadas de Orientación Escolar y Profesional en Canarias (20-22 de mayo de 1992), Las Palmas de Gran Canaria. Fueron financiadas íntegramente por la Universidad de Las Palmas de Gran Canaria y editadas por su Servicio de Publicaciones. Este volumen de 444 páginas contiene información sobre la organización, un prólogo, crónica de las jornadas, todas las ponencias, conferencias y comunicaciones, las conclusiones, la valoración de las jornadas y la relación alfabética de los participantes (ULPGC, 1993).

6) Actas de las I Jornadas Valencianas de la AEOEP (27-30 de septiembre de 1993), Valencia. La edición fue financiada conjuntamente por la DTV y la AEOEP que aportó 225.000 pesetas, a cambio, la DTV envió gratuitamente por correo, un ejemplar a todos los socios. En sus 439 páginas se presenta la organización, el programa, 
un prólogo, todas las conferencias, ponencias y comunicaciones, los actos sociales y las visitas organizadas, las conclusiones, la evaluación de las jornadas y la relación alfabética de los participantes (AEOEP-DTV, 1994).

7) Programa del XV Congreso Internacional de la AIOEP (13-16 de julio de 1994), Madrid. Editado y financiado por la AEOEP en formato A4, este Programa de 220 páginas contiene: presentación, organización, información general, el programa del Congreso en español e inglés y el resumen de todas las ponencias, conferencias y comunicaciones presentadas antes del inicio de las sesiones. Se entregó a los participantes en el momento de la acreditación y recogida de materiales (AEOEP, 1994).

\section{Proyección Internacional}

La AEOEP, perfectamente integrada en la AIOEP y con un bien ganado prestigio internacional, tanto por la organización y celebración en España del V Seminario Iberoamericano (Puerto de la Cruz, 1992) y el XV Congreso Internacional de la AIOEP (Madrid, 1994), como por la cantidad y calidad de las aportaciones de sus asociados en los distintos encuentros científicos de Orientación Educativa y Profesional a nivel mundial. Así, durante el Período de Consolidación, sus socios participaron activamente representando a la AEOEP con ponencias y comunicaciones en los siguientes eventos internacionales celebrados fuera de nuestro país:

- II Conferencia de la Comisión Europea sobre "Orientación profesional asistida por ordenador", celebrada en el Churchill College de la Cambridge University, Cambridge (U.K.), del 28 al 30 de junio de 1989, y en la que participaron como ponente, Elvira Repetto y como coordinadora de mesa redonda Elena Veiguela (Anónimo, 1990).

- XIII Congreso Internacional de la AIOEP sobre "Orientación de las minorías vulnerables", Napier Polytechnic de Edimburgo (U.K.), del 1 al 6 de julio de 1989, con asistencia de Elvira Repetto, que como Vocal de la JD de la AIOEP y Presidenta de la AEOEP, presentó una ponencia sobre la situación de las minorías vulnerables en España (Anónimo, 1990a).

- Conferencia Internacional para la creación de la Asociación Europea de "Euro-Orientación", Bruselas (Bélgica), del 19-20 de abril de 1990, bajo los auspicios de la Secretaría General de Recursos Humanos, Educación, Formación Vocacional y Juventud de la Comisión Europea y con el apoyo de la AIOEP. Fueron invitados los presidentes de las distintas Asociaciones Nacionales de Orientación de los países de la C.E.E. y asistieron representantes de Alemania, Bélgica, España, Holanda, Italia, Luxemburgo, Polonia y Portugal. La representación española estuvo a cargo de Elvira Repetto, por la AEOEP, y de nuestro socio, Ángel Lázaro, por la SEP (Sección Orientación). Se funda EURO-ORIENTACIÓN y se nombra un Comité Directivo provisional que fue ratificado en el mes de junio en la reunión de París. La AEOEP fue Asociación fundadora y Elvira Repetto ocupó una de las cuatro Vicepresidencias del Comité Directivo (Anónimo, 1991).

- II Encuentro Latinoamericano de Asociaciones Profesionales de la Orientación, celebrado en la Universidad de Colima, Colima (México), del 24 al 26 de mayo de 1990 y organizado por la FAPOAL y en el que participaron representando a la AEOEP, Elvira 
Repetto, con la ponencia, "Modelo curricular de la formación del Orientador como agente de intervención social" y Luis García Mediavilla, que presentó la ponencia, "Centro de Psicopedagogía Aplicada", y se firmó un convenio de colaboración entre la FAPOAL y la AEOEP (Anónimo, 1991a).

- XIV Congreso Mundial de Orientación de la AIOEP que tuvo lugar en Montreal (Canadá), del 13 al 17 de agosto de 1990, bajo el lema "La Orientación dentro de una economía global". Asistió una nutrida representación de socios de la AEOEP y participaron activamente, Elvira Repetto, con una ponencia sobre la formación del orientador, Carmen Oñate, que disertó sobre los servicios de orientación universitaria en España y, Daniel Anaya, que presentó una comunicación sobre la elección vocacional al final de la educación secundaria post-obligatoria (Anónimo, 1991b).

- Salones Internacionales del Estudiante (1991-1995). A través de EURO-ORIENTACIÓN, la AEOEP recibió ayuda económica, becas e invitación oficial para participar en el "Stand de Euro-Orientación" de los Salones Internacionales del Estudiante, patrocinados por la Comisión de Recursos Humanos, Educación, Formación Vocacional y Juventud de la C.E.E. Carmen Oñate e Inmaculada Martínez Gonzalo, en representación de la AEOEP, asistieron a los Salones Internacionales del Estudiante de I París (1991), II Bruselas (1991), III Birmingham (1992), IV South County (1992), V Barcelona (1993), VI Londres (1993), VII Luxemburgo (1994), y VIII Amsterdam (1994) y IX Lisboa (1995) (Martínez Gonzalo, 1994).

- En 1992, el Programa PETRA de la CEE subvenciona la investigación del equipo dirigido por Elvira Repetto sobre "La formación del personal de orientación a nivel europeo".

- I Curso de Formación Europea de Consejeros de Orientación Universitaria, desarrollado en Montpellier (Francia), del 19 al 23 de julio de 1993, organizado por FEDORA y reconocido por la CEE, con participación de especialistas de Alemania, España, Francia y el Reino Unido (U.K.). Por parte de España participaron como expertos con sus correspondientes lecciones magistrales: Frederic Company, Elvira Repetto, Manuel López Quero, Olga Carbó y Josep Vilarnau. Asistieron a los cursos un gran número de Orientadores españoles, casi un $40 \%$ del total de alumnos matriculados, lo que pone de manifiesto el interés de nuestros especialistas, entre los que se encontraban los socios de la AEOEP, Elena del Campo, Irene Colinas, Pablo Rejas, María Luisa Monera y Carmen Oñate (Del Campo, Colinas y Rejas, 1993).

- IV Encuentro Latinoamericano de Orientación y VIII Seminario de Orientación Vocacional, Buenos Aires (Argentina), del 9 al 11 de noviembre de 1994, organizado por la FAPOAL y la Asociación de Profesionales de la Orientación de la República Argentina y al que asistieron varios orientadores españoles, entre ellos, Elvira Repetto, que en representación de la AEOEP tuvo una activa participación (Anónimo, 1995).

- 50 a Conferencia Internacional de la Carrera de la NCDA, San Francisco (EE.UU.), del 5 al 9 de julio de 1995, organizada por la National Career Development Asociatión en honor a D. E. Super bajo el lema "Desarrollo de la carrera en una economía global: Puerta dorada hacia el futuro". En representación de la AEOEP asistieron, Daniel Anaya, Enriqueta de Lara, Elvira Repetto y Araceli Sebastián, que presentaron varios trabajos relacionados con la adaptación y validación del Career Development Inventory de Super para la población española y otro sobre el programa de orientación del 
COIE de la UNED. También asistió José Antonio Rodríguez Docavo, Tesorero de la AEOEP (Anaya, 1995).

- XVI Congreso Internacional de la AIOEP, Estocolmo (Suecia), del 7 al 10 de agosto de 1995, organizado por la Asociación Sueca para la Orientación Escolar y Profesional, con el título, "Orientación para la carrera y contexto social". Asistieron y participaron activamente 12 especialistas españoles. En la Asamblea General, celebrada el día 8 de agosto, se aprobaron dos importantes documentos: el "Código ético y la "Declaración de principios" (AIOEP, 1995 y 1995a). Además, se procedió a la elección del nuevo Comité Ejecutivo, resultando elegida Vicepresidenta, Elvira Repetto y Vocal suplente, José Antonio Rodríguez Docavo, en justo reconocimiento por la brillante labor y continuado esfuerzo de ambos en pro de la Orientación (Rodríguez Docavo, 1995).

- Finalmente, tan fecunda y prolífera participación de la AEOEP y sus asociados en eventos internacionales a lo largo de este Período, se cierra, con una nutrida asistencia al Seminario Internacional de la AIOEP celebrado en Buenos Aires (Argentina), del 1 al 4 de noviembre de 1995, organizado conjuntamente por la Asociación de Profesionales de la Orientación de la República Argentina (APORA) y la Asociación de Orientadores de las Universidades Nacionales Argentinas (AOUNAR) bajo el lema, "Orientación y Cambio sociocultural". Hubo casi 500 inscripciones y se presentaron un total de 120 trabajos, 19 de ellos firmados por españoles. La AEOEP estuvo representada por su Tesorero, José Antonio Rodríguez Docavo, y por su Presidenta, Elvira Repetto, que en el panel reservado a los miembros de la JD de la AIOEP expuso la ponencia "La Orientación como intervención pedagógica" (Rodríguez Docavo, 1995a).

\section{Período de desarrollo (1996-2000)}

El Período de Desarrollo se extiende, desde la aprobación de los nuevos Estatutos (1996) y denominación de Asociación Española de Orientación y Psicopedagogía (AEOP) por el Ministerio del Interior (31/01/1996), hasta el 31 de diciembre de 2000, en que la Asociación alcanza, con 991 socios, el máximo número de asociados de su historia. Se caracteriza por:

a) La nueva denominación de la Asociación (AEOEP por AEOP) y de su Revista, portavoz y órgano oficial de expresión (ROEV por ROP, y a partir del $2^{\circ}$ semestre de 1998, REOP).

b) La firma de convenios de colaboración para la formación y el perfeccionamiento del profesorado entre la AEOP y el MEC y entre las DTV, DTCn y DTZC y sus respectivas Consejerías de Educación.

c) Constitución oficial de las Vocalías y presentación de sus respectivos programas de actividades a partir del curso 1997-98.

d) La nueva situación profesional de los Orientadores generada por la implantación y proliferación de la Licenciatura de Psicopedagogía en las universidades españolas.

e) El nacimiento, desarrollo y consolidación del movimiento asociacionista de los profesionales de la Orientación con la creación de asociaciones de especialistas en distintas Comunidades Autónomas. 
f) Se inician contactos con las nuevas asociaciones de Orientación, y en 1999, se firma el primer convenio de colaboración entre la AEOP y la Asociación Aragonesa de Psicopedagogía (AAPs).

g) Continúa el aumento progresivo del número de socios gracias a las campañas informativas y se constituyen dos nuevas DTs, la de Galicia (DTG) y la de Castilla la Mancha (DTC-LM).

h) Informatización de la AEOP y aparición de tres páginas web en Internet editadas y gestionadas desde los servidores de la UNED (Madrid), Universidad de Valencia y Universidad de Oviedo.

\section{Acuerdos, actividades y acontecimientos}

El año 1996 se inicia con la aprobación por el Ministerio del Interior de los nuevos Estatutos (31/01/1996), en los que se amplían los objetivos y se potencia la programación de actividades conducentes a la captación, como asociados, de los nuevos titulados de Psicopedagogía; la toma de contacto y establecimiento de relaciones de cooperación con las nuevas asociaciones de Orientación que empiezan a surgir en distintas Comunidades Autónomas; el desarrollo de proyectos de investigación financiados; la ampliación de las relaciones internacionales y la promoción, mejora cuantitativa y cualitativa de la Revista, que aparece con la nueva cabecera de Revista de Orientación y Psicopedagogía (ROP) en el número correspondiente al primer semestre de 1996. En noviembre, se firma un convenio de colaboración entre la AEOP y el Departamento MIDE/UNED por el que se cede el despacho 119 del Edificio Humanidades para uso de la Asociación.

El 4 de abril de 1997 se celebran AGO y AGE, en las que se aprueba la constitución de las Vocalías y se elige nueva JD, quedando formada ésta, con la asignación de Vocalías a sus miembros, del modo siguiente: Presidenta, Elvira Repetto Talavera; Vicepresidenta, Laura Oliveros Martín-Varés; Secretaria, María de Codés Martínez González; Tesorero, José Antonio Rodríguez Docavo; Vocales electos responsables de las nuevas Vocalías:

1) Laura Oliveros, Publicaciones.

2) Narciso García Nieto, Diagnóstico y evaluación en Orientación.

3) Aurora Fernández-Peinado, Orientación educativa y tutorías.

4) María Luisa Pereira, Orientación profesional.

5) María Dolores Cadierno, Orientación-formación ocupacional y en la empresa.

6) Teófilo González, Orientación familiar y comunitaria.

7) Víctor Álvarez Rojo, Atención a la diversidad y

8) Inmaculada Martínez Gonzalo, Relaciones externas.

Vocales natos: José Antonio Benavent Oltra (DTV), Víctor José González Expósito (DTCn), Juan Ruiz Carrascosa (DTA) y Carmen Valdivia Sánchez (DTPV). Se aprobó la firma de un acuerdo entre la ROP y el Departamento MIDE/UNED, por el cual, éste financiará el $10 \%$ de los gastos de edición de la Revista a cambio de imprimir su logotipo en la portada. Se aprueba nombrar "Socios de Honor" a Luis García Mediavilla, María Teresa Gullón Jalón y Ángel Arévalo Caballero por los dilatados y valiosos servicios prestados a la Asociación, (Rodríguez Docavo, 1997). El año finaliza con la celebración 
en Valencia de las VIII Jornadas Nacionales de Orientación (8-11 de noviembre), y la AGO, reunida en esta ciudad, aprueba subir la cuota social anual a 5.000 ptas. para 1998 y dedicar el próximo número de la ROP a conmemorar el centenario del nacimiento de José Germain y José Mallart, a quienes se nombra por unanimidad "Socios de Honor" a título póstumo.

En marzo de 1998 la AEOP dirige un escrito razonado al MEC para que se equipare, a todos los efectos, la Licenciatura de Psicopedagogía con las de Psicología y Pedagogía. En junio, la JD aprueba iniciar una campaña de acercamiento y toma de contacto con las asociaciones de Orientadores que están emergiendo en distintas Comunidades autónomas y se nombra a José A. Benavent representante de la AEOP para iniciar negociaciones. En septiembre, la AEOP pone en funcionamiento, en su sede social de la Calle Núñez de Balboa $\mathrm{n}^{\circ} 90,2^{\circ}$ interior, dos Asesorías gratuitas para todos los asociados, una profesional, atendida por Aurora Fernández-Peinado, y otra legal, a cargo de Ángel Arévalo. Las consultas podían realizarse por correo postal o electrónico y los lunes por la tarde también por teléfono (Anónimo, 1999). En la AGO de 26 de junio se aprueba la propuesta de creación de la Delegación Territorial de Galicia (DTG) promovida por Elena Menéndez. El 14 de noviembre de 1998 se firma el Acuerdo de Cooperación entre la AEOP y la AAPs (Anónimo, 1999a). Finalmente, a principios de diciembre, se firma el convenio de colaboración entre la AEOP y el MEC para la formación y el perfeccionamiento del profesorado no universitario y llegan las subvenciones para financiar los cursos impartidos en Asturias, Canarias, Madrid y Valencia.

En el año 1999 se cumple el XX Aniversario de la fundación de la AEOP (Rodríguez Docavo, 1999). En enero la AEOP cuelga su primera página web en Internet en el URL www.uned.es/aeop En la AGO de 23 de abril se produce una remodelación de la JD al dimitir como Secretaria, María de Codes Martínez, siendo sustituida en funciones por Mari Fe Sánchez. Laura Oliveros deja la Vocalía de Publicaciones que ocupa Belén Ballesteros quien se hace cargo de la Secretaría Técnica de la REOP. Se aprueba la formalización del contrato laboral de Patricia Mata como Secretaria administrativa con efectos retroactivos de 1 de enero de 1999, dada la complejidad y volumen de gestión de la AEOP y de la REOP, con un sueldo anual bruto de 1.600 .000 pesetas. Con motivo de la jubilación de María Teresa Díaz Allué, Catedrática de Orientación Educativa de la Universidad Complutense de Madrid, se acuerda celebrar un sencillo acto de homenaje y dedicarle el próximo número de la REOP por su gran labor en favor de la Orientación. El acto se celebró el 5 de noviembre con asistencia de toda la JD que le entregó el número 17 de la REOP que se le había dedicado (Anónimo, 1999b). Del 11 al 13 de marzo se celebraron en la Universidad de Jaén las I Jornadas Andaluzas de Orientación y Psicopedagogía. En mayo, José A. Benavent, representando a la AEOP, contacta con la Asociación de Orientadores de Huelva y participa en el I Congreso de Psicopedagogía organizado por dicha Asociación. Siguen impartiéndose los cursos de formación y perfeccionamiento del profesorado del convenio AEOP-MEC en Asturias, Canarias, Galicia, Madrid y Valencia.

En la primera JD del año 2000, celebrada en abril, se dio la bienvenida al nuevo Presidente de la DTCn Alejandro Álamo Suárez, se acepta la solicitud de constitución de la Delegación Territorial de Castilla La Mancha (DTC-LM) presentada por Maria del Carmen Palomares Aguirre y se nombra a María Dolores Cadierno Vocal adjunta a la Tesorería para ayudar a José Antonio Rodríguez Docavo debido a la complejidad de su gestión por el aumento del volumen de asuntos económicos a despachar, al multiplicarse el número de con- 
venios, proyectos de investigación, cursos, publicaciones y otras actividades. En la AGO de 24 de marzo fue aprobada por unanimidad la propuesta elevada por la JD para la constitución de la DTC-LM y se informó de las actividades desarrolladas por las distintas DTs y Vocalías. En septiembre se firma el convenio de colaboración entre la AEOP y la Comunidad Autónoma de Madrid (CAM) para impartir cursos de formación y perfeccionamiento del profesorado no universitario y en octubre el de la AEOP con el Instituto Nacional de la Mujer (INM), se programan las primeras jornadas conjuntas y cuatro cursillos a celebrar en Madrid y Oviedo. En la JD de 20 de noviembre se aprueba la propuesta oficial para la renovación de la JD, se aumenta el sueldo de la Secretaria administrativa a 2.000 .000 de pesetas brutas para el año 2001 y presentan informes de sus actividades las distintas DTs y las Vocalías. El 31 de diciembre de 2000, la AEOP llega a los 991 socios inscritos (DTV, 119; DTG, 95; DTPV, 77: DTA, 139; DTCn, 284; DTZC, 151, DTC-LM, 30 y Nacional, 96), máximo número alcanzado por la Asociación, con el que cerramos el s. XX y que hemos utilizado como hito para finalizar el Período de Desarrollo.

\section{Delegaciones Territoriales}

Durante el Período de Desarrollo (1996-2000), estaban constituidas y en pleno funcionamiento la DTV (1980), la DTZC (1986), la DTCn (1987), la DTA (1995) y la DTPV (1995) y se solicita y aprueba la creación de dos nuevas Delegaciones, en 1998, la Delegación Territorial de Galicia (DTA), y en 2000, la Delegación Territorial de Castilla La Mancha (DTC-LM).

\section{Delegación Territorial de Valencia (DTV)}

Durante 1996 las principales actividades desarrolladas por esta DT fueron: preparar la organización de las VIII Jornadas Nacionales de Orientación Educativa, previstas para septiembre de 1997, e impartir los cursos del convenio firmado entre AEOP y el MEC. En octubre se firma el convenio de colaboración entre la DTV y la Consellería de Cultura, Educación y Ciencia de la Generalitat Valenciana (CCEC-GV) para la formación y el perfeccionamiento del profesorado y se aprueba su programación para 1996. En diciembre se edita y distribuye el Programa de las VIII Jornadas.

El 20 de febrero de 1997 se procede a la renovación de la JD, siendo elegida por unanimidad, la candidatura presidida por José Antonio Benavent Oltra, que renueva mandato. Se sigue trabajando en la preparación de las VIII Jornadas y se logra su reconocimiento y homologación como "acción formativa del profesorado" con un valor de 32 horas por la CCEC-GV. Se renueva el convenio de colaboración para 1997 y se aprueba el programa de actividades (Anónimo, 1997). Del 8 al 13 septiembre se celebran en la Universidad de Valencia las VIII Jornadas Nacionales de Orientación y se editan sus Actas.

En marzo de 1998 se inicia una campaña de información y promoción de la DT para la captación de nuevos socios, y en abril, se confecciona el programa de actividades del convenio de colaboración con la CCEC-GV para 1998. En junio se crea y cuelga la primera página web de la DTV en Internet, en la URL www.uv.es/AEOP y hasta final de año se siguen impartiendo los cursos de los convenios DTV-CCEC y AEOP-MEC. 
En febrero de 1999 se aprueba, por la CCEC-GV, el programa de actividades del convenio de colaboración presentado por DTV para 1999. El 2 de septiembre se firma un convenio de colaboración con la Universitat de València por el que dichos cursos se reconocen como créditos de libre opción para su alumnado, con un valor de 3 créditos por curso de 32 horas de duración. Los 7 cursos programados se impartieron de octubre a diciembre con nutrida matrícula y valoración positiva por parte de los asistentes (Anónimo, 1999c). En febrero de 2000, la CCEC-GV renueva el convenio de colaboración con la DTV y aprueba el programa de actividades, con un total de 13 cursos, a desarrollar a lo largo del año (Anónimo, 2000). Se renueva el convenio con la Universitat de Valencia y se imparten 11 cursos, con un valor de 3 créditos por curso (30 horas), que se integran en la oferta académica oficial de la Universitat de València como asignaturas específicas de libre elección (Anónimo, 2000a).

\section{Delegación Territorial de la Zona Centro (DTZC)}

En enero de 1996 dimite la Vicepresidenta María Teresa Muñoz Sastre por trasladar su domicilio a Francia; en marzo se renueva el 50\% de los cargos de la JD y se firma un Convenio de Colaboración con el MEC para impartir cursos de Formación Permanente del Profesorado que entrará en vigor el 1 de enero de 1997; en junio, se nombra el grupo de trabajo que se encargará de impartir los cursos del convenio y, en octubre, se edita el programa de las Jornadas y se inician las clases del convenio. La campaña de promoción y las actividades desarrolladas dan sus frutos, y a 31 de diciembre de 1996, la DTZC supera los 150 socios (Anónimo, 1996 y 1996a).

Finalizadas las Jornadas "Encuentro entre los profesionales de la Orientación”, celebradas los días 24 y 25 de enero de 1997 en la UNED (Madrid), la JD de 4 de febrero evalúa muy positivamente los resultados obtenidos y se propone una revisión y actualización de las Vocalías (Anónimo, 1997a). La remodelación de las Vocalías se aprueba en la AGO del 18 de febrero y se propone la conveniencia de que sean asumidas también a nivel nacional por la JD de la AEOP. Se aprueba la constitución de las siguientes Vocalías:

1) Relaciones nacionales e internacionales.

2) Publicaciones.

3) Diagnóstico y evaluación en Orientación.

4) Orientación educativa y Tutoría.

5) Orientación profesional.

6) Orientación, formación ocupacional y empresa.

7) Orientación familiar y comunitaria, y

8) Orientación y atención a la diversidad.

Se colabora con FOREM en el proyecto PROMETEO enmarcado en el Programa "Leonardo da Vinci" de la UE y cuya finalidad es mejorar los recursos de la Orientación Profesional en el actual contexto laboral europeo (Anónimo, 1997b). En las VII Jornadas Nacionales de Orientación, celebradas en el mes de septiembre en Valencia, se presentaron las conclusiones de las Jornadas de Madrid. En noviembre, la JD acuerda celebrar una cena-coloquio para hablar sobre la situación de la Orientación en la Comunidad Autónoma 
de Madrid (CAM), al haber asumido ésta las competencias en materia educativa transferidas por el MEC. También se propone que la DT sea un lugar de encuentro e intercambio para quienes estén preparando las oposiciones de orientación y que de cobertura a una asamblea de los Departamentos de Orientación de los IES de la CAM.

En la AGE de 18 de diciembre de 1998 se procede a la renovación de la JD a la que se presenta una candidatura unitaria presidida por Consuelo Vélaz de Medrano que es aprobada por unanimidad (Anónimo, 1998). Se reestructuran las Vocalías y se reducen a cuatro:

1) Relaciones externas.

2) Orientación educativa y tutoría.

3) Orientación profesional y

4) Diagnóstico y evaluación en Orientación.

Durante 1999 la principal actividad organizada por la DTZC fue la celebración, el 6 de octubre, del I Encuentro de Orientadores de la CAM para discutir las conclusiones de la investigación "El desarrollo profesional de los Orientadores de Educación Secundaria: evaluación de necesidades y propuestas de mejora" (CIDE/UNED/AEOP), celebrado en los locales de la UNED con una selecta asistencia de especialistas (Anónimo, 1999d). Durante el año 2.000 se siguieron impartiendo los cursos programados para la formación y perfeccionamiento del profesorado no universitario del convenio de colaboración entre la DTZC y la CAM.

\section{Delegación Territorial de Canarias (DTCn)}

La nueva JD elegida en mayo de 1995 y presidida por Víctor José González Expósito, inicia su andadura con el reto de mantener el prestigio alcanzado a nivel nacional e internacional por la DTCn durante el brillante mandato anterior. Durante el curso 1996-97 se impartieron 6 cursos de formación y perfeccionamiento del profesorado (Anónimo, 1996b y 1996c). También se participó en el programa de Renovación Pedagógica de la Consejería de Educación del Gobierno de Canarias y se firmó un convenio de colaboración con el Colegio Oficial de Psicólogos.

En abril de 1997 la DTCn, por medio de su Vicepresidente, Teófilo González, asume la Vocalía 6a "Orientación familiar y comunitaria" de la JD Nacional. Se prepara la participación en las VIII Jornadas Nacionales de Valencia a celebrar en septiembre, y para incentivar la inscripción de los socios de la DT, se dota una bolsa de 200.000 pesetas para ayudar a sufragar los costes de desplazamiento de los asistentes (Anónimo, 1997c) Desciende significativamente la matrícula en los cursos de formación organizados por la DT, y ante la falta de subvenciones de la Consejería de Educación y otras razones, se suspende su celebración (Anónimo, 1997d).

Al amparo del convenio de colaboración firmado con el MEC, se celebraron en Tenerife, del 18 al 25 de noviembre los cursos: "Competencia social: la agresividad en los alumnos y resolución de conflictos" y "Los temas transversales al curriculum: la prevención del consumo de drogas desde la escuela", ambos con nutrida asistencia. Se firma un convenio de colaboración con el Departamento de Didáctica e Investigación Educativa y del Comportamiento, de la Facultad de Educación de la Universidad de La Laguna, por el que se participa activamente en la organización y desarrollo del I Congreso Nacional "Educar y Orientar en una economía social y medioambiental", celebrado en la citada Universidad en diciembre de 1998. 
Durante 1999 se siguen impartiendo los cursillos de formación y perfeccionamiento para los orientadores y se decide aplazar la celebración de las Jornadas regionales programadas. Del 20 al 27 de mayo, la DTCn colabora con la Consejería de Educación en la organización de las Jornadas que se celebraron en el CIATEC (Centro de Innovación y Actualización Tecnológica) de Tegueste (Tenerife), invitando a todos los orientadores de secundaria de la isla, en la que un grupo de trabajo de nuestros socios presentó instrumentos informatizados para la evaluación psicopedagógica en Secundaria. Las Jornadas se repitieron los días 28 y 29 de septiembre en la isla de La Palma (Anónimo, 1999e). A finales de año, finalizado el mandato de la JD, se abre un período constituyente para la presentación de candidaturas.

En la AGE celebrada a principios del año 2000 se procede a la renovación de la JD, resultando elegida por unanimidad, la candidatura unitaria presidida por Alejandro Álamo Suárez, que asiste por vez primera, como Presidente de la DTCn y Vocal nato de la JD Nacional, a la AGO de la AEOP celebrada en Madrid el 24 de marzo de 2000. Siguen impartiéndose cursos de formación pero con un notable descenso en las matrículas. Se organiza un servicio de informatización de datos, pase de baterías de tests, encuestas y emisión de diagnósticos, con buena acogida, atendiendo a finales de año, a 25 centros educativos y a más de 1.100 alumnos. Se acuerda celebrar en 2001 las III Jornadas de Orientación de Canarias, pospuestas y aplazadas en varias ocasiones.

\section{Delegación Territorial de Andalucía (DTA)}

La DTA inicia el año 1996 con una campaña de información, divulgación y captación de nuevos socios. Su Presidente, Juan Ruiz Carrascosa, como Vocal nato de la JD Nacional, asiste por vez primera a la reunión de la JD de 23 de junio de 1996, en la que presentó el programa de actividades de su DT para el curso 1996-97.

Durante los primeros meses de 1997 se sigue con la campaña de información y divulgación. El 20 de junio de 1997 se celebra en la Universidad de Jaén, con gran asistencia de profesionales de la Orientación y estudiantes universitarios, una mesa redonda con el título "Presente y futuro de la Psicopedagogía" en la que participaron, Elvira Repetto, Presidenta AEOP, Aurelia Calzada, Delegada Provincial de la Consejería de Educación y Ciencia de la Junta de Andalucía y el Presidente de la DTA (Anónimo, 1997e). En este acto se vislumbra la posibilidad de celebrar unas jornadas regionales de orientación.

En la AGO de 17 de enero de 1998, la JD propone organizar las I Jornadas Andaluzas de Orientación para mejorar la imagen de la DT y captar nuevos socios, y en septiembre, cristaliza y se confirma su celebración para la primavera de 1999. En noviembre se firma un convenio de colaboración entre la DTA y la Universidad de Jaén para desarrollar cursos, seminarios y programas de investigación de interés común (Anónimo, 1998a). En diciembre se edita, publicita y distribuye el programa de estas I Jornadas Andaluzas (Anónimo, 1998b).

La actividad de la DTA durante los primeros meses de 1999 se centró en la organización y desarrollo de las I Jornadas Andaluzas de Orientación y Psicopedagogía, que con el título, "Orientación educativa e intervención psicopedagógica", se celebraron en la Universidad de Jaén del 11 al 13 de marzo. En los meses siguientes se prepararon las Actas que fueron editadas en 2000. En septiembre, finalizado el mandato legal de la JD, se abre un período constituyente para la presentación de candidaturas. El 23 de diciembre de 1999, la DTA ce- 
lebró en Jaén una AGE para la renovación de su JD. Tras la presentación de las candidaturas y la votación correspondiente, fue elegida la candidatura presidida por José Acosta Bautista, y la sede social se trasladó a El Puerto de Santa María (Cádiz), ciudad de residencia del nuevo Presidente (Anónimo, 2000).

\section{Delegación Territorial del País Vasco (DTPV)}

La DTPV celebró la AGE constituyente el 30 de mayo de 1996, resultando elegida la candidatura presidida por Carmen Valdivia Sánchez. Con el fin de organizar mejor las actividades en los dos distritos universitarios del País Vasco, San Sebastián y Bilbao, Carmen Valdivia pertenece a la Universidad de Deusto (Bilbao), se aprueba crear una Vicepresidencia para el campus de San Sebastián, para la que es elegida Francisca Arbe, y que en el futuro, se alternen la Presidencia y Vicepresidencia entre ambos campus. Para dinamizar la DT se proyecta celebrar unas Jornadas de Orientación coincidentes con la graduación de la primera promoción de Licenciados en Psicopedagogía de la Universidad de Deusto (Anónimo, 1996). Para ayudar al desarrollo de la DT, la JD Nacional de 29 de noviembre de 1996 aprueba eximirla de aportar a la AEOP el porcentaje correspondiente de las cuotas sociales.

La propuesta de las jornadas no prospera y a pesar de los esfuerzos de su JD la DTPV no consigue consolidarse ni coordinar un programa unitario de actividades a desarrollar en los campus de Bilbao y San Sebastián. Se constata la necesidad de abrir canales de comunicación entre los socios para intercambiar información, metodología, experiencias y apoyo mutuo. En la AGO de noviembre de 1999 se propone crear una página web en Internet y se firma un convenio con la Universidad de Deusto para que los socios puedan acceder a su Docimoteca con las mismas condiciones que sus alumnos. A finales de 1999 la DTPV contaba con 78 asociados (Anónimo, 1999g).

En mayo de 2000 finaliza el mandato legal de la JD y se abre período constituyente para la presentación de nuevas candidaturas. En la AGE celebrada en septiembre para renovar la JD, resultó elegida la candidatura presidida por Carmen Valdivia. Se crea un servicio gratuito de consulta y asesoramiento para los socios en la Universidad de Deusto, sede de la DT.

\section{Delegación Territorial de Galicia (DTG)}

En la AGO de la AEOP de 26 de junio de 1998 se aprueba la propuesta de la JD promovida por Elena Menéndez Martín y acompañada de las firmas de socios preceptivas para constituir la DTG. En septiembre se celebra en La Coruña la AGE constituyente en la que resulta elegida por unanimidad la candidatura presidida por Elena Menéndez que pasa a ser Vocal nato de la JD Nacional. La nueva Presidenta asiste por vez primera como Vocal a la JD Nacional del 13 de noviembre y presenta un completo programa de información y captación de socios para 1999.

Durante el primer trimestre de 1999 se celebra en La Coruña el primer curso de formación del profesorado del convenio de colaboración AEOP-MEC. El 30 de septiembre de 1999 la JD revisa las actividades realizadas y propone el programa a desarrollar durante el curso 1999-2000. En esta fecha, la DTG tenía 53 socios. Destaca el proyecto de celebrar unas jornadas de orientación y tutoría en primavera, y en el verano del 2000, un curso sobre 
"Cualificaciones profesionales" en colaboración con el ICE de la Universidad de Santiago y la UNED (Anónimo, 1999h).

Durante los días 28 y 29 de abril de 2000 se celebraron en La Coruña, unas Jornadas de formación del profesorado bajo el lema "Orientación y tutoría en educación", organizadas por la UNED con la colaboración de la Universidad de Santiago de Compostela y la DTG de la AEOP. Las Jornadas fueron dirigidas y coordinadas por Elvira Repetto, Presidenta de la AEOP; Elena Menéndez, Presidenta de la DTG; Carmen Delia García-Fuentes, de la JD de la DTG, y Enrique Vila, Director del Centro Asociado de la UNED en La Coruña. Se desarrollaron con gran asistencia de público, casi todos profesores de la ESO, y con la exposición de la mayoría de ponencias y comunicaciones a cargo de socios de la DT (Anónimo, 2000c).

\section{Delegación Territorial de Castilla-La Mancha (AEOP-CLM)}

En la AGO de la AEOP, celebrada en Madrid el 24 de marzo de 2000, se aprobó, a propuesta de la JD, la constitución de la Delegación Territorial de Castilla-La Mancha promovida por la socia María del Carmen Palomares Aguirre que presentó el pliego de firmas preceptivo, y en la que se facultó a los socios residentes en la Comunidad Autónoma de Castilla-La Mancha para iniciar el proceso constituyente de presentación de candidaturas. El 6 de abril, en la AGE reunida en Cuenca, es elegida por unanimidad, la candidatura presidida por María del Carmen Palomares Aguirre y se fija el domicilio social de la DT en el IES "Alfonso VIII" de Cuenca (Anónimo, 2000d). Desde su constitución hasta el 31 de diciembre de 2000 la DT había realizado las siguientes actividades:

a) Actualización del fichero de sus asociados.

b) Iniciación de los trámites para firmar un convenio de colaboración con la Universidad de Castilla La Mancha y

c) Elaboración de un programa de formación del profesorado para el curso 2000-2001 que se ha presentado para la firma de un convenio con la Consejería de Educación de la Junta de Comunidades de Castilla-La Mancha (2000e).

\section{Congresos, Jornadas y Seminarios}

Durante el Período de Desarrollo (1996-2000), la AEOP, en colaboración con sus DTs, organizó y celebró las siguientes reuniones científicas: las VIII Jornadas Nacionales de la Asociación Española de Orientación y Psicopedagogía (AEOP), en Valencia, y las I Jornadas Andaluzas de Orientación y Psicopedagogía en Jaén.

\section{Jornadas Nacionales de la AEOP}

Las VIII Jornadas Nacionales de la AEOP, bajo el lema "La Orientación educativa y la intervención psicopedagógica integradas en el curriculun", se celebraron en Valencia, del 8 al 11 de septiembre de 1997 organizadas por la DTV con la colaboración de la AEOEP, la Consellería de Cultura, Educación y Ciencia de la Generalitat Valenciana, la Universitat de 
València, el Ayuntamiento de Valencia y Bancaja. Las sesiones se desarrollaron en el Campus "Blasco Ibáñez" de la Universitat de València, con 322 congresistas inscritos, numeroso invitados y una nutrida asistencia.

Las VIII Jornadas se desarrollaron en un acto inaugural, seis sesiones plenarias y un acto de clausura. Se presentaron un total de 95 trabajos que se distribuyeron en 6 ponencias y 15 mesas redondas para la exposición y discusión de las 89 comunicaciones presentadas. Todos los trabajos, la valoración de las Jornadas y la relación de los participantes inscritos, se publicaron en las Actas, que se entregaron a los asistentes en el momento de la acreditación y recogida de materiales (AEOP, 1997). Las conclusiones se publicaron inmediatamente después en la Revista de Orientación y Psicopedagogía (Anónimo, 1997f).

El Acto de apertura fue presidido por el Conseller de Cultura, Educación y Ciencia de la Generalitat Valenciana, Francisco Camps Ortiz. Cada una de las seis sesiones plenarias, vertebradas por las ponencias, se continuaban con sus respectivas mesas redondas para la exposición y discusión de las comunicaciones afines. Las ponencias trataron los siguientes temas:

1) Orientación y tutoría en Educación Infantil y Primaria.

2) La inserción sociolaboral desde el curriculum de Secundaria.

3) Curriculum y mundo del trabajo en la Educación Postsecundaria.

4) Orientación y tutoría en la Universidad.

5) La formación continua en España y

6) Formación de Orientadores en la Unión europea.

El Acto de clausura estuvo presidido por el Rector de la Universitat de València, Pedro Ruiz Torres, dando lectura a las Conclusiones los Secretarios de cada una de las seis ponencias.

\section{Jornadas Andaluzas de Orientación y Psicopedagogía}

Las I Jornadas Andaluzas de Orientación y Psicopedagogía sobre el tema "Orientación Educativa e Intervención Psicopedagógica", se celebraron en la Universidad de Jaén, del 11 al 13 de marzo de 1999 organizadas por la DTA en estrecha colaboración con la AEOP y el Departamento de Pedagogía de la Universidad de Jaén y fueron patrocinadas por la Universidad de Jaén, la Consejería de Educación de la Junta de Andalucía, el Ayuntamiento de Jaén y otras instituciones y organismos públicos y privados. Las sesiones se desarrollaron en el Campus de la Universidad de Jaén con más de 300 inscripciones y una numerosa asistencia.

Las I Jornadas Andaluzas se desarrollaron en un acto inaugural, cinco sesiones plenarias y un acto de clausura. Se presentaron un total de 33 trabajos que se distribuyeron en 12 ponencias, con seis mesas para la exposición y discusión de las 21 comunicaciones presentadas. Todos los trabajos que cumplieron los requisitos de formateado electrónico se publicaron en las Actas, que no recogen información sobre las sesiones de apertura y clausura, ni aportan las conclusiones (Ruiz y Medina, 2000).

Las cinco sesiones plenarias de trabajo se organizaron vertebradas en torno a tres grandes áreas temáticas:

1) Orientación educativa. 
2) Modelos de investigación y metodología de evaluación de programas y

3) Intervención psicopedagógica.

Estos tópicos se desarrollaron a través de 12 ponencias que aglutinaron las comunicaciones afines en seis mesas. Los temas desarrollados por las ponencias fueron los siguientes:

1.a) La Orientación Educativa: Situación actual de la teoría y la práctica.

1.b) La Orientación Educativa a través de la tutoría, los departamentos de orientación y los EOEPS.

1.c) Organización de la Orientación en Andalucía.

1.d) La Orientación en los centros educativos.

2.a) La investigación en Orientación educativa: modelos y principales variables.

2.b) Metodología de la evaluación de programas.

2.c) Aplicación de las nuevas tecnologías en los alumnos con n.e.e.

2.d) La Orientación en la Universidad en el contexto de una educación de calidad.

3.a) Intervención psicopedagógica. Estrategias de aprendizaje.

3.b) La Orientación para la inserción profesional.

3.c) Intervención cognitiva en los procesos de comprensión y

3.d) La atención a la diversidad en Andalucía.

En estas I Jornadas Andaluzas se expuso y se reflexionó sobre la Orientación educativa y la intervención psicopedagógica desde los ángulos teórico, práctico, legal, técnico y metodológico, consiguiendo los asistentes al finalizar las Jornadas, una visión bastante amplia e integrada de la situación actual de nuestra actividad en general y de la andaluza en particular (García-Fuentes y Téllez, 1999).

\section{Publicaciones}

Durante el Período de Desarrollo (1996-2000) se editaron diez números de la Revista, órgano oficial y portavoz de la AEOP, cinco con la cabecera Revista de Orientación y Psicopedagogía - del número 7 (11), correspondientes al $1^{\circ}$ semestre de 1996, al 9 (15), del $1^{\circ}$ semestre de 1998-, y otros cinco, con el título actual de Revista Española de Orientación y Psicopedagogía - del 9 (16), del $2^{\circ}$ semestre de 1998, al 11 (20), del $2^{\circ}$ semestre de 2000 - En 1996 se editan los Estatutos (1996) y el Reglamento General de Régimen Interior (1996a); en 1997, se publicaron las Actas de las VIII Jornadas Nacionales de la AEOP celebradas en Valencia; en 1998, aparece el Boletín de la AEOP y las Actas del XV Congreso Internacional de la AIOEP celebrado en Madrid en 1994; y en 2000, las Actas de las I Jornadas Andaluzas de Orientación y Psicopedagogía de Jaén.

Consolidada la Revista de Orientación Educativa y Vocacional (ROEP), de la que ya se habían publicado 11 números (1990-1995), en la AGO de 24 de noviembre de 1995 se decidió cambiar la cabecera y se aprobó una nueva con la denominación de Revista de Orientación y Psicopedagogía (ROP) que empezó a utilizarse a partir del número 11, correspondiente al $1^{\circ}$ semestre de 1996. La ROP modifica ligeramente la organización de sus contenidos que se estructuran en las siguientes secciones: 

a) Editorial.
b) Estudios.
c) Experiencias.
d) Recursos y material de Orientación.
e) Recensiones $y$
f) Información general.

La solicitud presentada por la AEOP en enero de 1996 ante la Agencia Nacional de Títulos, Patentes y Marcas, para registrar la cabecera de la ROP es rechazada en julio de 1997 por ser demasiado genérica, lo que obliga a tramitar una nueva solicitud con el título de Revista Española de Orientación y Psicopedagogía (REOP) que es aceptada por la Agencia, quien aprueba y registra la nueva cabecera en septiembre de 1998, con lo que a partir del número 9 (16) del $2^{\circ}$ semestre de 1998 se editará con la actual denominación de REOP. Las portadas de la revista con las dos cabeceras se presentan en las figuras 5 y 6 . Ver tabla resumen de contenidos en Anexo IV.

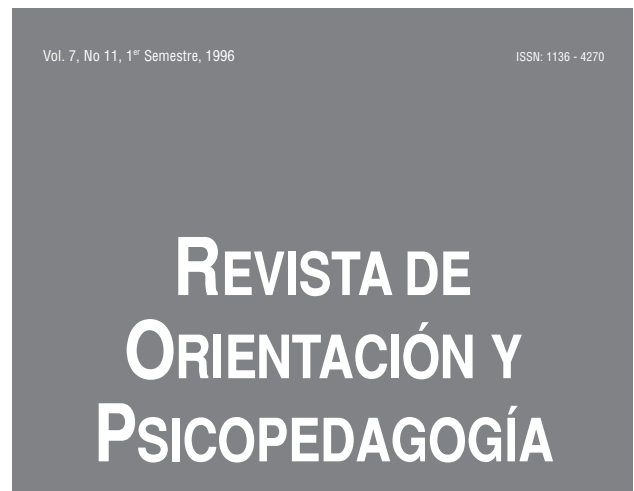

(Anteriormente Revista de Orientación Educativa y Vocacional)
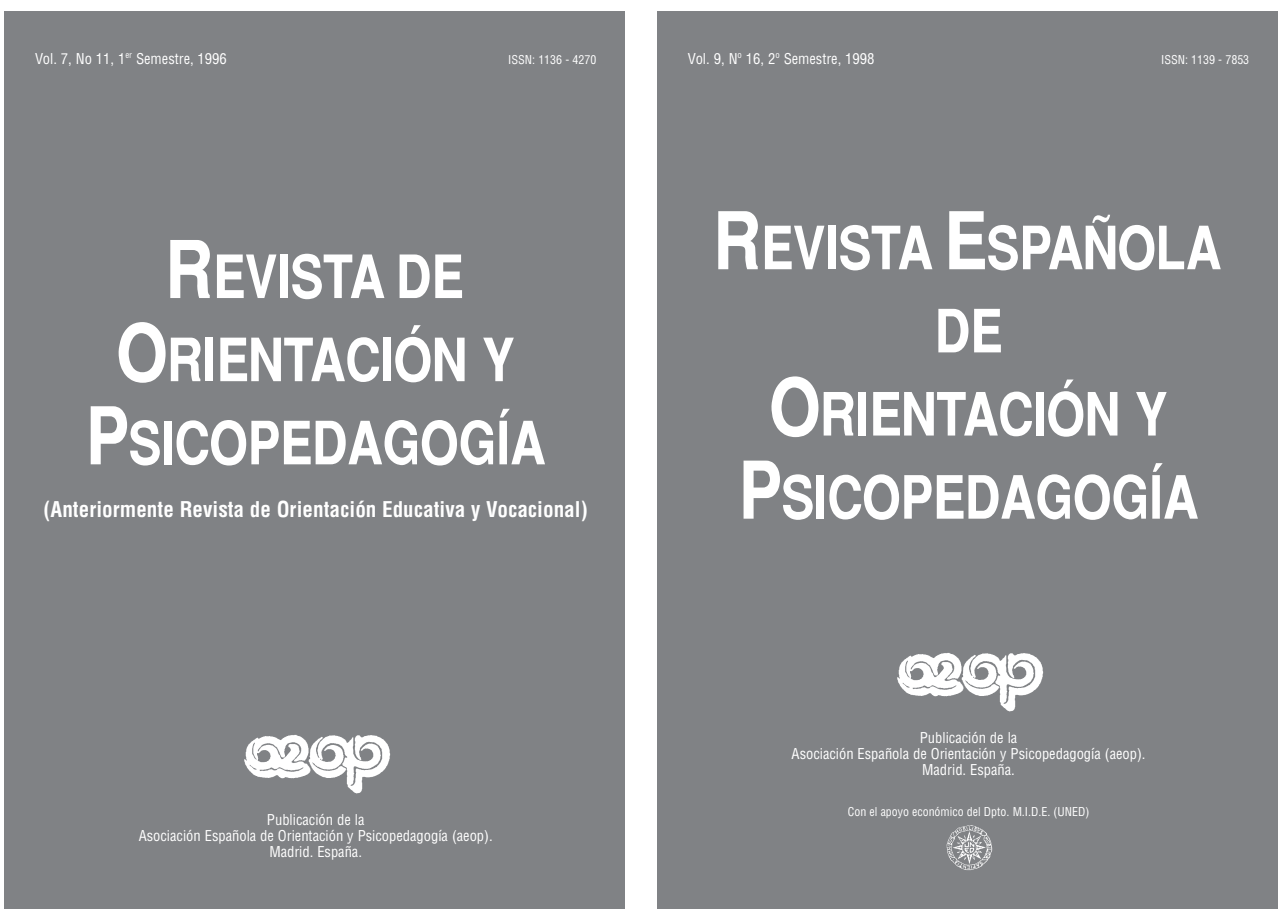

FIGURA 5 y 6.

Portadas de la revista de la AEOP con las cabeceras ROP (1996-1998) y REOP (1998-2003).

En la AGO de abril de1997 se aprueba aumentar el número de ejemplares de tirada de la ROP, que pasa de 1.000 a 1.500 y se firma un convenio con el Deparamento MIDE/UNED, 
para que financie el $10 \%$ de las tiradas de la revista a cambio de imprimir su logotipo en la portada, logotipo que aparecerá por vez primera en el número 8 (13) del $1^{\circ}$ semestre de 1997. En septiembre, se acuerda dedicar un número monográfico a conmemorar el nacimiento de José Germain y José Mallart, el $n^{\circ} 8$ (14), correspondiente al $2^{\circ}$ semestre.

En abril de 1998 sale el no 1 del Boletín de la AEOP con novedades editoriales, bibliografías, noticias puntuales y de actualidad, convocatoria de reuniones científicas, etc., editado en formato A4 por Marisa Pereira desde la Universidad de Oviedo y su versión electrónica aparece en abril de 1999 y se cuelga en la página web www.uniovi.es/ aeop de Internet. Hasta el 31 de diciembre de 2000 habían aparecido cuatro números. A principios de 1999 Laura Oliveros deja la Secretaría Técnica de la REOP y pasa a Vicepresidenta de la AEOP, siendo sustituida por Belén Ballesteros que se encarga de preparar el $n^{\circ} 10$ (17) de la REOP, correspondiente al $1^{\circ}$ semestre de 1999, en homenaje a María Teresa Díaz Allué con motivo de su jubilación. El n ${ }^{\circ} 20,2^{\circ}$ semestre del 2000, es monográfico sobre "Orientación y atención a la diversidad en Secundaria”. La REOP, en su afán de adaptarse a los criterios vigentes sobre normalización de revistas científicas ha introducido en el año 2000 las siguientes mejoras: un sumario en inglés, la traducción al inglés de los títulos de los artículos y el URL de la página web de la AEOP en Internet donde aparecen los resúmenes de sus artículos. A 31 de diciembre de 2.000 la REOP se distribuía gratuitamente a nuestros 991 asociados y tenia 156 suscriptores, 61 individuales y 95 institucionales.

En cuanto a las Actas, a lo largo del Período de Desarrollo aparecieron las siguientes publicaciones:

1) Actas de las VIII Jornadas Nacionales de Orientación y Psicopedagogía de la AEOP, Valencia, 8 al 11 de septiembre de 1997 . Se entregaron a los congresistas en la sesión inicial, en el momento de acreditarse y recoger los materiales. Fueron financiadas íntegramente por la DTV, en una tirada de 1.000 ejemplares en formato A4. Bajo el título La Orientación educativa y la intervención psicopedagógica integradas en el currículum, sus 426 páginas, tras el Índice y un Prólogo, recogen, seleccionadas y sistematizadas, todas las ponencias y comunicaciones presentadas, estructurándose su contenido en seis unidades temáticas básicas correspondientes a las seis ponencias de las Jornadas:

I) Orientación en Educación Infantil y Primaria.

II) Orientación en Educación Secundaria Obligatoria.

III) Orientación en la Secundaria Post-obligatoria.

IV) Orientación en la Universidad.

V) Orientación y formación continua y

VI) Formación de Orientadores.

Cada unidad temática se ilustra con una sección titulada "Estudios a la unidad" que recoge las comunicaciones afines. La publicación se cierra con un Apéndice que contiene la organización, el programa y la relación de participantes (AEOP, 1997). Las conclusiones se publicaron posteriormente en la REOP (Anónimo, 1997f).

2) Actas del XV Congreso Internacional de la AIOEP, Madrid, 13-16 de julio de 1994. Después de superar varias intentos fallidos para su publicación, debido a la magnitud de su contenido y al coste de la edición, finalmente, la UNED, a través del Vice- 
rrectorado de Metodología, Medios y Tecnología y del Departamento MIDE hizo posible su aparición en 1998, cuatro años después de la celebración del Congreso. Bajo el título general, Orientación de la carrera, recursos humanos y mercado laboral se publicaron todos los trabajos presentados, en su versión original (español o inglés) y en dos volúmenes, gracias al esfuerzo de sistematización y corrección de Elvira Repetto y Consuelo Vélaz de Medrano (Eds.). El volumen I, con el mismo subtítulo que el título general del Congreso, recoge en sus 932 páginas, tras los Agradecimientos, la Presentación y el Índice, 78 trabajos ordenados y agrupados por afinidad en cinco grandes áreas temáticas:

a) Orientación y desarrollo de la carrera.

b) Orientación profesional y transición a la vida activa.

c) Orientación de recursos humanos y mercado laboral.

d) Sinergias Universidad-Empresa: La Orientación de los alumnos universitarios y

e) Orientación e inserción laboral de sujetos con necesidades educativas especiales.

El volumen II, subtitulado Orientación educativa e intervención psicopedagógica: Programas, servicios y evaluación, compila en sus 644 páginas, tras los Agradecimientos, la Presentación y el Índice, 52 trabajos ordenados y agrupados en dos amplias áreas:

a) Orientación educativa e intervención psicopedagógica, y

b) Análisis de necesidades y evaluación de la orientación.

No se recogen los actos de apertura y clausura del Congreso ni se presentan las conclusiones (Repetto y Vélaz de Medrano, 1998).

3) Actas de las I Jornadas Andaluzas de Orientación y Psicopedagogía, Jaén, (11-13 de marzo de 1999). Se publicaron con el título "Orientación Educativa e Intervención Psicopedagógica" y fueron financiadas íntegramente por la Universidad de Jaén a través del Departamento de Pedagogía. Sus 462 páginas, tras el Índice y una breve Presentación, recogen 32 de los 33 trabajos presentados (falta una ponencia) agrupados en dos partes:

a) Ponencias, con 11 trabajos $y$

b) Comunicaciones, con 21 títulos.

No se da información de los actos de apertura y clausura y no contiene conclusiones ni relación de participantes (Ruiz y Medina, 2000).

\section{Proyección internacional}

Durante el Período de Desarrollo, los socios de la AEOP, representando a nuestra Asociación, participaron activamente en proyectos de investigación, congresos, jornadas, seminarios y otros eventos internacionales:

- En 1996 se celebra en Dublín (Irlanda), del 8 al 12 de julio, un Seminario organizado por la AIOEP bajo el título "Orientación y consejo para el s. XXI" y al que asistió una delegación de la AEOP presidida por Elvira Repetto. En la AGO de 26 de junio se aprueba que la AEOP contribuya con 300 \$ a la creación de la Fundación Donald E. 
Super de San Francisco (EE.UU.). Los días 25 y 26 de octubre, la JD de la AIOEP celebra una reunión en El Escorial (Madrid), para preparar el Memorial en honor de D. E. Super a la que asistieron Elvira Repetto y José Antonio Rodríguez Docavo, que presentó un documentado trabajo sobre la figura de Super.

- En febrero de 1998 se celebra en Tampere (Finlandia) un Encuentro Internacional organizado por la Asociación Finlandesa de Orientadores Escolares, miembro de la AIOEP, con el título, "Luz y oscuridad: Orientadores para tiempos de incertidumbre", con participación de 550 delegados de 33 países. En representación de la AEOP asistieron y participaron activamente Elvira Repetto y Araceli Sebastián (Anónimo, 1998c). En la AGO de 26 de junio se informa sobre la colaboración y participación de un equipo de especialistas de la AEOP en el proyecto de investigación "Desarrollo de la carrera profesional de los estudiantes de $10^{\circ}$ curso, $2^{\circ}$ de la ESO" patrocinado por la UNESCO. En la reunión del Comité Ejecutivo de la AIOEP celebrada en París en el mes de octubre, y a la que asistió Elvira Repetto en calidad de Vicepresidenta, se tomaron entre otros acuerdos: a) Editar los Estatutos de la AIOEP en ingles, francés, alemán y español. b) Traducir al español el Boletín Informativo de la AIOEP y al gallego el Glosario de la AIOEP. (Anónimo, 1998d),

- Del 19 al 21 de enero de 1999 se celebró en Wellington (Nueva Zelanda) el 47 Seminario de la AIOEP bajo el lema "Coyuntura crítica: dirigiendo el cambio de carrera". Asistieron 230 delegados de 15 países. La AEOP estuvo representada por Elvira Repetto y Daniel Anaya que participaron exponiendo sus trabajos (Anónimo, 1999i).

- Del 4 al 7 de agosto de 1999 se celebró en la Universidad de Warwick (U.K.) el Congreso "Lifelong Career Guidance for Lifelong Career Development" de la AIOEP. Nuestra Asociación estuvo representada por Elvira Repetto, Araceli Sebastián, Daniel Anaya, Beatriz Malik y José Antonio Rodríguez Docavo que participaron con ponencias y comunicaciones. En la AGE de la AIOEP se renovó el Comité ejecutivo, siendo reelegida Vicepresidenta, Elvira Repetto y Vocal suplente, José Antonio Rodríguez Docavo (1999j).

- En octubre de 1999 la JD de la AIOEP aprueba el cambio de formato y denominación de su revista, que a partir de 2001 se denominará "International Journal for Educational and Vocational Guidance" (IJEVG). Se nombra a Elvira Repetto coordinadora del proyecto de investigación patrocinado por la AIOEP, "Counselor Qualifications Standarts" (CQS), mediante el cual se pretende diseñar las pautas internacionales sobre las competencias profesionales de los orientadores y los requisitos mínimos para su formación (Anónimo, 2000f).

- Del 30 de agosto al 1 de septiembre de 2000 se celebra en Berlín (Alemania), la Conferencia Internacional de la AIOEP con el título, "Orientación educativa, profesional y para el empleo: Nuevos retos", asistiendo unos 800 especialistas de 55 países con una importante y activa participación española, estando la AEOP representada por su Presidenta, Elvira Repetto, el Tesorero, José Antonio Rodríguez Docavo y los socios Daniel Anaya, Beatriz Malik, Luis Sobrado, Ma Luisa Rodríguez y Sofía Gallego. Cabe destacar la participación de nuestra Presidenta, coordinadora junto con el Prof. Hiebert de Canadá, de la investigación CQS sobre las competencias y el rol del orientador, con la pretensión de establecer unas normas consensuadas a nivel internacional para su cualificación profesional (Gelvan, 2000). 
- A nivel internacional finaliza el año 2000, cierre de este Período, con una buena noticia para la AEOP, se confirma que la editorial holandesa Kluwer Academic Pbl. se hace cargo de la publicación y distribución comercial del International Journal for Educational and Vocational Guidance (IJEVG), portavoz y órgano oficial de la AIOEP, cuyo primer número, monográfico en memoria de D. E. Super, aparecerá en 2001, y se nombra a Elvira Repetto, Co-editora, y a José Antonio Benavent, miembro del Consejo Asesor de la revista.

\section{Período actual o del s. XXI (2001-2004)}

Este Período, de un cuatrienio de duración, se extiende, desde el 1 de enero de 2001, primer año del s. XXI, hasta el 31 de diciembre de 2004, fin del año en que se cumple el $25^{\circ}$ Aniversario de la fundación de la AEOEP, actual AEOP. Se caracteriza por:

a) La activación del movimiento asociacionista de los profesionales de la Orientación, que iniciado en los últimos años del s. XX e impulsado por los nuevos licenciados en Psicopedagogía, se ve favorecido por la aprobación de la Ley Orgánica 1/2002, de 22 de marzo, reguladora del Derecho de Asociación, que propicia el nacimiento y consolidación de nuevas asociaciones de Orientación y Psicopedagogía en distintas Comunidades Autónomas.

b) El impacto de las nuevas tecnologías de la información y la comunicación (TIC), que abren una nueva vía para los contactos profesionales y el intercambio de informes, metodologías, investigaciones y experiencias.

c) La recesión de las actividades, debida a una significativa bajada de la demanda de cursos y jornadas, tanto por la saturación de los usuarios como por el cansancio de las JDs, producto del intenso ritmo de trabajo llevado en años anteriores.

d) El descenso del número de asociados de la AEOP, que el 31 de diciembre de 2000 había alcanzado la máxima cota de afiliación con 991 socios, decrece por primera vez en la historia de forma progresiva, y se situaba el 11 de junio de 2004 (última fecha de la que disponemos de datos), en 720. En la tabla 4 se muestra la evolución de la afiliación desde la fundación de la Asociación hasta el momento actual.

e) La concienciación de la nueva situación y los esfuerzos realizados por la JD a nivel nacional, internacional y de sus DTs, para reactivar y potenciar su funcionamiento, y que no dan los resultados esperados.

f) El cambio de estrategias estructurales y funcionales operado en la AEOP a partir de la aprobación de la Ley Orgánica 1/2002, conducente a transformar la Asociación en una federación de asociaciones (FEOP), y a favorecer la cooperación con las asociaciones y organizaciones afines del Estado Español para la futura constitución de una "Confederación de Organizaciones de Psicopedagogía y Orientación de España” (COPOE).

\section{Acuerdos, actividades y acontecimientos}

El siglo XXI se inicia con la revisión y actualización de los archivos y ficheros de la Asociación, con especial atención al listado de socios, dado el número de cuotas impagadas y 
TABLA 4: Evolución del número de socios de la AEOP a 31 de diciembre (1989-2004).

\begin{tabular}{|c|c|c|c|c|c|c|c|}
\hline Año & $\mathbf{N}^{\mathbf{0}}$ socios & Año & $\mathbf{N}^{\mathbf{0}}$ socios & Año & $\mathbf{N}^{\mathbf{0}}$ socios & Año & $\mathbf{N}^{\mathbf{0}}$ socios \\
\hline 1979 & 28 & 1986 & 380 & 1993 & 622 & 2000 & 991 \\
\hline 1980 & 110 & 1987 & 431 & 1994 & 719 & 2001 & 903 \\
\hline 1981 & 130 & 1988 & 457 & 1995 & 822 & 2002 & 865 \\
\hline 1982 & 197 & 1989 & 468 & 1996 & 850 & 2003 & 810 \\
\hline 1983 & 246 & 1990 & 497 & 1997 & 887 & $2004^{*}$ & 720 \\
\hline 1984 & 301 & 1991 & 563 & 1998 & 896 & & \\
\hline 1985 & 345 & 1992 & 591 & 1999 & 906 & & \\
\hline
\end{tabular}

Tabla: Elaboración propia. (*) Número de socios a fecha 11 de junio de 2004.

Fuente: Registro de Socios de la AEOP (1979-2004).

de correspondencia devuelta en los últimos meses, y con la intención de crear una base de datos común, a la que tengan acceso a través de Internet, con el código secreto correspondiente, los secretarios de las distintas JDs, tanto de la Nacional como de las DTs.

Los días 2 y 3 de marzo de 2001, la AEOP organiza con la colaboración de la UNED (Dto. MIDE) y el Instituto de la Mujer, unas jornadas formativas con el título de "Orientación y formación en el ámbito de la igualdad", con una nutrida asistencia de profesionales de la orientación, la educación formal, la educación social, la formación y la inserción profesional, y del mundo empresarial en torno a tres mesas:

1) Realidad e intervención en el aula.

2) Formación profesional e intermediación laboral y

3) Empleo y desarrollo profesional (Anónimo, 2001).

En la AGO de 30 de marzo de 2001 se aprueba subir la cuota social a 5.500 pesetas anuales, de las que se destinarán 1.760 a la edición de la REOP, y se acepta la propuesta de la DTG de asumir la invitación cursada por la AIOEP para organizar próximamente en España una Conferencia Internacional que se celebraría en La Coruña, ciudad a la que se desplazó posteriormente nuestra Presidenta para apoyar los primeros contactos y gestiones realizados por la JD de la DTG. José Antonio Rodríguez Docavo, Tesorero de la AEOP durante los últimos 18 años, finalizado su actual mandato, anuncia que no se presenta a la reelección del cargo. En la AGE celebrada a continuación se procedió a la renovación preceptiva de la JD siendo elegida por unanimidad la única candidatura presentada, quedando constituida la nueva JD por: Elvira Repetto, Presidenta; Laura Oliveros, Vicepresidenta; M ${ }^{a}$ Fe Sánchez García, Secretaria; Nuria Manzano, Tesorera; Vocales electos responsables de las Vocalías: Belén Ballesteros, Vocal $1^{\circ}$ (Publicaciones); Narciso García Nieto, Vocal $2^{\circ}$ (Diagnóstico y evaluación en Orientación); Inmaculada Martínez, Vocal $3^{\circ}$ (Orientación educativa y vocacional); Marisa Pereira, Vocal $4^{\circ}$ (Orientación profesional); Maria Dolores Cadierno, Vocal $5^{\circ}$ (Orientación-formación ocupacional); Teófilo González, Vocal $7^{\circ}$ (Orientación familiar y comunitaria) y José Antonio Rodríguez Docavo, Vocal $8^{\circ}$ (Relaciones externas); y Vocales 
natos por las DTs: José A. Benavent (DTV); Alejandro Álamo (DTCn): Consuelo Vélaz de Medrano (DTZC); José Acosta (DTA); Carmen Valdivia (DTPV); Elena Menéndez (DTG) y Maria del Carmen Palomares (DTC-LM). Se hacen gestiones para obtener del Ministerio del Interior la declaración de asociación de utilidad pública para la AEOP. A lo largo del año se imparten 7 cursos de formación del profesorado del convenio de colaboración entre la Consejería de Educación de la CAM y la AEOP. La JD Nacional, celebrada en Madrid, el 15 de noviembre de 2001, aprueba la estructura de la Conferencia Internacional de la AIOEP, se nombra a Jesús Miguel Muñoz Cantero Coordinador de la misma y se acuerda que tendrá lugar en La Coruña, en septiembre de 2004.

En la AGO de 1 de marzo de 2002 se informa sobre las gestiones realizadas en relación a la próxima Conferencia Internacional de la AIOEP a celebrar en La Coruña, y se acuerda, que bajo el título provisional de "Orientación, desarrollo de la carrera e inclusión social", los temas centrales de debate giren en torno al tratamiento intercultural de la Orientación, la diferencia de género y la inclusión social de las minorías en los contextos comunitario, laboral y educativo. Se informa del descenso del número de asociados y se fija la cuota social anual para 2001 en 33'06 euros. Los días 18 y 19 de abril se celebran en Madrid unas jornadas sobre "Prevención de la violencia de género" en colaboración con la Facultad de Educación de la UNED y patrocinadas por el Instituto de la Mujer. Se presentan los primeros resultados parciales de la investigación "Counselor Qualification Standars" (CQS), que bajo los auspicios de la AIOEP, coordina nuestra Presidenta con un equipo de profesores de la UNED, todos ellos socios de la AEOP. Se siguen impartiendo diversos cursos y cursillos de los convenios de colaboración firmados por la AEOP cuya actividad se centra cada vez más en la preparación del Congreso Internacional de La Coruña. Se amplía y mejora la página web de la Asociación en Internet.

La AGO de 21 de marzo de 2003 aprueba el título definitivo de "Orientación, Inclusión Social y Desarrollo de la Carrera" para el Congreso Internacional de la AIOEP en La Coruña y las fechas del 15 al 17 de septiembre para su celebración, que tendrá lugar en la Universidade da Coruña (Campus de Elviña), gracias al acuerdo de colaboración entre dicha Universidad y la AEOP. Se presenta el pre-programa con la temática de las conferencias, ponencias, simposios, mesas y asignación de responsabilidades. El número de socios sigue bajando y a 31 de diciembre de 2002 era de 865 . Ante las dificultades económicas que atraviesa la Asociación se aumenta a $39 €$ la cuota social anual. El proyecto CQS llega a su fase final. Laura Oliveros, en representación de la AEOP, realiza gestiones con el Instituto Nacional de Cualificaciones para la elaboración del perfil y el reconocimiento profesional del Orientador: se mantiene una entrevista con su Directora, se le hace entrega de los resultados parciales del proyecto CQS y se invita al Instituto a participar en el Congreso Internacional de La Coruña. De enero a mayo se celebró en la UNED el seminario "Orientación y educación afectivo-sexual" organizado por la AEOP en colaboración con el Departamento MIDE II/UNED y el Instituto de la Mujer. El 30 de mayo se celebra una jornada sobre "Educación en valores de igualdad" organizadas por la AEOP en colaboración con el Instituto de la Mujer, el Ministerio de Trabajo y Asuntos Sociales y la UNED.

El 28 de junio de 2003, José A. Benavent, en representación de la AEOP, asiste en Zaragoza, en el marco del I Congreso Internacional sobre "Orientación y Tutoría”, organizado por la Asociación Aragonesa de Psicopedagogía (AAPs), a una reunión para constituir la "Comisión Gestora Interorganizaciones de Psicopedagogía" con el objetivo de crear una federación que reúna a todas las asociaciones existentes en España en el ámbito de la orienta- 
ción y la psicopedagogía. Las 11 Asociaciones representadas en la reunión acuerdan constituirse en la Comisión Gestora de una futura federación que adopta la denominación provisional de "Federación de Asociaciones de Psicopedagogía y Orientación de España" (FAPOE) y celebrar la próxima reunión en Madrid, los días 19 y 20 de septiembre. En la JD de la AEOP de 12 de septiembre, después del informe presentado por José A. Benavent sobre la reunión de Zaragoza, se propone transformar la AEOP en FEOP y convocar una AGE para aprobar la propuesta. A la reunión de la Comisión Gestora de la FAPOE de Madrid, acudieron delegados de ocho Asociaciones y excusaron su asistencia cuatro. Por la AEOP asistieron, Elvira Repetto, Consuelo Vélaz de Medrano y María Dolores Cadierno. A propuesta de la AEOP, que informa de su transformación en FEOP, las Asociaciones presentes acuerdan: constituirse en Comisión Coordinadora de una futura confederación que aglutine bajo la denominación provisional de "Confederación de Organizaciones de Psicopedagogía y Orientación de España" (COPOE), a las Federaciones, Asociaciones, Organizaciones, Secciones de los Colegios Oficiales de Doctores y Licenciados y otros organismos existentes en España que trabajan en pro de la Orientación y la Psicopedagogía; elaborar un borrador de Estatutos y otro del Reglamento general de régimen interior; fijar la sede de la Comisión en el domicilio social de la AAPs, en Zaragoza, y celebrar la próxima reunión en la primavera del 2004.

El 13 de julio de 2003, fallece en Valencia, a la edad de 91 años, José Zaragozá Antich, socio fundador de la AEOEP, promotor de la DTV, ex-miembro de la JD, ex-presidente en funciones, "Miembro Permanente de Honor" de la JD y "Socio de Honor". La JD decide dedicar en su memoria el próximo número de la REOP, correspondiente al $2^{\circ}$ semestre de 2003.

El 15 de octubre, fallece en Madrid, a la edad de 68 años, José Antonio Rodríguez Docavo, socio fundador de la AEOEP, miembro de la JD y ex Tesorero, que ejerció el cargo durante 18 años. La JD decide dedicar en su honor el número de la REOP correspondiente al $1^{\circ}$ semestre de 2004 .

Ante la dimensión que está tomando el movimiento asociacionista entre los profesionales de la Orientación y la Psicopedagogía, la JD convoca el 21 de noviembre una AGE en la que propone, de acuerdo con la Ley Orgánica 1/2002, de 22 de marzo, reguladora del Derecho de Asociación, transformar las DTs en Asociaciones independientes, y la AEOP en FEOP para aglutinar a las nuevas Asociaciones resultantes. Tras un extenso debate se aprueba la propuesta y se insta a las DTs a que activen el proceso legal para adquirir personalidad jurídica propia. Patricia Mata, Secretaria administrativa, deja voluntariamente su puesto de trabajo, vacante que es ocupada por María Dolores Cadierno. En diciembre, la AEOP y AULA (Salón Internacional del Estudiante y de la Oferta Educativa), firman un convenio de colaboración por el que la AEOP se compromete a participar en su XII edición, a celebrar del 10 al 14 de marzo de 2004 en Madrid, y AULA le cederá un stand para que informe de sus actividades y publicaciones.

El año 2004 se inicia con la finalización del mandato de Elvira Repetto como Vicepresidenta de la AIOEP y representante de la AEOP en su Comité Ejecutivo. Se redacta el Borrador de los Estatutos de la FEOP. El 28 de febrero se reúne la Comisión coordinadora de la COPOE en el ICE de la Universidad de Zaragoza, en el marco del I Encuentro de "Orientación y atención a la diversidad", organizado por la AAPs, se aprueban los Estatutos y se acuerda constituir la COPOE el día 8 de mayo en Guadalajara. A la reunión de Zaragoza 
asistieron 11 Asociaciones, una excusó su asistencia y la AEOP estuvo representada por José A. Benavent, Consuelo Vélaz de Medrano y María Dolores Cadierno. La XII edición de AULA, en la que participó AEOP con un stand, quedó ensombrecida por el terrible atentado terrorista del 11 de marzo. En la AGO de la AEOP, de 26 de marzo, se aprueban los Estatutos de la FEOP y se acuerda que la FEOP se constituirá tan pronto como las DTs hayan tramitado y legalizado su transformación en Asociaciones independientes. José Antonio Benavent recuerda que este año se cumple el XXV Aniversario de la fundación de la AEOP, y dado que se va a transformar en FEOP, asume el compromiso de elaborar su historia.

La reunión de la Comisión coordinadora de la COPOE, programada para el 8 de mayo en Guadalajara, se aplaza hasta el 18 de septiembre en La Coruña, en el marco de la Conferencia Internacional. Se siguen impartiendo los cursos de formación del profesorado de los convenios vigentes. Se obtienen subvenciones del Instituto de la Mujer para celebrar unas Jornadas en La Coruña, cursos en Madrid y Cuenca y financiar las ponencias de una Mesa redonda sobre género en la Conferencia Internacional de La Coruña. Del 15 al 17 de septiembre se celebra la Conferencia Internacional, y el 18, en la Facultad de Educación de la Universidade da Coruña, se reúnen: a las 9'00 horas, la Comisión gestora de la FAPOE, que acuerda aplazar la constitución de la Federación; y a las 12’00, con una nutrida representación, la Comisión gestora de la COPOE (ver foto de los participantes en Fig. 7). Seis Asociaciones presentan la documentación para constituirse como fundadoras de la Confederación, tres se adhieren verbalmente y otras tres están indecisas. Se aprueba aplazar la constitución de la COPOE hasta el 12 de marzo de 2005, en Madrid, en el marco de AULA (Salón Internacional del Estudiante y de la Oferta Educativa), para dar la oportunidad a que más Asociaciones figuren como fundadoras. La AEOP cierra este ejercicio con la publicación del número 15 (2) de la REOP, correspondiente al $2^{\circ}$ semestre de 2004, conmemorativo del XXV Aniversario de la fundación de nuestra Asociación.

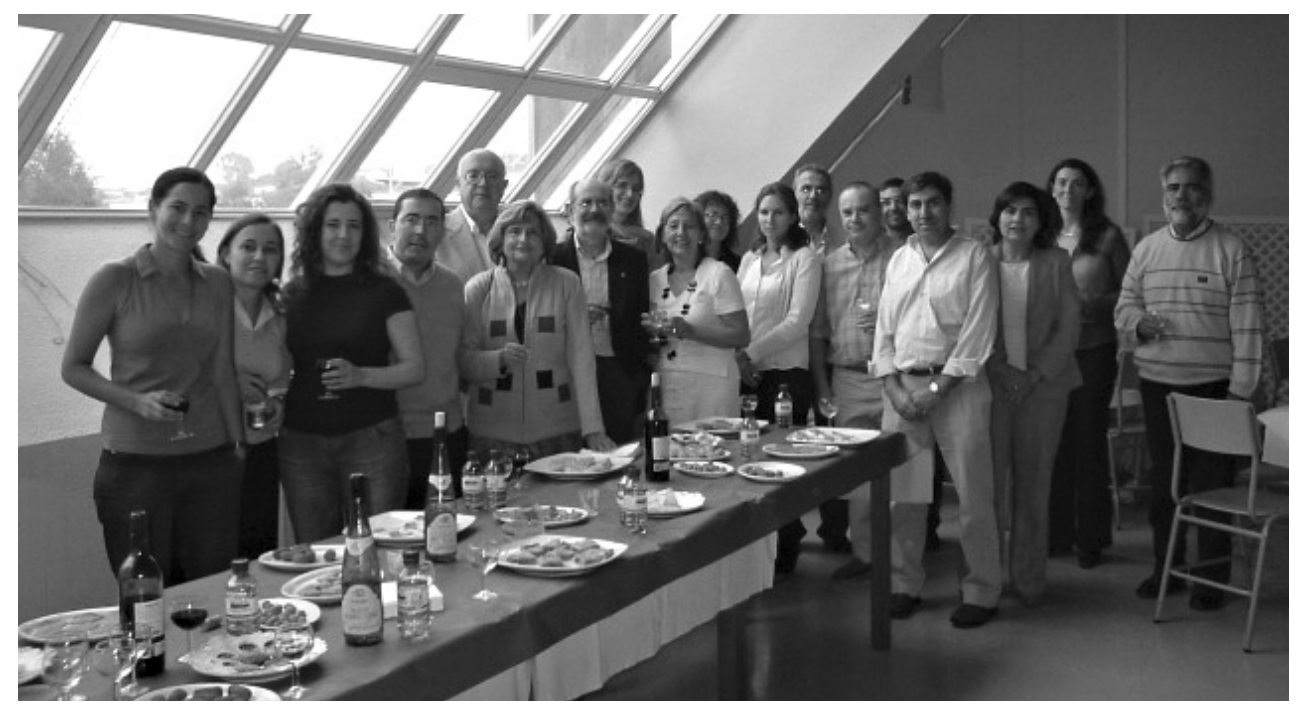

FIGURA 7.

Comisión gestora de la COPOE. (La Coruña, 18 de septiembre de 2004). 


\section{Delegaciones Territoriales}

Durante el Período Actual o del s. XXI (2001-2004), están constituidas y en pleno funcionamiento la DTV (1980), la DTZC (1986), la DTCn (1987), la DTG (1998) y la DTCLM (2000), todas ellas se disolverán en el momento en que se constituya la Federación Española de Orientación y Psicopedagogía (FEOP). La DTA (1995) y la DTPV (1995), por problemas funcionales, se disolvieron y sus socios se reintegraron en la AEOP en 2003.

\section{Delegación Territorial Valenciana (DTV)}

El año 2001 se inicia con el traslado, en el mes de febrero, del domicilio social a la nueva ubicación, sita en la Facultad de Filosofía y Ciencias de la Educación, Departamento MIDE, Seminario de Orientación Educativa, Avda. Blasco Ibáñez, no 30, 46010 Valencia. No se programaron nuevos cursos formativos para el año académico 2001-2002, pues los desarrollados durante el curso anterior, fueron absorbidos por la oferta académica de la Universitat de València como asignaturas específicas de libre elección y no se renovó el convenio de colaboración con la Consellerìa de Cultura, Educación y Ciencia de la Generalitat Valenciana.

En marzo de 2002 se constituyeron tres grupos de trabajo o seminarios permanentes, sobre los siguientes temas:

1) Reforma educativa del Bachillerato: El papel del Orientador en los IES.

2) Conflictividad en los centros educativos $y$

3) Mejora del clima institucional en los IES: Técnicas (Anónimo, 2002).

En octubre se solicita que los socios comuniquen a la Secretaria de la DT su dirección de email, a fin de constituir una lista electrónica que facilite información contactos, formación "on line", "chats" e intercambios de metodologías y experiencias entre todos los asociados. La lista electrónica empezó a funcionar a finales de noviembre. A 31 de diciembre de 2002, la página web de la DTV en Internet había recibido más de 40.000 visitas.

En la AGE de 6 de marzo de 2003 se renueva la JD, siendo elegida por unanimidad la candidatura presidida por José Antonio Benavent Oltra. En la AGE de 18 de noviembre, se aprueba la constitución de la Comisión gestora encargada de redactar y tramitar los Estatutos de la futura Asociación Valenciana de Orientación y Psicopedagogía (AVOP). El 10 de diciembre, la Comisión gestora de la AVOP, presenta en el Registro de Asociaciones de la Consellería de Justicia y Administraciones Públicas la solicitud de legalización.

El 25 de marzo de 2004, se aprueba la solicitud y se inscribe la AVOP en el Registro de Asociaciones de la Generalitat Valenciana con el no CV-01-036748-V de la Sección Primera. A partir de este momento, los socios de la DTV pertenecen a la vez a la AEOP y a la AVOP. En la AGE de 17 de mayo, se aprueba por unanimidad la primera JD de la AVOP presidida por José Antonio Benavent. En junio, se cambia la denominación y titularidad de la página web de la DTV en Internet, que pasa a ser de AVOP, se mejora su formato y se actualiza, habiendo recibido hasta el momento de redactar estas líneas más de 75.000 visitas. La AVOP, como asociación independiente de la AEOP, participa, representada por su Presidente en: 
a) La reunión constitutiva de la Comisión gestora de la Confederación de Organizaciones de Orientación y Psicopedagogía de España (COPOE), celebrada en Zaragoza, el 28 de febrero.

b) En la reunión constituyente de la Comisión gestora de la Federación Española de Orientación y Psicopedagogía (FEOP), celebrada en Madrid, el 26 de marzo, como Asociación fundadora y

c) Las reunión de la Comisión gestora de la FEOP y de la COPOE, celebradas en La Coruña, el 18 de septiembre, como miembro de ambas comisiones, y en la que presentó la solicitud y los documentos reglamentarios para ser Asociación fundadora de la futura COPOE.

\section{Delegación Territorial Zona Centro (DTZC)}

Desde 2001 hasta el momento presente, Consuelo Vélaz de Medrano y su JD siguen al frente de la DTZC. Durante el curso 2002-2003 se impartieron ocho cursos de formación y perfeccionamiento del profesorado del convenio de colaboración entre la DT y la Consejería de Educación de la CAM (Anónimo, 2003). En el curso 2003-2004 continúan los cursos de formación patrocinados por la CAM y el Instituto de la Mujer con la colaboración del Departamento MIDE II de la UNED.

En la AGE de 24 de marzo de 2004, en la que se aprobó la conversión de la Delegación Territorial Zona Centro (DTZC) de la AEOP, en Asociación Madrileña de Orientación y Psicopedagogía (AMOP) acogiéndose a lo dispuesto en la Ley 1/2002 Reguladora del Derecho de Asociación, la Presidenta hizo una somera narración de las vicisitudes por las que ha atravesado la DTZC, desde su nombramiento hasta la fecha de dicha asamblea. Factores estructurales, estratégicos y coyunturales imprevistos impidieron una mayor actividad de la Delegación, que por lo demás, ha seguido siempre atendiendo las demandas de sus socios en lo que respecta a formación e información sobre Orientación. En la AGE de 19 de junio de 2004 se aprueba por unanimidad la única candidatura presentada para la JD de la AMOP presidida por Consuelo Vélaz de Medrano, procediéndose a continuación, a la lectura y aprobación de sus Estatutos. La AMOP nace con el propósito expreso de dinamizar la vida asociativa, prueba de ello, son los 4 cursos de formación del profesorado realizados en la primavera de 2004 y los 10 programados para el otoño, todos ellos consecuencia del convenio de colaboración con la Consejería de Educación de la CAM y en estrecha cooperación con la AEOP, el Departamento MIDE II de la UNED y el Instituto de la Mujer (Anónimo, 2004).

\section{Delegación Territorial de Canarias (DTCn)}

A comienzos de 2001 se cuelga en Internet la página web de la DTCn con el siguiente URL: http://www.educa.rcanaria.es/usr/aeop/default.htm

Se siguieron impartiendo cursos de formación para orientadores y profesores de primaria y secundaria. Se colabora con el Cabildo y los Ayuntamientos en la formación de profesionales de los servicios sociales. La actividad de la DT se centra durante este ejercicio en la organización de las III Jornadas Regionales de Orientación y Psicopedagogía que se cele- 
braron en La Laguna (Tenerife), del 9 al 11 de octubre de 2001. Una información completa de las mismas está colgada en su página web, en la que además, se encuentran datos actualizados sobre la organización, el funcionamiento, los cursos y las actividades que actualmente está desarrollando la DTCn.

Durante los años 2002 y 2003. y a pesar de los esfuerzos realizados para organizar actividades, el número de socios de la DT sigue descendiendo por diversas razones: falta de apoyos institucionales para la organización de encuentros, cursos y jornadas; saturación de reuniones, convocatorias y ofertas formativas de la administración pública para los orientadores; excesivo coste de las actividades por la insularidad; dificultad para contratar expertos y ponentes cualificados de la Península, etc.

Finalmente, en la AGE celebrada a principios de 2004, la Delegación Territorial de Canarias (DTCn) decide constituirse en Asociación de Orientación y Psicopedagogía de Canarias (AOP-Canarias), atendiendo las recomendaciones de la AEOP y acogiéndose a la Ley 1/2002 Reguladora del Derecho de Asociación. La AOP-Canarias, representada por su Presidente, asistió a la reunión de la Comisión Gestora de la COPOE celebrada en La Coruña el 18 de septiembre. Actualmente la AOP-Canarias está tramitando la legalización de sus Estatutos y de su inscripción en el Registro de Asociaciones del Gobierno de Canarias.

\section{Delegación Territorial de Galicia (DTG)}

En 2001 la DTG supera los 80 socios, sigue organizando cursos de formación, y en septiembre, celebra en Orense, unas Jornadas sobre "Cualificaciones profesionales". En la AGO Nacional del 30 de marzo de 2001 se acepta la propuesta de la DTG de asumir la invitación cursada por la AIOEP para organizar próximamente en España una Conferencia Internacional que se celebraría en La Coruña, ciudad a la que se desplazó posteriormente nuestra Presidenta para apoyar los primeros contactos y gestiones realizados por la JD de la DTG.

La JD Nacional, celebrada en Madrid, el 15 de noviembre de 2001, aprueba la estructura de la Conferencia, se nombra a Jesús Miguel Muñoz Cantero Coordinador de la misma y se acuerda que tendrá lugar en La Coruña, en septiembre de 2004. A principios de 2003 se edita y distribuye el primer folleto de la Conferencia, se cuelga en Internet una página web informativa y la DT centra su actividad en su preparación. Se siguen impartiendo cursos de formación y jornadas patrocinadas por el Instituto de la Mujer en colaboración con la AEOP, se celebran unas Jornadas sobre Género en La Coruña y Santiago de Compostela (Anónimo, 2003a). Del 27 al 29 de abril de 2004, patrocinadas por el Instituto Nacional de la Mujer, en Colaboración con la AEOP y el Centro Asociado de la UNED en La Coruña, se celebran unas Jornadas de Sensibilización sobre "Contexto femenino: Formación y Orientación respecto al género" (Anónimo, 2003b y 2004a). Se ultiman los preparativos y se perfilan los detalles organizativos para la celebración de la Conferencia Internacional de la AIOEP, que con gran brillantez tiene lugar en La Coruña, del 15 al 17 de septiembre de 2004. La DTG asistió, en calidad de invitada, a la reunión de la Comisión gestora de la COPOE celebrada el día 18 en la Facultad de Educación de la Universidade da Coruña. 


\section{Delegación Territorial de Castilla La Mancha (AEOP-CLM)}

La AEOP-CLM inició el ejercicio de 2001 con una campaña de información y divulgación de sus actividades para la captación de nuevos socios. A principios de año, se firma un convenio de colaboración entre la DT y la Consejería de Educación de la Junta de Comunidades de Castilla-La Mancha en materia de formación. Como consecuencia del mismo, se han venido realizando, desde dicha fecha hasta el curso 2003-04, diferentes actividades formativas para el profesorado y los profesionales de la orientación y la psicopedagogía, entre otras, los cursos de: "Orientación laboral: conocimiento de estrategias y herramientas para su desarrollo" y "Orientación escolar y tratamiento de la diversidad desde una intervención de Pedagogía Terapéutica”, celebrados en Cuenca y Toledo durante el mes de septiembre de 2001 (Anónimo, 2001a); y los impartidos durante 2002 y 2003 sobre: "Desarrollo de habilidades sociales y autoconcepto desde el contexto de la educación formal" "Agrogimnasia. Un enfoque integrador para la enseñanza de las habilidades motrices"; y "Educación infantil: contexto para la formación integral". La valoración de estos cursos ha sido muy positiva, destacando la alta participación del profesorado y la metodología activa que han utilizado los ponentes. (Anónimo, 2003c).

En julio de 2002 la AEOP-CLM firmó un Convenio de colaboración con la Universidad de Castilla-La Mancha y se pudo incluir la página web de la Asociación en el portal de la Universidad con el siguiente URL: www.uclm.es/aeop donde se encuentran datos actualizados sobre su organización, funcionamiento y las actividades que actualmente se están desarrollando. Este convenio supone el reconocimiento y la acreditación universitaria de las actividades de formación impartidas por la DTC-LM.

En marzo de 2003, dentro del convenio de colaboración entre la AEOP y el Instituto de la Mujer, se celebra un curso sobre "Habilidades sociales y autoconcepto desde la perspectiva de género" (Anónimo, 2003d).

El 16 de agosto de 2004, AEOP-CLM se constituye en asociación independiente con la denominación de Asociación de Castilla-La Mancha de Orientación y Psicopedagogía (CLM-AOP), de ámbito regional y que con los mismos objetivos que la anterior DT, pretende promover el rigor científico en la Orientación, potenciarla, e impulsar actividades de debate, reflexión e investigación orientadora en las instituciones educativas, laborales y empresas, así como en los contextos familiares y comunitarios.

\section{Delegación Territorial de Andalucía (DTA)}

Las II Jornadas Andaluzas de Orientación, previstas para la primavera de 2001 son aplazadas por problemas técnicos, y finalmente, nunca llegarían a celebrarse. Se agudizan los problemas para la reunión de la JD, dada la dispersión geográfica de sus miembros y las dificultades para desplazarse. Al no realizar actividades, se dan de baja bastantes socios, y otros, dejan de abonar la cuota social, por lo que en la AGO Nacional de 1 de marzo de 2002, José Domínguez, miembro de la JD, en representación de su Presidente, excusa el pago del porcentaje preceptivo de cuotas a la AEOP y solicita que ésta vuelva a gestionar los cobros. La AGO concede a la DTA una moratoria de un año para el cobro de las cuotas atrasadas y satisfacer la deuda de la DT. En la AGO de 21 de marzo de 2003, a la que no asiste ningún representante de la DTA, se lee el informe emitido por el Presidente de la 
DTA, José Acosta, al que acompaña el listado de socios, en el que faculta a la JD Nacional para que efectúe las gestiones que estime pertinentes para el cobro de las cuotas impagadas hasta las elecciones de la nueva JD de la DT previstas para el mes de diciembre. Elecciones que nunca se convocaron, con lo que la DTA desaparece y sus socios se reintegran en el corpus asociativo de la AEOP.

\section{Delegación Territorial del País Vasco (DTPV)}

En 2001 se continúa con el servicio gratuito de consulta y asesoramiento para los socios de la DT que lo solicitan. En marzo de 2001, se aprueba el proyecto y se inicia la preparación de las I Jornadas de Psicopedagogía del País Vasco, cuya celebración se programa para la primavera del 2002. En la AGO Nacional de 30 de marzo, su Presidenta, Carmen Valdivia, informa de la apertura de negociaciones para organizar actividades conjuntas con la recién fundada Sociedad de Pedagogía del País Vasco y propone que la REOP acepte publicar artículos en las lenguas oficiales de las CC.AA. para atraer asociados, propuesta que no prospera.

Los días 18 y 19 de abril de 2002, con el título "Definición y perspectivas profesionales de la Psicopedagogía", tienen lugar en la Facultad de Filosofía y Ciencias de la Educación de la Universidad de Deusto (Bilbao), las I Jornadas de Psicopedagogía del País Vasco, organizadas por la DT en estrecha colaboración con la AEOP y la Universidad de Deusto. Asistieron unas 160 personas entre especialistas y estudiantes, siendo muy alta la valoración de las Jornadas por los participantes. No se editaron actas (Anónimo, 2002a). En mayo, se crea la Asociación de Profesionales de la Orientación de Euzkadi (APOE), fundación que resta asociados a la DT y activa los problemas entre los miembros de la JD pertenecientes a los campus de Deusto y San Sebastián que se venían arrastrando desde su constitución.

En la AGO Nacional de 21 de marzo de 2003, a la que no asiste ningún representante de la DTPV, se da lectura a la carta remitida por su Presidenta, Carmen Valdivia, en la que explica la situación que atraviesa esta DT, así como otras circunstancias personales que impiden el cobro regular de las cuotas, y adjunta el listado de socios con la solicitud de que la JD Nacional negocie directamente el cobro de las mismas con carácter provisional hasta que se regularice la situación. La AEOP asume la petición, reintegra los socios de la DTPV en el listado general y negocia el cobro de las cuotas sociales del 2003 y el 2004, sin que hasta el momento la DTPV haya retomado sus funciones.

\section{Congresos, Jornadas y Seminarios}

Durante el Período Actual (2001-2004), la AEOEP, en colaboración con sus DTs, organizó y celebró las siguientes reuniones científicas: las III Jornadas Regionales de Orientación y Psicopedagogía en La Laguna (Tenerife) y la Conferencia Internacional de la AIOEP en La Coruña.

\section{Jornadas Regionales de Orientación y Psicopedagogía de Canarias}

Las III Jornadas Regionales de Orientación y Psicopedagogía de Canarias, bajo el lema, "La Orientación del s. XXI en los actuales modelos de intervención”, se celebraron en La 
Laguna (Tenerife), del 9 al 11 de octubre de 2001, organizadas por la DTCn con la colaboración de la AEOP, el Ayuntamiento de La Laguna, el Cabildo Insular de Tenerife, la Consejería de Educación, Cultura y Deportes del Gobierno de Canarias el Instituto Canario de Formación y Empleo, las Universidades de La Laguna y Las Palmas de Gran Canaria, y Caja Canarias. Las sesiones tuvieron lugar en el Campus de la Universidad de La Laguna, con 217 inscripciones y una gran asistencia.

Estas III Jornadas se desarrollaron en un acto inaugural, dos sesiones plenarias y un acto de clausura. Se presentaron un total de 25 trabajos que se distribuyeron en 2 conferencias, 6 ponencias, 2 paneles de expertos, 4 talleres y 1 mesa redonda para la lectura de las 17 comunicaciones presentadas. Todos los trabajos, que se formatearon cumpliendo los requisitos recomendados por la organización de las Jornadas, se publicaron en un CD-Rom que sirve de Actas (AEOP-DTCn, 2001).

Después de las palabras de bienvenida, a cargo de las Autoridades de Canarias y del Presidente de la DT Alejandro Álamo, Carlos Monereo pronunció la conferencia inaugural sobre "Orientación e intervención psicopedagógica". Las dos sesiones plenarias se vertebraron en torno a seis ponencias, cuatro versaron sobre los modelos vigentes de Orientación en las CC. AA. del País Vasco, Madrid, Valencia y Canarias, y las otras dos sobre los modelos de gestión e investigación en Orientación educativa. En el acto de clausura se leyeron las conclusiones y la conferencia de cierre sobre "La Orientación intercultural: Problemas y perspectivas" fue pronunciada por Elvira Repetto.

\section{Conferencia Internacional de la AIOEP}

La Conferencia Internacional de la AIOEP, con el título "Orientación. Inclusión Social y Desarrollo de la Carrera”, se celebró en La Coruña, del 15 al 17 de septiembre de 2004, auspiciada por la AIOEP y organizada conjuntamente por la AEOP y el Departamento MIDE de la Universidade da Coruña, con la colaboración de: los Ministerios de Trabajo y Asuntos Sociales, Asuntos Exteriores y de Cooperación, e Industria, Turismo y Comercio; las Consellerias de Educación y Ordenación Universitaria, e Innovación, Industria y Comercio de la Xunta de Galicia; las Universidades de La Coruña y UNED; la Diputación y el Ayuntamiento de La Coruña; ANECA; y otras instituciones gallegas públicas y privadas. El Comité de Honor estuvo presidido por, SS. MM. el Rey y la Reina de España; el Comité Científico, por B. Jenschke, Presidente de la AIOEP y el Comité Organizador, por Jesús Miguel Muñoz Cantero. Las sesiones tuvieron lugar en el Campus de Elviña de la Universidade da Coruña, con unos 400 congresistas inscritos pertenecientes a 27 nacionalidades distintas, numerosos invitados y una nutrida asistencia.

La Conferencia se desarrolló en un acto inaugural, tres sesiones plenarias y un acto de clausura. Se presentaron un total de 245 trabajos en los idiomas oficiales (español e inglés), que se distribuyeron en: 4 conferencias (apertura, clausura y dos temáticas); 3 mesas redondas con 12 ponencias; 7 simposia con 50 aportaciones; 19 foros para la lectura y discusión de 140 comunicaciones y 39 posters, expuestos en el hall de la Facultad de Económicas. Todos los trabajos presentados en el plazo previsto y formateados electrónicamente cumpliendo los requisitos recomendados por la organización de la Conferencia se publicaron en dos documentos: un libro, que recoge las conferencias y mesas redondas y un CD-Rom, que sirve de Actas, (AIOSP-AEOP, 2004 y 2004a). 
El Acto de apertura estuvo presidido por Celso Currás Fernández, Consejero de Educación y Ordenación Universitaria de la Xunta de Galicia y pronunció la conferencia inaugural sobre "Fundamentos y principios de la inclusión social", Peter Plant. Las tres sesiones plenarias se vertebraron en torno a las tres mesas redondas, con cuatro ponentes por mesa, que disertaron sobre: "Diagnóstico e inclusión social: nuevas perspectivas", "Las competencias profesionales, mercado laboral y educación superior" e "Inclusión social de la mujer en la sociedad globalizada". Las conferencias temáticas fueron pronunciadas por Luis Sobrado Fernández, "Análisis de necesidades de los colectivos de riesgo de exclusión social" y Elvira Repetto Talavera, "Orientación intercultural e inclusión social”. En el Acto de clausura, presidido por Bernhard Jenschke, Presidente de la AIOEP, pronunció la conferencia de clausura sobre "Perspectivas de la Orientación para la inclusión social en la sociedad global", Bryan Hiebert, Vicepresidente de la AIOEP.

\section{Publicaciones}

Durante el Período Actual (2001-2004), se han editado ocho números de la REOP, 2 ejemplares del Boletín de la AEOP, las Actas de las III Jornadas Regionales de Orientación y Psicopedagogía de Canarias y las Actas de la Conferencia Internacional de la AIOEP.

Con la cabecera Revista Española de Orientación y Psicopedagogía, se han publicado seis números como órgano oficial y portavoz de la AEOP: del 12 (21), del $1^{\circ}$ semestre de 2001, al 14 (2), del $2^{\circ}$ semestre de 2003. En 2002 se modifica la datación de la REOP, se mantiene la numeración correlativa del volumen, pero se cambia la numeración de los ejemplares de cada volumen: deja de ser correlativa para adoptar las cifras 1 y 2 correspondientes a su periodicidad semestral. En los otros dos números, a partir del 15 (1), correspondiente al $1^{\circ}$ semestre de 2004, aunque mantiene la misma cabecera, aparece como órgano oficial y portavoz de la Federación Española de Orientación y Psicopedagogía (FEOP), con la misma estructura de contenidos pero diferente formato de portada (Fig. 8). El último número editado, el 15 (2) del $2^{\circ}$ semestre de 2004, que tienes en tus manos, es conmemorativo del XXV Aniversario de la fundación de nuestra Asociación. En la AGE de 21 de noviembre de 2003 presentó la dimisión como Secretaria técnica de la REOP Belén Ballesteros, siendo sustituida en funciones, hasta las próximas elecciones de la JD, por María Teresa Alañón Rica. Para potenciar su difusión la REOP ha sido incluida en las bases de datos electrónicas PSICODOC, CIRBIC y REBIUN y se hacen gestiones para su inclusión en ERIC.

Del Boletín de la AEOP, que redacta, compone y edita desde la Universidad de Oviedo, Marisa Pereira, al haber estado largo tiempo de baja por enfermedad, sólo ha publicado durante este Período dos números, el 5 y el 6.

En cuanto a las Actas, se han editado las dos siguientes:

1) Actas de las III Jornadas Regionales de Orientación y Psicopedagogía de Canarias, La Laguna, 9 al 11 de octubre de 2001. Fueron financiadas íntegramente por la DTCn en formato electrónico CD-Rom y se colgaron el la página web que la DTCn gestiona en Internet (www.educa.rcanaria.es/usr/aeop).

Con el título La Orientación del s. XXI en los actuales modelos de intervención, el CD-Rom contiene cinco archivos: Inicio, Asistentes, Programa, Trabajos e Imáge- 


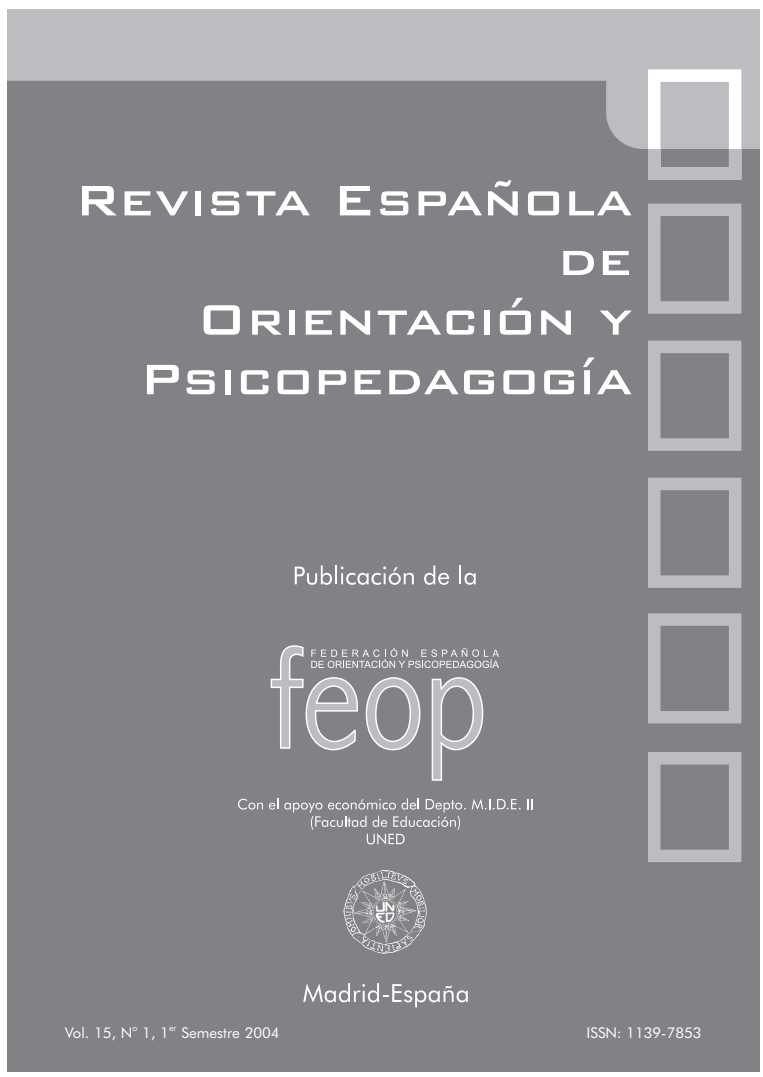

FIGURA 8.

Portada del no 15 (1) de la REOP.

nes. Al activar Inicio se abre la unidad lectora que permite el acceso a los contenidos del CD-Rom estructurados en seis secciones: Léame, con los requisitos para usar el CD; Utilidades, incluye el programa "Acrobat" y los navegadores "Netscape" y "Explorer"; Programa, presenta la programación de las Jornadas; Documentos, contiene los trabajos presentados en el formato electrónico requerido por los organizadores en tres apartados: conferencias, ponencias y comunicaciones y talleres; también se tiene acceso a la valoración de las Jornadas y a la lista de inscritos y La Laguna, con imágenes y textos para la promoción turística de la ciudad. (AEOPDTCn, 2001).

2) Actas de la Conferencia Internacional de la AIOEP, La Coruña, del 15 al 17 de septiembre de 2004. Se entregaron a los congresistas en la sesión inicial, en el momento de acreditarse y retirar el dossier de materiales. Han sido financiadas íntegramente por los organizadores de la Conferencia y consta de dos documentos: un libro de 142 páginas, con el título genérico de Orientación, inclusión social y desarrollo de la ca- 
rrera (AIOSP-AEOP, 2004), que recoge las conferencias y las ponencias de las mesas redondas debidamente formateadas electrónicamente y presentadas dentro del plazo dado por la organización, previo a su celebración, y un CD-Rom con el mismo título (AIOSP-AEOP, 2004 ${ }^{a}$ ), que sirve de Actas, y en el que se estructuran sus contenidos en los siguientes apartados:

a) Índice.

b) Presentación.

c) Organización.

d) Programa.

e) Mesas redondas.

f) Simposia.

g) Comunicaciones.

h) Posters.

i) Información general.

j) Qué visitar en A Coruña.

k) Organizadores y entidades colaboradoras.

El libro publica tres conferencias de las cuatro pronunciadas, falta la conferencia inaugural, mientras que de las 12 ponencias desarrolladas en las mesas redondas, sólo se publican siete. El CD-Rom presenta en su archivo de 1.260 páginas, además de repetir el contenido del libro, 30 de los 50 trabajos expuestos en las mesas redondas y 186 comunicaciones, 46 más de las leídas públicamente en los foros, y no se editan los posters.

\section{Proyección internacional}

Durante el Período Actual, los socios de la AEOP, representando a nuestra Asociación, han participado activamente con su asistencia, intervenciones y trabajos en los siguientes eventos y proyectos de investigación internacionales:

- II Simposio Internacional sobre "Desarrollo de la carrera y políticas públicas", celebrado en Vancouver (Canadá), los días 5 y 6 de marzo de 2001, auspiciado por la Human Resources Development of Canada y la Fundación Canadiense para el Desarrollo de la Carrera, con participación de 17 países. Por parte española asistieron y presentaron trabajos Elvira Repetto y Beatriz Malik, que también participaron activamente, junto a Daniel Anaya, en el Congreso Internacional "Going for Gold", sobre el desarrollo de la carrera, que a continuación, del 7 al 9 de marzo, tuvo lugar en el mismo escenario y en conmemoración del $50^{\circ}$ Aniversario de la fundación de la AIOEP con participación de 1300 delegados pertenecientes a 32 países (Anónimo, 2001b y 2002b). En Vancouver se presentó el número inicial del International Journal for Educational and Vocational Guidance (IJVEG), nuevo órgano oficial y portavoz de la AIOEP, número doble especial conmemorativo del $50^{\circ}$ Aniversario y dedicado a Donald E. Super y en el que figuran como Co-editor, Elvira Repetto, y como Miembro del Consejo Asesor, José A. Benavent (Anónimo, 2002c). 
- El segundo gran acontecimiento en conmemoración del 50 Aniversario de la AIOEP fue el Congreso Internacional, "Orientación: restricciones y libertad", celebrado en París del 17 al 21 se septiembre de 2001, con participación de más de 1.700 delegados de 50 países y con una nutrida representación de la AEOP. Un grupo de delegados hispano-parlantes presentó por escrito una petición a la JD de la AIOEP para que se otorgase mayor importancia al idioma español en futuros eventos y se le considere idioma oficial (Anónimo, 2001c y 2002b). El Congreso, con significativa presencia española, ofreció 5 grandes mesas redondas, 5 conferencias principales, varios foros para exposición y discusión de 189 comunicaciones, 33 visitas profesionales y acontecimientos, e importantes acuerdos, entre los que destaca la aprobación del documento Declaración de París sobre Orientación Educativa y Profesional (AIOEP, 2001).

- En cuanto al proyecto CQS patrocinado por la AIOEP y que coordina Elvira Repetto, tanto en el Congreso de Vancouver como en el de París, se presentaron informes y se celebraron dos sesiones de trabajo. Se pretende finalizar el proyecto de investigación antes de la Asamblea General de 2003. En el Congreso de París, la AIOEP manifestó su gratitud a la Coordinadora y a su equipo de expertos por el buen trabajo realizado y a la UNED por el apoyo prestado en todo momento (AIOEP, 2002).

- Del 30 de mayo al 1 de junio de 2002, bajo el lema, "El Orientador: profesión, pasión y vocación" se celebra en Varsovia (Polonia), una Conferencia Internacional patrocinada por la AIOEP y organizada por la Asociación de Orientadores Escolares y Profesionales de Polonia y en la que participa la AEOP presentando un breve informe sobre competencias profesionales del orientador, extraído del proyecto CQS (Anónimo, 2002d).

- El Congreso Internacional sobre "Calidad y evaluación de la calidad en Orientación Educativa", así como la Asamblea General de la AIOEP de 2003, se celebraron en Berna (Suiza), del 3 al 6 de septiembre de 2003. La organización del Congreso corrió a cargo de la Asociación Suiza de Orientación Escolar y Profesional. Se presentó el informe final del proyecto CQS. La Asamblea de la AIOEP aprobó el marco general de las competencias internacionales para la Orientación Educativa y Profesional, que como punto de partida, estarán sujetas a constante actualización y contextualización (Anónimo, 2003e).

- Finalmente, del 15 al 17 de septiembre de 2004, se celebra en La Coruña la Conferencia Internacional bajo los auspicios de la AIOEP "Orientación, desarrollo de la carrera e inclusión social”, de la que hemos dado amplia información en el apartado de Congresos, Jornadas y Seminarios.

\section{Conclusiones}

Este trabajo pretende ser una modesta aportación a la conmemoración del XXV Aniversario de la fundación de la AEOP, al narrar el origen y evolución de nuestra Asociación, al mismo tiempo que ofrece el testimonio de los esfuerzos, aportaciones y colaboraciones desinteresadas de un grupo de profesionales de la Orientación y la Psicopedagogía, que con escasos medios, generosa entrega e incontenible ilusión han hecho posible la continuidad de la AEOP durante estos 25 años de fecunda e inestimable labor en pro de la mejora científi- 
ca, promoción y divulgación de la Orientación escolar y profesional. Después de haber intentado historiar su trayectoria durante este período de tiempo, llega el momento de considerar lo que este fenómeno científico, cultural y sociológico ha supuesto para nuestro quehacer como orientadores y realizar un balance de los resultados y objetivos alcanzados, a fin de sacar algunas conclusiones para potenciar y mejorar el desarrollo de nuestro campo científico aplicado en un futuro inmediato. En resumen, y a modo de epílogo, podemos constatar a través de este cuarto de siglo de actividad ininterrumpida, entre otros, los siguientes logros:

1) Nuestra Asociación, a nivel nacional, ha tenido la virtud de vertebrar una actividad profesional tradicionalmente invertebrada, aunando voluntades en la tarea común de promover una confluencia de intereses entre los especialistas de la Orientación, dividida y atomizada no solo por la diversidad de las áreas de intervención psicopedagógica, sino también por las distintas titulaciones que legalmente facultan para su ejercicio profesional (Diploma en Psicología por las Escuelas de Madrid y Barcelona, Licenciaturas de Pedagogía, Psicología y Psicopedagogía). Actualmente, rememorando el espíritu fundacional, estamos al frente del movimiento asociacionista, que pretende, con la participación de las distintas asociaciones de orientadores existentes en el Estado Español, la creación de una Confederación de Organizaciones de Orientación y Psicopedagogía de España (COPOE).

2) LA AEOP fue la primera asociación científica española sin ánimo de lucro, que redactó sus Estatutos (1979) teniendo en cuenta el espíritu y la letra de la Constitución Española de 1978, propiciando la creación de ocho Delegaciones Territoriales con suficiente autonomía para elegir sus Juntas Directivas y gestionar su funcionamiento: Delegación Territorial de Valencia (1980-2004); Cataluña (1983-1986), se separa y se constituye como asociación nacional independiente en 1986; Zona Centro (1986-2004), aglutina asociados de las CC. AA. de Castilla-La Mancha, CastillaLeón, Extremadura y Madrid; Canarias (1987-2004); Andalucía (1995-2003), se reintegra en la AEOP en 2003; País Vasco (1995-2003), se reintegra en la AEOP en 2003; Galicia, (1999-2004); y Castilla-La Mancha (2000-2004), se desglosa de la Zona Centro en el 2000. La AEOP alcanzó el máximo desarrollo corporativo en el año 2000, llegando a tener inscritos 991 asociados.

3) En la primera Asamblea General de la AEOEP (1980), se aprobó la creación de un órgano oficial de expresión y portavoz de la Asociación, editándose el Boletín AEOEP (1980-1983), posterior Boletín de Información AEOEP (1984-86), luego INDEFOR (1987), y finalmente, nace la Revista, que se editará con tres cabeceras distintas y periodicidad semestral: Revista de Orientación Educativa y Vocacional (1990-95); Revista de Orientación y Psicopedagogía (1996-1998) y la actual Revista Española de Orientación y Psicopedagogía (1998-2004). Nuestra revista es la primera publicación periódica española monográfica sobre Orientación y Psicopedagogía, y desde 1980 hasta la actualidad, recoge en sus 5.062 páginas, 267 artículos y 58 experiencias.

4) Desde el momento de su fundación, la AEOP se preocupó por favorecer los encuentros científicos entre los profesionales de la Orientación, organizando congresos, jornadas y seminarios, tanto a nivel autonómico, como nacional e internacional. Durante estos 25 años, la AEOP, en estrecha colaboración con sus Delegaciones Territoriales, ha organizado 6 Jornadas autonómicas, 8 Jornadas nacionales, 2 Seminarios y 2 
Congresos internacionales. En estos 18 eventos se han presentado un total de 1.282 trabajos (conferencias, ponencias, comunicaciones y posters).

5) Estos eventos científicos han tenido reflejo documental en la publicación de las Actas editadas por la AEOP, excepto las I Jornadas Nacionales de Valencia (1980) y las IV Jornadas Nacionales de Ávila (1986), que no se editaron por problemas económicos, y las Actas del II Seminario Iberoamericano (Madrid, 1982), financiadas, preparadas y editadas por el Instituto de Orientación Educativa y Profesional de Madrid (IOEP-M). En total, la AEOP es la responsable de la edición de 14 libros-actas con 5.854 páginas y dos CD-Rom con las Actas de las III Jornadas de Canarias (2001) y la Conferencia Internacional de La Coruña (2004).

6) Toda esta literatura científica, con sus aportaciones doctrinales, principios teóricos, metodologías, investigaciones, técnicas, instrumentos, descripción de experiencias y conclusiones de los congresos, jornadas y seminarios, ha tenido una clara influencia en el desarrollo de la Orientación y la Psicopedagogía en España en sus vertientes teórica y aplicada, así como en la adaptación de la práctica profesional a las necesidades generadas en el sistema educativo y el mundo laboral durante los últimos 25 años.

7) La AEOP también se ha ocupado de mejorar profesionalmente a sus asociados, organizando e impartido innumerables jornadas, cursos y cursillos de formación y perfeccionamiento de los orientadores escolares y profesionales en particular y del profesorado no universitario en general, abiertos al público y reconocidas oficialmente como "actividades formativas" gracias a la firma de convenios de colaboración a escala nacional, con el MEC, el Ministerio de Trabajo, el INEM y el Instituto de la Mujer, y a nivel autonómico, con las Consejerías de Educación de las CC.AA. donde existen Delegaciones Territoriales. Además, se han firmado conciertos de cooperación con las Universidades de Castilla-La Mancha, Deusto, Jaén, La Coruña, La Laguna, Las Palmas de Gran Canaria, Politécnica de Valencia, Santiago de Compostela, UNED y Valencia, con el reconocimiento de los cursos impartidos por la Asociación como créditos de libre elección, la participación en investigaciones de interés mutuo, la disponibilidad gratuita de infraestructuras, el disfrute de locales cedidos para ubicar las sedes sociales, el acceso a Internet, a través de sus portales. para poder colgar y gestionar cuatro páginas web y tener e-mails para comunicarse con los socios, construir listas, organizar "chats" y utilizar los recursos electrónicos de última generación.

8) También es evidente la influencia ejercida en la teoría y la práctica de la Orientación y la Psicopedagogía por los socios de la AEOP, Profesores de Universidad de las Licenciaturas de Psicología, Pedagogía y Psicopedagogía, profesores y tutores de Educación Primaria y Secundaria, Orientadores de los Departamentos de Orientación de los IES, del INEM, de los Servicios psicopedagógicos de apoyo externos a la escuela (SOEVs, EOEPs, SPEs, COPs, EAPs, EPOEs, GPMs, etc.), de gabinetes privados, etc., a través de sus publicaciones, clases, conferencias y práctica profesional.

9) La AEOP desde su fundación entró a formar parte del movimiento asociacionista de la Orientación escolar y profesional a nivel mundial, ingresando en la AIOEP en 1980 y siendo Asociación fundadora de Euro-Orientación en 1990. En estos momentos se encuentra perfectamente integrada y reconocida a nivel internacional, con un bien ganado prestigio, tanto por la organización y celebración en España de congre- 
sos y seminarios, como por la cantidad y calidad de las aportaciones de sus asociados a los distintos encuentros científicos internacionales de Orientación y Psicopedagogía. Desde 1980 hasta la actualidad tenemos documentada la participación activa de sus socios, como ponentes y/o comunicantes, en 35 eventos internacionales, aunque nos consta, que han asistido representando a la AEOP a otros muchos de los que no poseemos testimonio escrito. Buena prueba de este reconocimiento internacional han sido las Vicepresidencias de la Junta Directiva de la AIOEP detentadas por Pilar García Villegas (1976-1983) y Elvira Repetto Talavera (1995-2004), la Vocalía suplente de José Antonio Rodríguez Docavo (1995-2003), y los nombramientos de Coeditora y Miembro del Consejo Asesor del International Journal for Educational and Vocational Guidance, órgano oficial y portavoz de la AIOEP, de Elvira Repetto y José A. Benavent (2001-2004).

10) La AEOP, por medio de equipos liderados por sus socios, ha participado en el desarrollo de proyectos de investigación internacionales financiados, entre otros: "La formación del personal de orientación a nivel europeo" (1992), proyecto subvencionado por el programa PETRA de la CEE; "Formación de consejeros de educación universitaria" (1993), de FEDORA; varios trabajos del CEDEFOP sobre investigaciones conducentes a la elaboración del perfil y el reconocimiento profesional del orientador (1996-1999); colaboración con el FOREM en el proyecto PROMETEO enmarcado en el programa "Leonardo da Vinci" de la UE; "Desarrollo de la carrera profesional de los estudiantes de $10^{\circ}$ curso, $2^{\circ}$ de la ESO” (1998), patrocinado por la UNESCO; y la coordinación del proyecto de la AIOEP "Counselor Qualification Standards" (1999-2003).

11) Todas estas actividades, publicaciones, cursos, encuentros, congresos e investigaciones, propiciados y/o participados por la AEOP, permiten la actualización del ejercicio profesional del orientador en los campos educativo, laboral y asistencial y facilitan su puesta al día en los principios teórica que justifican su práctica, y en la utilización de las nuevas tecnologías de la información y la comunicación (TIC), de metodologías de vanguardia en la docencia y la investigación y los últimos modelos de orientación e intervención psicopedagógica.

Como colofón y despedida de este XXV Aniversario, conmemoremos gozosamente las Bodas de Plata de nuestra Asociación y que esta celebración nos sirva de serena reflexión de todo lo que hemos sido capaces de llevar a feliz término durante este tiempo, y de firme plataforma de lanzamiento para abordar con éxito la aventura de nuestra inminente transformación en Federación Española de Orientación y Psicopedagogía (FEOP) y su posterior integración, en la primavera del 2005, en la Confederación de Organizaciones de Orientación y Psicopedagogía de España (COPOE), con la que inauguraremos una nueva etapa que nos llevará en el 2029, si somos perseverantes, a festejar las Bodas de Oro, que supongo es el deseo de todos nosotros.

\section{Referencias bibliográficas}

Actas y trabajos. (1983). Orientación Escolar y Profesional. $2^{\circ}$ Seminario Iberoamericano de Orientación Escolar y Profesional (AIOEP-AEOEP). 2 vol. Madrid: Instituto de Orientación Educativa y Profesional de Madrid (IOEP-M). 
AEOEP. (1979). Estatutos de la Asociación Española para la Orientación Escolar y Profesional. Madrid: Autor.

AEOEP. (1983). Orientación para la educación y el empleo. Actas de las II Jornadas de Orientación Escolar y Profesional. Valencia: Universidad de Valencia. Instituto de Ciencias de la Educación.

AEOEP. (1986). La Orientación ante las dificultades de aprendizaje. Actas de las III Jornadas de Orientación Educativa. Valencia: ICE Universidad de Valencia. Servicio de Formación Permanente-AEOEP.

AEOEP. (1993). El compromiso de la Orientación Escolar y Profesional con los cambios de la sociedad. V Seminario Internacional de Orientación de la AIOEP. Madrid: Autor.

AEOEP. (1994). Programa del XV Congreso Internacional de Recursos Humanos, Orientación y Mercado Laboral. Madrid: Autor

AEOEP-DTCn. (1989). I Jornadas de Orientación Escolar y Profesional en Canarias. La Laguna (Sta. Cruz de Tenerife): Autor.

AEOEP-DTCn. (1991). La Orientación Profesional ante la unidad europea. (Comunicaciones). VI Jornadas Nacionales de Orientación Escolar y Profesional. La Laguna (Tenerife): Autor.

AEOEP-DTV. (1980). La función del Orientador. I Jornadas de Orientación. Valencia, mayo-junio 1980. Documento policopiado de difusión interna.

AEOEP-DTV. (1990). La Reforma Educativa: Un reto para la Orientación. V Jornadas Nacionales de Orientación Educativa. Valencia: Autor.

AEOEP-DTV. (1994). Desarrollo de la carrera: Modelos y programas actuales. I Jornadas Valencianas de la AEOEP. Valencia: Autor.

AEOP. (1996). Estatutos de la Asociación Española de Orientación y Psicopedagogía. Madrid: Autor.

AEOP. (1996a). Reglamento General de Régimen Interior de la AEOP. Madrid: Autor.

AEOP. (1997). (Comp.). La Orientación educativa y la intervención psicopedagógica integradas en el curriculum. Valencia: Asociación Española de Orientación y Psicopedagogía. Delegación Valencia.

AEOP-DTCn. (2001). La Orientación del s. XXI en los actuales modelos de Intervención. Actas de las III Jornadas Regionales de Orientación y Psicopedagogía. CD-Rom. La Laguna (Tenerife): Autor.

AIOEP. (1995). "Normas éticas de la AIOEP". Revista de Orientación Educativa y Vocacional, 6 (10), pp. 150-155.

AIOEP. (1995a). "Declaración de principios de la AIOEP". Revista de Orientación Educativa y Vocacional, 6 (10), pp. 155-156.

AIOEP (2001). "Declaración de la AIOEP sobre Orientación Educativa y Profesional, París 2001". Revista Española de Orientación y Psicopedagogía. 12 (22), pp. 378-380.

AIOEP (2002). "Memoria anual de actividades de la AIOEP 2001 - 50 Aniversrio". Revista Española de Orientación y Psicopedagogía. 12 (22), pp. 151-156.

AIOSP-AEOP. (2004). Orientación, Inclusión social y desarrollo de la Carrera. Conferencia Internacional. A Coruña 15-17 de septiembre de 2004. A Coruña: Autor.

AIOSP-AEOP. (2004a). Orientación, Inclusión social y desarrollo de la Carrera. Actas de la Conferencia Internacional. A Coruña 15-17 de septiembre de 2004. CD-Rom. A Coruña: Autor.

Anaya, D. (1995). "50 Conferencia Nacional de la Carrera de la NCDA". Revista de Orientación Educativa y Vocacional, 6 (10), p. 148.

Anónimo. (1984). "Actividades realizadas por la Delegación de la AEOEP de Cataluña en el último trimestre de 1983". Boletín de Información AEOEP, 4 (3), pp. 42-43. 
Anónimo. (1984a). "Información sobre los cursillos organizados por la Delegación Territorial de la AEOP de Valencia en colaboración con el ICE de la Universidad Literaria". Boletín de Información AEOEP, 4 (3), p. 49.

Anónimo. (1984b). "Informe sobre las reuniones de los socios de la AEOEP de la Delegación Territorial de Valencia". Boletín de Información AEOEP, 4 (3), p. 50.

Anónimo. (1985). "Delegación Territorial de Cataluña". Boletín de Información AEOEP, 5 (4), pp. 82-83.

Anónimo. (1985a). "Actividades docentes complementarias del ICE de la Universidad Politécnica de Valencia en colaboración con la AEOEP”. Boletín de Información AEOEP, 5 (4), pp. 87-88.

Anónimo. (1986). "Editorial”. Boletín de Información AEOEP, 6 (6), pp. 2-3.

Anónimo. (1987). "Se celebraron las Jornadas Nacionales de Orientación Escolar y Profesional de la AEOEP en Ávila". INDEFOR, no 0, p. 8.

Anónimo. (1987a). "Se celebró el XII Congreso Mundial de Orientación”. INDEFOR, n² 2, p. 1.

Anónimo. (1990). "Segunda Conferencia Europea sobre la Orientación profesional asistida por ordenador". Revista de Orientación Educativa y vocacional, 0 (1), pp. 112-113.

Anónimo. (1990a). "Participación de la AEOEP en el XIII Congreso de la AIOEP sobre 'Minorías vulnerables" ". Revista de Orientación Educativa y vocacional, 0 (1), p. 113.

Anónimo. (1991). "Participación de la AEOEP en la Conferencia Internacional celebrada en Bruselas para la creación de la asociación 'Euro-orientación'". Revista de Orientación Educativa y vocacional, 1 (1), pp. 99-101.

Anónimo. (1991a). "Participación de la AEOEP en el II Encuentro Latinoamericano de Asociaciones y Profesionales de Orientación". Revista de Orientación Educativa y vocacional, 1 (1), p. 99.

Anónimo. (1991b). "XIV Congreso Mundial de Orientación”. Revista de Orientación Educativa y vocacional, 1 (1), p. 101.

Anónimo. (1994). "XV Congreso Internacional de Recursos Humanos, Orientación y Mercado Laboral". Revista de Orientación Educativa y vocacional, 5 (8), pp. 132-134.

Anónimo. (1995). "IV Encuentro Latinoamericano de Orientación y VIII Seminario de Orientación Vocacional". Revista de Orientación Educativa y Vocacional, 6 (9), p. 130.

Anónimo. (1996). "Nota informativa sobre las actividades realizadas por la Delegación Centro". Revista de Orientación y Psicopedagogía. 7 (11), pp. 172-173.

Anónimo. (1996a). "Delegación Centro". Revista de Orientación y Psicopedagogía. 7 (12), pp. 315 316.

Anónimo. (1996b). "Nota informativa sobre las actividades programadas en Canarias para el curso 1996/1997". Revista de Orientación y Psicopedagogía. 7 (11), p. 173

Anónimo. (1996c). "Delegación Canaria”. Revista de Orientación y Psicopedagogía. 7 (12), pp. $314-$ 315.

Anónimo. (1996d). "Delegación del País Vasco”. Revista de Orientación y Psicopedagogía. 7 (12), p. 316

Anónimo. (1997). "Delegación de Valencia”. Revista de Orientación y Psicopedagogía. 8 (14), p. 328.

Anónimo. (1997a). "Delegación Centro". Revista de Orientación y Psicopedagogía. 8 (13), p. 118.

Anónimo. (1997b). "Delegación Centro". Revista de Orientación y Psicopedagogía. 8 (14), pp. 327-328.

Anónimo. (1997c). "Delegación de Canarias". Revista de Orientación y Psicopedagogía. 8 (13), p. 118.

Anónimo. (1997d). "Delegación de Canarias". Revista de Orientación y Psicopedagogía. 8 (14), p. 327.

Anónimo. (1997e). "Delegación de Andalucía”. Revista de Orientación y Psicopedagogía. 8 (13), pp. 118-119. 
Anónimo. (1997f). "VIII Jornadas Nacionales de la AEOP. Conclusiones". Revista de Orientación y Psicopedagogía. 8 (14), pp. 329-335.

Anónimo. (1998). "Delegación Territorial de Andalucía". Revista Española de Orientación y Psicopedagogía. 9 (16), p. 311.

Anónimo. (1998a). "Delegación Territorial de Andalucía”. Revista Española de Orientación y Psicopedagogía. 9 (16), p. 311.

Anónimo. (1998b). "Primeras Jornadas Andaluzas de Orientación y Psicopedagogía". Revista Española de Orientación y Psicopedagogía. 9 (16), p. 313

Anónimo. (1998c). "Congreso de Finlandia”. Revista Española de Orientación y Psicopedagogía. 9 (16), p. 313

Anónimo. (1998d). "Reunión oficial del Comité Ejecutivo de la AIOEP en París". Revista Española de Orientación y Psicopedagogía. 9 (16), p. 315

Anónimo. (1999). "Servicio de Asesoría Legal para Orientadores". Revista Española de Orientación y Psicopedagogía. 10 (18), p. 463.

Anónimo. (1999a). "Acuerdo de Cooperación entre la Asociación Española de Orientación y Psicopedagogía (AEOP) y la Asociación Aragonesa de Psicopedagogía (AAPs)". Revista Española de Orientación y Psicopedagogía. 10 (17), p. 249.

Anónimo. (1999b). "Homenaje a María Teresa Díaz Allué". Revista Española de Orientación y Psicopedagogía. 10 (18), p. 463.

Anónimo. (1999c). "Delegación Territorial de Valencia". Revista Española de Orientación y Psicopedagogía. 10 (18), pp. 451-452.

Anónimo. (1999d). "Delegación Territorial de Centro". Revista Española de Orientación y Psicopedagogía. 10 (18), p. 451.

Anónimo. (1999e). "Delegación Territorial de Canarias". Revista Española de Orientación y Psicopedagogía. 10 (18), p. 453.

Anónimo. (1999g). "Delegación Territorial del País Vasco". Revista Española de Orientación y Psicopedagogía. 10 (18), pp. 452.

Anónimo. (1999h). "Delegación Territorial de Galicia". Revista Española de Orientación y Psicopedagogía. 10 (18), p. 453.

Anónimo. (1999i). "Seminario de la AIOEP en Nueva Zelanda". Revista Española de Orientación y Psicopedagogía. 10 (17), p. 247.

Anónimo. (1999j). "Información de reuniones y congresos. Congresos celebrados". Revista Española de Orientación y Psicopedagogía. 10 (18), p. 454.

Anónimo. (2000). "Delegación Territorial de Valencia". Revista Española de Orientación y Psicopedagogía. 11 (19), p. 165.

Anónimo. (2000a). "Delegación de Valencia". Revista Española de Orientación y Psicopedagogía. 11 (20), pp. 295-296.

Anónimo. (2000b). "Delegación Territorial de Andalucía". Revista Española de Orientación y Psicopedagogía. 11 (19), p. 164.

Anónimo. (2000c). "Delegación Territorial de Galicia". Revista Española de Orientación y Psicopedagogía. 11 (19), pp. 162-163.

Anónimo. (2000d). "Delegación Territorial de Castilla La Mancha". Revista Española de Orientación y Psicopedagogía. 11 (19), pp. 164-165.

Anónimo. (2000e). "Delegación de Castilla La Mancha". Revista Española de Orientación y Psicopedagogía. 11 (20), pp. 295. 
Anónimo. (2000f). "Proyectos de investigación”. Revista Española de Orientación y Psicopedagogía. 11 (19), p. 155.

Anónimo. (2001). "Información sobre reuniones y congresos". Revista Española de Orientación y Psicopedagogía. 12 (21), pp. 193-198.

Anónimo. (2001a). "Delegación de Castilla-La Mancha". Revista Española de Orientación y Psicopedagogía. 12 (22), p. 381.

Anónimo. (2001b). "Segundo Simposio Internacional sobre Desarrollo de la Carrera y Políticas Públicas". Revista Española de Orientación y Psicopedagogía. 12 (21), pp. 201-202.

Anónimo. (2001c). "Información sobre reuniones y congresos". Revista Española de Orientación y Psicopedagogía. 12 (22), pp. 375-376.

Anónimo. (2002). "Delegación de Valencia”. Revista Española de Orientación y Psicopedagogía. 13 (1), p. 157.

Anónimo. (2002a). "Delegación del País Vasco". Revista Española de Orientación y Psicopedagogía. 13 (1), pp. 156-157.

Anónimo. (2002b). “Conferencias de la AIOEP”. Revista Española de Orientación y Psicopedagogía. 13 (1), pp. 153-154.

Anónimo. (2002c). "Publicaciones de la AIOEP". Revista Española de Orientación y Psicopedagogía. 13 (1), pp. 152-153.

Anónimo. (2002d). "Información sobre reuniones y congresos". Revista Española de Orientación y Psicopedagogía. 13 (1), pp. 149-150.

Anónimo. (2003). "Información de las Delegaciones". Madrid. Revista Española de Orientación y Psicopedagogía. 14 (1), p. 137.

Anónimo. (2003a). "Delegación Territorial de Galicia". Revista Española de Orientación y Psicopedagogía. 14 (1), p. 136

Anónimo. (2003b). "Delegación Territorial de Galicia". Revista Española de Orientación y Psicopedagogía. 14 (2), p. 156

Anónimo. (2003c). "Delegación Territorial de Castilla-La Mancha”. Revista Española de Orientación y Psicopedagogía. 14 (1), p. 136

Anónimo. (2003d). "Delegación Territorial de Castilla-La Mancha". Revista Española de Orientación y Psicopedagogía. 14 (2), p. 157.

Anónimo. (2003e). "Información sobre reuniones y congresos". Revista Española de Orientación y Psicopedagogía. 14 (1), p. 135

Anónimo. (2004). “Asociación Madrileña de Orientación y Psicopedagogía”. Revista Española de Orientación y Psicopedagogía. 15 (1), pp. 179-180.

Anónimo. (2004a). "Información sobre reuniones y congresos". Revista Española de Orientación y Psicopedagogía. 15 (1), pp. 175-177.

Benavent, J. A. (2000). La Orientación Psicopedagógica en España. Desde 1939 hasta la Ley General de Educación de 1970. Valencia: Edit. Promolibro.

Benavent, J. A. (2004). La Orientación Psicopedagógica en España. Desde la Ley General de Educación (1970) hasta la LOGSE (1990). Valencia: Edit. Promolibro. (En prensa).

Del Campo, E., Colinas, I. y Rejas, P. (1993). "FEDORA organismo aglutinador de la Orientación europea". Revista de Orientación Educativa y Vocacional, 4 (6), pp. 115-118.

Garcia-Fuentes, C. D. y Téllez, J. A. (1999). "I Jornadas Andaluzas de Orientción y Psicopedagogía”. Revista Española de Orientación y Psicopedagogía, 10 (17), pp. 250-254. 
Gelvan, S. B. (2000). "Informe sobre el congreso Internacional de la AIOEP celebrado en Berlín". Revista Española de Orientación y Psicopedagogía, 11 (20), pp. 285-289.

Martínez Gonzalo, I. (1994). "Orientación en Europa desde el 'Stand de Euro-orientadores'”. Revista de Orientación Educativa y Vocacional, 5 (7), pp. 117-119.

MEC-CIDE. (1991). La Orientación Profesional ante la unidad europea. VI Jornadas de Orientación Escolar y Profesional. Madrid: Centro de Publicaciones-Secretaría General Técnica del MEC.

MEC-INEM. (Edit.). (1985). La Orientación escolar ante la reforma de las Enseñanzas Medias y el empleo juvenil. I Congreso de Orientación Escolar y Profesional. Madrid: Autores.

MIDE/UNED-AEOEP. (1993). La Orientación en el sistema educativo y en el mundo laboral. VII Jornadas Nacionales de Orientación Escolar y Profesional. Madrid: Autor.

Orts, J. M. (1986). "Las III Jornadas de Orientación y sus antecedentes". En AEOEP. (1986). La Orientación ante las dificultades de aprendizaje. Actas de las III Jornadas de Orientación Educativa. Valencia: Universidad de Valencia. Servicio de Formación Permanente-AEOEP pp. 13-18.

Pascual, M. y Bonet, M. (1981). "Orientación profesional y mercado de trabajo". Boletín AEOEP, 2 (4), pp. 7-10.

Repetto, E. y Vélaz de Medrano, C. (Eds.) (1998). Orientación de la carrera, recursos humanos y mercado laboral. Actas del XV Congreso Internacional de la AIOEP. 2 vol. Madrid: UNED.

Rodríguez Docavo, J. A. (1987). Boletín AEOEP. Compilación 1-9. Madrid: AEOEP. Documento policopiado de difusión interna.

Rodríguez Docavo, J. A. (1993). "Asociación Española para la Orientación Escolar y Profesional. Historia de una ilusión". Revista de Orientación Educativa y Vocacional, 4 (5), pp. 261-282.

Rodríguez Docavo, J. A. (1994). XV Aniversario AEOEP. Catálogo de publicaciones: Revistas y Actas. Madrid: AEOEP. Documento policopiado de difusión interna.

Rodríguez Docavo, J. A. (1995). "XVI Congreso Internacional de la AIOEP. Asamblea General de la AIOEP”. Revista de Orientación Educativa y Vocacional, 6 (10), pp. 149-150.

Rodríguez Docavo, J. A. (1995a). "Seminario Internacional. Orientación y cambio sociocultural". Revista de Orientación Educativa y Vocacional, 6 (10), pp. 157-159.

Rodríguez Docavo, J. A. (1997). "Nombramiento de los Miembros de Honor". Revista de Orientación y Psicopedagogía, 8 (13), p. 119.

Rodríguez Docavo, J. A. (1999). "XX Aniversario de la Asociación Española de Orientación y Psicopedagogía". Revista Española de Orientación y Psicopedagogía, 8 (13), pp. 257-260.

Rodríguez Moreno, $\mathrm{M}^{\circ}$. L. (1986). "Memoria resumen de las I Jornadas sobre la Escuela y la Orientación de los adolescentes". Boletín de Información AEOEP, 6 (6), pp. 14-15.

Ruiz, J. y Medina, A. Orientación Educativa e Intervención Psicopedagógica. I Jornadas Andaluzas de Orientación y Psicopedagogía. Jaén: Universidad de Jaén. Servicio de Publicaciones.

ULPGC. (1993). II Jornadas de Orientación Escolar y Profesional en Canarias. Las Palmas de Gran Canaria: Autor.

Zaragozá, J. (1980). "La función del Orientador”. Boletín AEOEP, 1 (2), pp. 4-7.

\section{Legislación}

Ley 191/1964, de 24 de diciembre, de Asociaciones. (BOE del 28).

Real Decreto-Ley 36/1978, de 18 de noviembre, sobre gestión institucional de la Seguridad social, la salud y el empleo. (BOE del 18). 
Orden de 30 de abril de 1977 por la que se regula la organización con carácter experimental del Servicio Provincial de Orientación Escolar y Vocacional para alumnos de Educación General Básica. (BOE de 13 de mayo).

Real Decreto 708/1979, de 5 de abril, por el que se reestructuran determinados órganos de la Administración Central del Estado. (BOE del 6).

Ley Orgánica 1/2002, de 22 de marzo, reguladora del Derecho de Asociación. (BOE del 26).

\section{Fuentes}

1. Archivo de AEOEP-AEOP (1979-2004). UNED. Edif. Biblioteca. Calle Senda del Rey, $\mathrm{n}^{\circ}$ 5, Dcho. 03. Madrid.

1.1. Libro de Actas (Asambleas Generales, Vols., I y II).

1.2. Libro de Actas (Juntas directivas, Vols., I y II).

1.3. Libro de Registro de Socios.

1.4. Libro de Cuentas.

1.5. Registro de correspondencia (entradas y salidas).

1.6. Carpeta con informes de las Delegaciones Territoriales.

1.7. Folletos informativos sobre congresos, jornadas y reuniones científicas.

1.8. Actas de congresos, conferencias, jornadas, seminarios y reuniones científicas.

1.9. Legajos y documentos varios.

1.10. Libros de Actas de la Delegación Territorial Zona Centro.

2. Archivo de la Delegación Territorial de Valencia, AEOEP-AEOP-CV (1980-2004). Universitat de València. Facultad de Filosofía y Ciencias de la Educación. Departamento MIDE. Avda. Blasco Ibáñez, nº 30. Valencia.

2.1. Libro de Actas (Asambleas Generales, Vols., I y II).

2.2. Libro de Actas (Juntas Directivas).

2.3. Libro de Registro de Socios.

2.4. Libro de Cuentas.

2.5. Registro de correspondencia (entradas y salidas).

2.6. Folletos informativos sobre congresos, jornadas y reuniones científicas.

2.7. Actas de congresos, conferencias, jornadas, seminarios y reuniones científicas.

2.8. Documentos de difusión interna elaborados por José Antonio Rodríguez Docavo.

2.9. Legajos y documentos varios.

2.10. Hemeroteca.

2.10.1. Boletín de Información AEOEP (1984-1986).

2.10.2. INDEFOR (1987).

2.10.3. Revista de Orientación Educativa y Vocacional (1980-1995).

2.10.4. Revista de Orientación y Psicopedagogía (1996-1998).

2.10.5. Revista Española de Orientación y Psicopedagogía (1998-2004). 


\section{ANEXOS}

\section{Anexo I}

\section{Boletín AEOEP (1980-1983)}

Se editaron un total de 9 números, todos ellos diseñados y dirigidos por Pilar García Villegas. Dejó de publicarse tras su fallecimiento y actualmente no poseemos ningún ejemplar. La información que facilitamos a continuación sobre los mismos se debe a Rodríguez Docavo (1987 y 1994).

\begin{tabular}{|c|c|c|}
\hline \multicolumn{3}{|c|}{ Boletín AEOEP(1980-1983) } \\
\hline Número & Fecha publicación & Páginas \\
\hline 1 & Mayo 1980 & $1-16$ \\
\hline 2 & Octubre 1980 & $17-33$ \\
\hline 3 & Mayo 1981 & $34-51$ \\
\hline 4 & Octubre 1981 & $52-66$ \\
\hline 5 & Mayo 1982 & $67-92$ \\
\hline 6 & Octubre 1982 & $93-114$ \\
\hline 7 & Enero 1983 & $115-140$ \\
\hline 8 & Mayo 1983 & $141-176$ \\
\hline 9 & Octubre 1983 & $177-193$ \\
\hline
\end{tabular}

Los 26 artículos publicados en estos 9 números ordenados alfabéticamente por autores son los siguientes:

- AEOEP Valencia. Escuela de padres.

- Aguirraganda Vavril, E. La orientación como prevención del consumo de drogas.

- Aldomar, C. La minusvalía física como determinante de la Orientación escolar y Profesional.

- Álvarez, O. Orientación para la dinámica de la vida.

- Asensi Díaz y Gonzalo. Las actividades de información escolar y profesional.

- Avent, C. Orientación norteamericana.

- Batla, E. y Forcinitti, N. La incidencia de los modelos de identificación en la elección vocacional de los adolescentes.

- Cáceres, E. y Condal, J. El abandono de los estudios antes de la edad laboral.

- Estrada, A. y Sandoval, L. Influencia del lenguaje del entrevistador en la comprensión empática del consultante.

- Fonseca, E. y Monge, V. Campaña de prevención de consumo de drogas por niños y jóvenes en Costa Rica. 
- Gras Tornero, M. La Orientación escolar en los niños hipercinéticos.

- Hermans, K. La orientación profesional en pequeños países.

- Izquierdo, G. y Alonso, F. Problemática al terminar la Educación General Básica.

- M'Bow, A.-M. Educación de adultos y desarrollo rural en Yemen.

- Marí Mollá, R. Proyecto-plan de desarrollo para alumnos en las actividades básicas de aprendizaje. Orientación autodirectiva según C. Rogers.

- Martín, J. A. Exploración de la personalidad a través de los tests Beta y Cappa.

- Monera, Olmos, M. L. La orientación ante la elección de estudios universitarios.

- Pascual, M. y Bonet, J. Orientación profesional y mercado de trabajo.

- Poves Jiménez, M. Variables predictivas del rendimiento escolar en $5^{\circ}$ de EGB.

- Repetto Talavera, E. Algunos valores diferenciales de la decisión vocacional: Un estudio experimental.

- Rodríguez Docavo, J. A. Las aptitudes de los titulados universitarios.

- Romeo Martínez-Lecea, J. El estudio sobre la importancia del trabajo. Participación española en este estudio internacional.

- Romeo Martínez-Lecea, J. La Orientación profesional en el Ministerio de Trabajo. Los Centros de Orientación Profesional del INEM.

- Rubio, A. El paso de la escuela al trabajo.

- Sánchez, E. Resumen de un estudio de orientación profesional a escolares minusválidos sordo-mudos.

- Zaragozá, J. Objetivos de la Orientación.

\section{Anexo II}

\section{Boletín de Información AEOEP (1984-1986)}

Fue la publicación periódica que sustituyó al Boletín AEOEP tras la muerte de García Villegas. Para su edición se nombró un Consejo de Redacción formado por Luis García Mediavilla, Elvira Repetto Talavera, José Antonio Rodríguez Docavo y Tomás Terrados Jarabo, además de dos Corresponsales, Santiago Martí García (D.T. de Cataluña) y Josefa Bellod García (D.T. de Valencia). Se publicaron en total cuatro números que fueron impresos en CALPA por Luis García Mediavilla. La colección completa se encuentra en el Archivo de la AEOP-CV.

\begin{tabular}{|c|c|c|c|}
\hline \multicolumn{4}{|c|}{ Boletín de Información AEOEP (1984-1986) } \\
\hline Año & Número & Fecha de publicación & $\mathbf{N}^{0}$ de páginas \\
\hline 4 & 3 & Marzo 1984 & 58 \\
\hline 5 & 4 & Febrero 1985 & 97 \\
\hline 6 & 5 & Enero 1986 & 64 \\
\hline 6 & 6 & Marzo 1986 & 117 \\
\hline
\end{tabular}


A continuación presentamos la relación completa de los artículos publicadas en cada uno de sus números:

- Año 4, no 3, marzo 1984.

- Anónimo. Editorial, p. 4.

- Repetto Talavera, E. Incidencia de las diferencias axiológicas en la decisión vocacional en la Orientación Educativa (I), pp. 5-28.

- Rodríguez Moreno, M. L. Propuesta a una clasificación analítica decimal de las disciplinas de Orientación y Consejo, pp. 29-38.

- Martí, S. La Orientación Profesional del I.N.E.M. hoy, pp. 39-41.

- Año 5, no 4, febrero 1985.

- Repetto Talavera, E. Incidencia de las diferencias axiológicas en la decisión vocacional en la Orientación Educativa (y II), pp. 4-47.

- Bertrán Quera, M. El fracaso escolar y la Orientación Educativa, pp. 48-55.

- Guevara Martínez, A. Aprendizaje de la lecto-escritura, pp. 56-58.

- Rodríguez Moreno, M. L. Modelo de capacitación de orientadores basado en el desarrollo de capacidades o competencias (competency-based training programs, ESTP). Sugerencias para planificar las prácticas (practicum) de los alumnos universitarios de segundo y tercer ciclos, pp. 59-81.

- Año 6, no 5, enero 1986 (Monográfico Premio "Pilar García Villegas”).

- Gutiérrez Sanmartín, M. y Musitu Ochoa, G. La disciplina familiar y su relación con la autoestima, rendimiento escolar y adaptación social, pp. 6-37.

- Bertrán Quera, M. La Orientación educativa: Reflexiones retrospectivas, actuales y prospectivas, pp. 38-42.

- Castillo Arredondo, S. Una experiencia de más de veinte años de Orientación Escolar y Profesional, pp. 43-54.

- Año 6, nº 6, marzo 1986. (Monográfico I Jornadas Catalanas de Orientación).

- Anónimo. Editorial, pp. 2-3.

- Anónimo. Curriculum vitae del Dr. D. Miguel Bertrán Quera, pp. 4-12.

- Rodríguez Moreno, M. L. Memoria resumen de las I Jornadas sobre "La escuela y la orientación de los adolescentes", pp. 14-21.

\section{Ponencias:}

- Bertrán Quera, M. Perspectivas futuras de la Orientación Educativa: Necesidades, objetivos y funciones, pp. 23-33.

- Rodríguez Moreno, M. L. Planteamiento de la situación actual de la Orientación, pp. 34-46.

\section{Comunicaciones:}

- Rodríguez Espinar, S. Un convenio sin firma: Una experiencia de orientación en $8^{\circ}$ de $E G B$, pp. 48-50. 
- Serra, C. y otros. Diseño de un programa de orientación ocupacional para personas sin preparación específica y en edad laboral, pp. 51-52.

- C.P. “Torrent d'en Melis". La realidad de la orientación escolar en la EGB. (Escuela pública), pp. 53-54.

- Buxarrais Estrada, J. Ma. y García Salazar, E. El problema de los contenidos mínimos en la Orientación Escolar/Vocacional. El ámbito de $8^{\circ}$ de EGB: Factores de intervención, p. 55.

- Estruch Tobella, I. Los tutores de bachillerato y el orientador, pp. 56-57.

- González Rosas, J. L. Integración del Servicio de Orientación en la comunidad educativa, pp. 58-59.

- I.F.P. "Ramón Berenguer IV". Anteproyecto del Departamento de Orientación para un instituto de Formación Profesional, pp. 60-61.

- Pfefferkorn, I. y otros. La Orientación escolar y profesional, una de las funciones prioritarias del equipo psicopedagógico, pp. 62-63.

- Planas, J. y Hernández, J. La Orientación especial continuada, como método para la iniciación profesional, pp. 64-67.

- Rausa Gerez, Ma. L. Un gran reto: La mejora de la orientación que reciben los adolescentes, pp. 68-69.

- Gras Tornero, M. Un modelo de Orientación Escolar-Profesional, pp. 71-73.

- Jofre i Tardá, R. Ma ¿ ¿Cómo trabajamos la Orientación Escolar-Profesional el Equipo de Asesoramiento Psicopedagógico de Sants-Montjuich?, pp. 74-75.

- Royo Arpón, M. Orientación escolar en el marco de la educación compensatoria, pp. 76-77.

- Falgueras Ruscadella, F. Funciones del orientador en Formación Profesional. Aportaciones desde la praxis educativa, pp. 78-89.

- Rimbau Almendros, J. Experiencia de un programa de orientación en BUP, pp. 90-91.

- Forns Santacana, M. La Orientación en su perspectiva de futuro. La formación del orientador, pp. 93-95.

- Hornero Jarque, L. La Orientación profesional en el marco del Instituto de Psicología Aplicada y Psicotecnia, pp. 96-98.

- Brunet Riba, J. Experiencia de un modelo participativo de Orientación EscolarProfesional en $8^{\circ}$ de EGB de las escuelas de Barcelona, pp. 100-101.

- Freixas Ortega, O. ¿Hay un lugar para el orientador?, p. 102-103.

\section{Anexo III}

\section{INDEFOR (1987)}

INDEFOR. Información, Desarrollo, Formación y Orientación. Periódico trimestral de información para los orientadores españoles. Órgano de expresión de la Asociación Española para la Orientación Escolar y Profesional, fue la publicación periódica que sustituyó al 
Boletín de Información AEOEP tras la dimisión de Luis García Mediavilla en 1986. Su creador y Director fue Juan José García Jiménez.

En total se publicaron tres números que se editaron en los talleres del Diario de Ávila S. A. Depósito Legal: Av-10-1987. La colección completa se encuentra en el Archivo de la AEOP-CV.

\begin{tabular}{|c|c|c|c|}
\hline \multicolumn{5}{|c|}{ INDEFOR (1987) } \\
\hline Año & Número & Fecha de publicación & $\mathbf{N}^{\mathbf{0}}$ de páginas \\
\hline 1 & 0 & Primer trimestre 1987 & 8 \\
\hline 1 & 1 & Segundo trimestre 1987 & 8 \\
\hline 1 & 2 & Tercer trimestre 1987 & 8 \\
\hline
\end{tabular}

Contenidos:

- $N^{o}$ 0. Monográfico sobre las IV Jornadas Nacionales de Orientación de Ávila. Septiembre 1986.

- $N^{o}$ 1. Monográfico sobre IV Seminario Iberoamericano de la AIOEP. Buenos Aires (Argentina). Octubre 1986.

- $N^{o}$ 2. Monográfico sobre XII Congreso Internacional de la AIOEP Annecy (Francia). Septiembre de 1987. 


\section{Anexo IV}

Tabla resumen de contenidos de la Revista (1990-2004).

\begin{tabular}{|c|c|c|c|c|c|c|c|c|c|}
\hline \multirow{3}{*}{ Año } & \multicolumn{6}{|c|}{ Semestres } & \multicolumn{3}{|c|}{ Totales } \\
\hline & \multicolumn{3}{|c|}{$\mathbf{1}^{\mathrm{o}}$} & \multicolumn{3}{|c|}{$2^{\circ}$} & \multirow{2}{*}{ Páginas } & \multirow{2}{*}{ Artícul. } & \multirow{2}{*}{ Experi. } \\
\hline & Páginas & Artícul. & Experi. & Páginas & Artícul. & Experi. & & & \\
\hline \multicolumn{10}{|c|}{ Revista de Orientación Educativa y Vocacional (ROEV). } \\
\hline 1990 & - & - & - & 130 & 4 & 2 & 130 & 4 & 2 \\
\hline 1991 & 116 & 6 & 3 & 180 & 5 & 3 & 296 & 11 & 6 \\
\hline 1992 & 119 & 6 & 3 & 127 & 6 & 3 & 246 & 12 & 6 \\
\hline 1993 & 285 & 18 & - & 124 & 8 & - & 409 & 26 & - \\
\hline 1994 & 120 & 6 & 1 & 136 & 6 & 2 & 256 & 12 & 3 \\
\hline 1995 & 141 & 6 & 3 & 165 & 6 & 3 & 306 & 12 & 6 \\
\hline Total & 781 & 52 & 10 & 862 & 35 & 13 & 1.643 & 77 & 23 \\
\hline \multicolumn{10}{|c|}{ Revista de Orientación y Psicopedagogía (ROP). } \\
\hline 1996 & 173 & 6 & 4 & 148 & 6 & 3 & 321 & 12 & 7 \\
\hline 1997 & 119 & 6 & 1 & 224 & 12 & 2 & 343 & 18 & 3 \\
\hline 1998 & 173 & 6 & 2 & - & - & - & 173 & 6 & 2 \\
\hline Total & 465 & 32 & 8 & 372 & 24 & 7 & 837 & 56 & 15 \\
\hline \multicolumn{10}{|c|}{ Revista Española de Orientación y Psicopedagogía (REOP). } \\
\hline 1998 & - & - & - & 146 & 6 & 2 & 146 & 6 & 2 \\
\hline 1999 & 260 & 14 & 1 & 203 & 7 & 2 & 463 & 21 & 3 \\
\hline 2000 & 165 & 7 & - & 136 & 5 & 2 & 301 & 12 & 2 \\
\hline 2001 & 207 & 7 & 4 & 174 & 6 & 2 & 381 & 13 & 6 \\
\hline 2002 & 158 & 6 & 3 & 282 & 6 & 2 & 440 & 12 & 5 \\
\hline 2003 & 138 & 6 & 1 & 160 & 7 & 2 & 298 & 13 & 3 \\
\hline 2004 & 180 & 7 & 2 & - & - & - & 180 & 7 & 2 \\
\hline Total & 1.108 & 47 & 11 & 1.101 & 37 & 12 & 2.209 & 84 & 23 \\
\hline Totales & 2.354 & 107 & 28 & 2.335 & 90 & 30 & 4.689 & 197 & 58 \\
\hline
\end{tabular}

Tabla cuantitativa de la Revista (1990-2004) con sus tres cabeceras (ROEV-ROPREOP), fechas de publicación, número de páginas, artículos y experiencias publicadas durante los quince años de su edición.

Fecha de aceptación: 05-11-2004 